\title{
Differentially expressed genes in the mutualistic Neotyphodium coenophialum-tall fescue interaction
}

Linda Joy Johnson

West Virginia University

Follow this and additional works at: https://researchrepository.wvu.edu/etd

\section{Recommended Citation}

Johnson, Linda Joy, "Differentially expressed genes in the mutualistic Neotyphodium coenophialum-tall fescue interaction" (2002). Graduate Theses, Dissertations, and Problem Reports. 1677.

https://researchrepository.wvu.edu/etd/1677

This Dissertation is protected by copyright and/or related rights. It has been brought to you by the The Research Repository @ WVU with permission from the rights-holder(s). You are free to use this Dissertation in any way that is permitted by the copyright and related rights legislation that applies to your use. For other uses you must obtain permission from the rights-holder(s) directly, unless additional rights are indicated by a Creative Commons license in the record and/ or on the work itself. This Dissertation has been accepted for inclusion in WVU Graduate Theses, Dissertations, and Problem Reports collection by an authorized administrator of The Research Repository @ WVU.

For more information, please contact researchrepository@mail.wvu.edu. 


\title{
DIFFERENTIALLY EXPRESSED GENES IN THE MUTUALISTIC NEOTYPHODIUM COENOPHIALUM-TALL FESCUE INTERACTION
}

\author{
Linda Joy Johnson
}

Dissertation submitted to the

Davis College of Agriculture, Forestry and Consumer Sciences at West Virginia University

in partial fulfillment of the requirements

for the degree of

\author{
Doctor of Philosophy \\ in \\ Plant and Soil Sciences
}

\author{
Daniel G. Panaccione, Ph.D., Chair \\ William MacDonald, Ph.D. \\ Joseph B. Morton, Ph.D. \\ Christopher L. Schardl, Ph.D. \\ Sven Verlinden, Ph.D.
}

\section{Morgantown, West Virginia 2002}

Keywords: Endophyte, Differential gene expression, Neotyphodium, SSH, Symbiosis, Tall fescue 


\section{ABSTRACT \\ Differentially expressed genes in the mutualistic \\ Neotyphodium coenophialum-tall fescue interaction}

\section{Linda Joy Johnson}

Tall fescue (Lolium arundinaceum), an agronomically important forage grass, is typically associated with a mutualistic asexual fungus Neotyphodium coenophialum. Endophytic fungal growth is confined to the intercellular spaces of the plant and induces no symptoms. The endophyte partner enhances its host's fitness by improving nutrient acquisition as well as by providing protection from various abiotic and biotic stresses. However, grass-endophyte partnerships are detrimental to grazing livestock, due to the production of an array of fungal alkaloids. To investigate this interaction at the molecular level, suppressive subtractive hybridization was used to identify differentially expressed genes from the symbiosis. In total, twenty-nine transcripts that may be fundamentally important for the effective functioning of this association have been identified. Two of these $(\mathrm{Nc} 12$ and $\mathrm{Nc25})$ were novel endophyte genes highly up-regulated in planta. $\mathrm{Nc12}$ is also up-regulated by phosphorus supplementation, and by infection with mutualistic arbuscular mycorrhizal fungi. The high expression of both fungal genes in planta suggests that they play crucial roles in the tall fescue-endophyte association. Confirmation of differential plant gene expression (either up- or down-regulated) was confirmed for 13 tall fescue genes by a combination of RT-PCR and Northern analysis. Of the genes that had matches to known genes present in the NCBI databases (approximately $40 \%$ ), many had roles related to plant defense and stress tolerance. Evidence for the functional role of one of the down-regulated tall fescue genes (TFR53), putatively encoding a pathogenesis-related (PR-10) protein, was obtained by showing that TFR53 gene expression could be induced by infection with a fungal pathogen. Additionally, the expression of selected tall fescue and fungal genes were studied in immature tissues. Not all genes were differentially expressed at this early stage of the symbiosis. Overall these results indicate that both partners in this symbiosis are active participants, and that the endophyte may be suppressing at least one plant defense gene (putatively encoding PR-10). Analyses of genes with altered transcription in grass-endophyte symbiotic associations should aid in understanding the fundamental processes of establishment and maintenance of mutualistic symbioses, as well as provide insight into genes important for the documented endophyte-enhanced plant improvements. 


\section{ACKNOWLEDGEMENTS}

Firstly, I would like to thank my PhD supervisor Dr. Dan Panaccione for his support during this long road towards achieving my $\mathrm{PhD}$. I would especially like to express my gratitude for giving me the freedom to often carry out my experiments as I saw fit, and for supporting my decision to return to $\mathrm{NZ}$ to complete my $\mathrm{PhD}$. I also learnt a lot more than I ever could have imagined from Dan's enthusiastic teachings about fungi and mushrooms!

I would like to thank all the past and present members of Brooks Hall, who I interacted with during my two and a half year stay at WV. In particular I would like to thank my fellow PhD student Ked Damrongkool, who shared many of the same pains with me as a PhD student. I must also thank her for introducing me to the gym and encouraging me to keep going! I was lucky to meet true West Virginia girls Betsy Kurnik and Nancy Sheets, who provided lots of laughs! Nan and Joe, thanks guys, it wouldn't have been the same experience without your friendship and is something neither Richard nor I will forget. Thanks to Satish Bhatia for providing technical support in the lab as well as for all his caring advice. I also thank Andrea Sedlock, a fellow student in our lab as well as Erin Zervos for helping in the lab.

Dr. Joe Morton, I really appreciated your enthusiasm in teaching plant pathology and for your interest in my research. Thanks for the faith you appeared to have in my abilities, which encouraged me endlessly. Also, I thank you for helping me to learn 
how to inoculate tall fescue with mycorrhizae. I also thank Bill Wheeler for technical help with the mycorrhizal experiment and for your friendship during our stay at WV.

I would also like to extend my thanks to all my committee members who have all in some way contributed towards this PhD. I thank them for kindly suffering the inconvenience of editing my thesis electronically and for defending from afar. I would especially like to express my gratitude to Prof. Chris Schardl who has journeyed a long way from Kentucky to West Virginia on a couple of occasions to participate as a committee member. Thank you for all the helpful advice given throughout this $\mathrm{PhD}$, particularly for advocating $\mathrm{SSH}$ as the subtractive procedure of choice and for readily supplying plant material for this project. I thank both Alfred Byrd and Walter Hollin from Chris's lab for providing technical support.

I thank Dr. Mark Farman, for giving me the valuable opportunity to come to your lab in Kentucky, and for taking the time to teach me how to inoculate tall fescue with $P$. grisea .

My sincere thanks goes to Prof. Barry Scott, who was kind enough to offer me a space in his lab in $\mathrm{NZ}$ to finish up my $\mathrm{PhD}$ research at this critical time. I would also like to thank all members of the Scott Base lab at Massey University who offered their friendship and made me feel part of the lab for this short time. In particular, thanks to Carolyn Young for her kindness in sharing her desk and lab bench with me. 
Lastly, my deepest gratitude and heartfelt thanks to my husband, Richard Johnson, who I could not have completed this $\mathrm{PhD}$ without due to his continual support, encouragement and scientific guidance. We have worked alongside one another in the same lab in two different countries for over five years. A feat I feel few couples could have accomplished so successfully. There were some rough times, but his teaching over all these years has significantly contributed to the scientist I am today, and from this I have benefited enormously and thus feel extremely fortunate. I must also acknowledge that this $\mathrm{PhD}$ project was his idea, and as he had always wanted to do this project himself, I would like to applaud his selflessness for in essence giving me that opportunity instead. 


\section{TABLE OF CONTENTS}

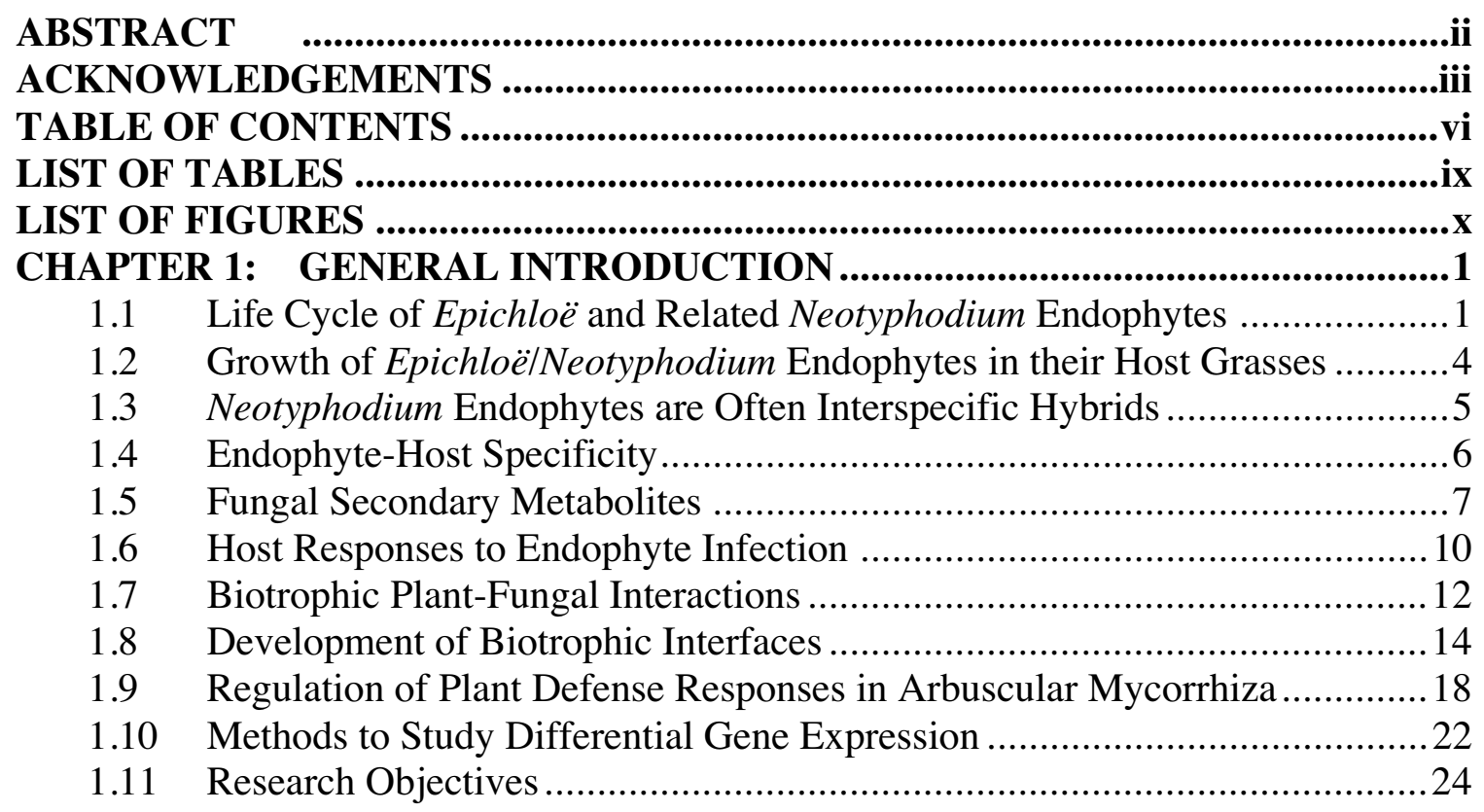

CHAPTER 2: IDENTIFICATION OF DIFFERENTIALLY EXPRESSED

GENES IN THE MUTUALISTIC NEOTYPHODIUM COENOPHIALUM-

TALL FESCUE INTERACTION ..................................................................27

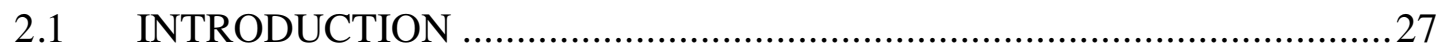

2.2 MATERIALS AND METHODS ........................................................... 31

2.2.1 Biological Materials .............................................................................. 31

2.2.2 Preparation of Subtracted cDNA Libraries by Suppression Subtractive

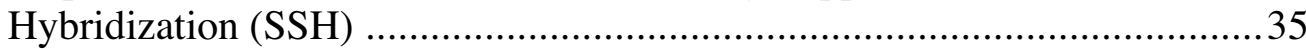

2.2.3 Differential Screening of Subtracted cDNA Libraries ............................... 37

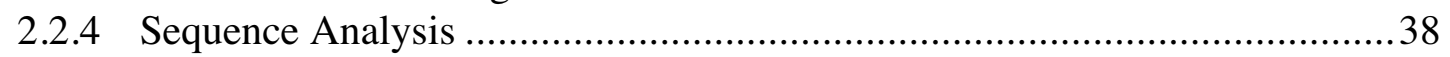

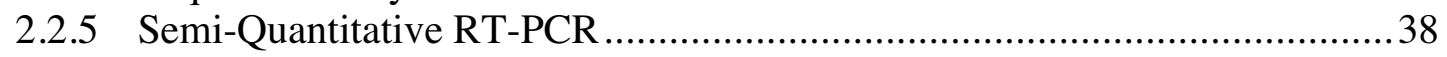

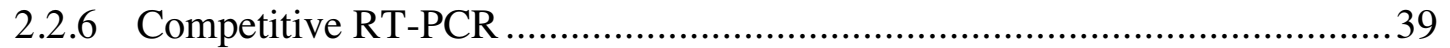

2.2.7 Screening of Lambda ZAP II cDNA Libraries ........................................ 41

2.2.8 Southern Blot Hybridization.................................................................. 42

2.2.9 Northern Blot Analysis ..................................................................... 44

2.3 RESULTS: IDENTIFICATION OF DIFFERENTIALLY EXPRESSED cDNA CLONES .............................................................................44

2.4 RESULTS: CONFIRMATION OF DIFFERENTIALLY EXPRESSED PLANT GENES BY SEMI-QUANTITATIVE AND COMPETITIVE RT-PCR

2.5 RESULTS: IDENTIFICATION OF DIFFERENTIALLY EXPRESSED FUNGAL TRANSCRIPTS ..............................................................53

2.6 RESULTS: IN PLANTA EXPRESSION OF FUNGAL TRANSCRIPTS

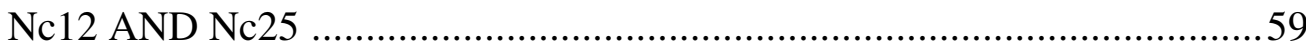

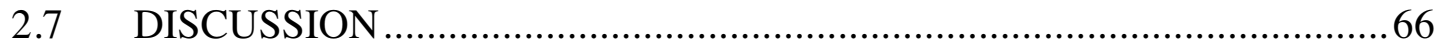




\section{CHAPTER 3: EXPRESSION ANALYSIS OF TALL FESCUE AND ENDOPHYTE GENES IN OTHER GRASS-ENDOPHYTE ASSOCIATIONS AND THE EFFECTS OF FUNGAL INFECTION BY MYCORRHIZAL FUNGI AND PYRICULARIA GRISEA}

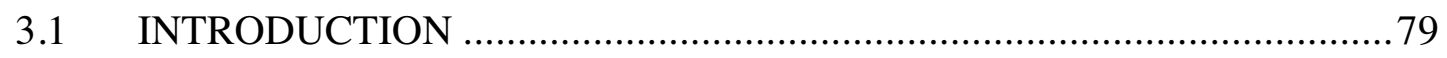

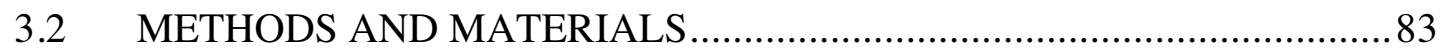

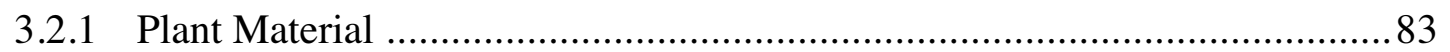

3.2.2 Northern Blot Analysis of Endophyte-Grass Associations .......................... 84

3.2.3 Southern Blot Hybridization.............................................................. 84

3.2.4 Inoculation of Tall Fescue with Arbuscular Mycorrhizal Fungi (AMF) .......86

3.2.5 Microscopic Detection of AMF-Colonization........................................... 87

3.2.6 Gene Expression Studies of AMF-Infected Tall Fescue ..............................8 87

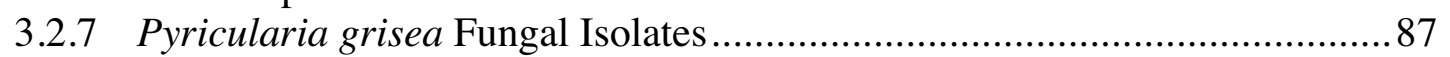

3.2.8 Inoculation of tall fescue with $P$. grisea isolates ................................... 88

3.2.9 Northern Analysis of $P$. grisea Infected Tall Fescue.................................. 88

3.3 RESULTS: ANALYSIS OF TALL FESCUE AND N. COENOPHIALUM GENE EXPRESSION IN DIFFERENT GRASS-ENDOPHYTE

ASSOCIATIONS ......................................................................89

3.3.1 Northern Analysis of the Putative Tall Fescue PR-10 gene (clone TFR53) ..89

3.3.2 Northern Analysis of the Putative Tall Fescue $A B C$ Transporter Gene (Clone TFF32)

3.3.3 Northern Analysis of Clone TFF24, Putatively Encoding an RNA-binding

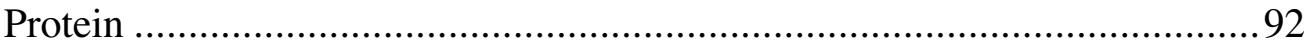

3.3.4 Northern analysis of clone TFF25, putatively encoding a metallothionein

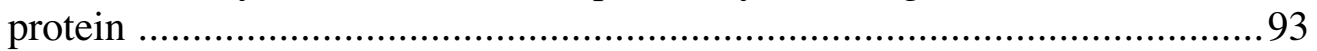

3.3.5 Transcripts not detected by Northern Analysis .........................................96

3.3.6 Southern Analysis .................................................................................96

3.4 RESULTS: EFFECT OF INFECTION WITH ARBUSCULA MYCORRHIZAL FUNGI GLOMUS CLARUM AND G. ETUNICATUM ON EXPRESSION OF SYMBIOSIS-RELATED GENES ........................98

3.4.1 Infection of Tall Fescue with AMF ........................................................98

3.4.2 Affect of AMF-Colonization on the Expression of a Putative Tall Fescue

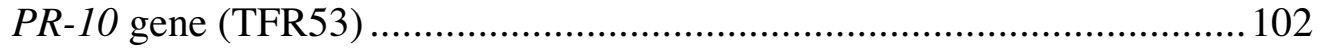

3.4.3 Expression of a Putative Tall Fescue $A B C$ Transporter Gene (TFF32) in AMF-Colonized Tall Fescue ............................................................... 103

3.4.4 Analysis of TFF25 and Nc25 Gene Expression ..................................... 103

3.4.5 Expression of Nc12 is Up-Regulated by Phosphorus and AMF Colonization 104

3.4.6 TFF26 is Differentially Expressed by Infection with Endophyte but not by

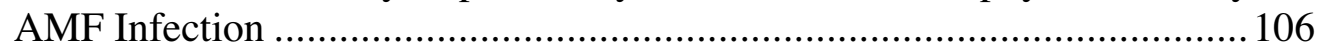

3.4.7 TFF41 is not Differentially Expressed in Immature Stems......................... 107

3.5 RESULTS: INFECTION OF E+ AND E- TALL FESCUE WITH COMPATIBLE FUNGUS PYRICULARIA GRISEA.............................. 109

3.5.1 Expression of the Putative Tall Fescue PR-10 gene (TFR53) in Leaves ..... 111

3.5.2 Expression of the Putative Tall Fescue $P R-10$ gene (TFR53) in 
Pseudostems............................................................................... 111

3.5.3 Expression of the Putative Tall Fescue $A B C$ gene (TFF32) in Leaves ........ 111

3.5.4 Expression of Fungal Genes Nc12 and Nc25 in Pseudostems ................... 112

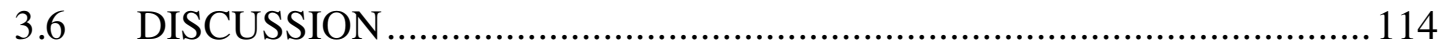

CHAPTER 4: GENERAL DISCUSSION ...................................................121

$4.1 \quad \mathrm{Nc} 12$ and Nc25 are Novel Fungal Genes ........................................... 123

4.2 Expression of select Tall Fescue Genes in other Endophyte-Grass Associations ............................................................................. 124

4.3 Influence of AMF-Colonization on Tall Fescue Gene Expression............... 125

4.4 Identification of Possible Roles for some Tall Fescue Genes in the

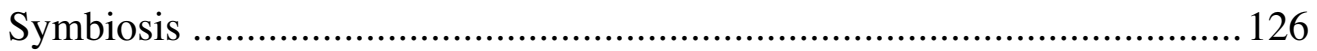

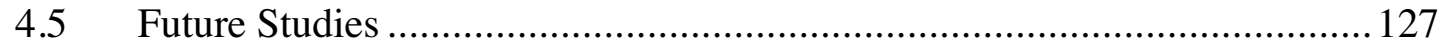

4.6 Complementary Studies ............................................................... 128

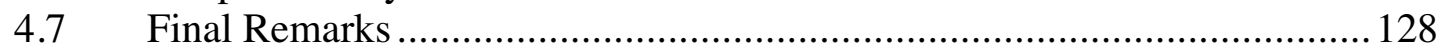

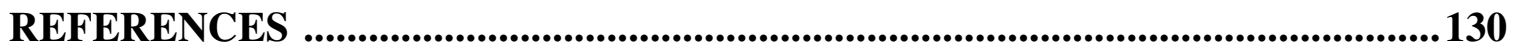




\section{LIST OF TABLES}

Table 2.1. Grass-Endophyte Associations Used in Study.................. 33

Table 2.2. $\quad$ PCR Primers.............................................. 34

Table 2.3. Genes Putatively Up-Regulated in the Tall Fescue-

N. coenophialum Symbiosis................................... 48

Table 2.4. Genes Putatively Down-Regulated in the Tall Fescue-

N. coenophialum Symbiosis....................................... 49

Table 3.1. Grass-Endophyte Associations Used in Study................... 83

Table 3.2. PCR Primers.......................................... 85

Table 3.3. Pyricularia grisea isolates used in this study.................... 88 


\section{LIST OF FIGURES}

Figure 1.1. Characteristic Appearance of Intercellular Fungal Hyphae in Leaf Sheaths of Tall Fescue................................... 5

Figure 2.1. Duplicate cDNA Dot Blots............................... 47

Figure 2.2. Semi-Quantitative RT-PCR Analysis of Differentially Expressed Clones............................................ 51

Figure 2.3. Quantitative RT-PCR Analysis of Clone TFF41................. 52

Figure 2.4. Alignment of N. coenophialum and N. lolii $\mathrm{Nc} 25$

Fungal Sequences...................................... 57

Figure 2.5. Southern Blot Analysis of Fungal Clones Nc25

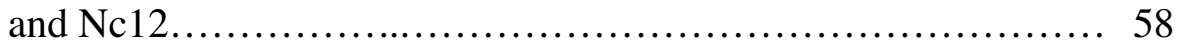

Figure 2.6. Fungal Clones Nc12 and Nc25 are Up-Regulated In Planta................................................. 60

Figure 2.7. Northern Analysis of Nc12 and Nc25 in other Endophyte-Grass Associations............................. 63

Figure 2.8. Quantitative RT-PCR Analysis of Nc12 ..................... 65

Figure 3.1. Northern Analysis of Tall Fescue Genes....................... 94

Figure 3.2. Northern analysis of TFR53 and TFF32 in related grasses perennial ryegrass and meadow fescue...................... 95

Figure 3.3. Southern Analysis of Tall Fescue Clones TFR53, TFF32, and TFF41....................................... 97

Figure 3.4. Appearance of Tall Fescue Plants Colonized by Arbuscular Mycorrhiza.............................................. 100

Figure 3.5. Sections of Roots Stained for AMF colonization by Microscopy........................................... 101

Figure 3.6. Northern analysis of Nc25/TFF25, Nc12, TFF32, TFR53 transcripts................................... 105

Figure 3.7. Semi-Quantitative RT-PCR Analysis of TFF26 in Immature Pseudostems.............................................. 107

Figure 3.8. Quantitative RT-PCR analysis of TFF41 in Mycorrhizal Infected Tall Fescue........................................ 108

Figure 3.9 Pyricularia grisea Disease Symptoms in Tall Fescue............ 110

Figure 3.10 Northern analysis of Pyricularia grisea Infection of Tall Fescue on the Expression of Transcripts TFR53 and TFF32............. 113 


\section{CHAPTER 1: GENERAL INTRODUCTION}

In this study, my main aim was to investigate the mutually beneficial Neotyphodium coenophialum-tall fescue interaction at the molecular level. My research project has focused on identifying genes that have altered expression in the $N$. coenophialum-tall fescue symbiosis as compared to their expression from each of the free-living partners. I have searched for plant and fungal genes that are both up- and down-regulated during the symbiosis by using suppression subtractive hybridization (SSH) (Diachenko et al.1996) to create two subtracted libraries.

In this introductory chapter, the background of endophyte-grass associations is reviewed, to set a context for future discussions of the possible function of genes discovered in the course of my research that have putative identities to the NCBI database (BlastX analysis; Altscul et al. 1997). The physiology of the symbiosis is described and compared alongside other symbioses. The documented host responses to endophyte infection are also discussed to make the reader aware of endophyte-induced phenotypic alterations. Current knowledge on the regulation of plant defense responses to arbuscular mycorrhizal (AM) fungi (another mutualistic plant-fungal association) also are included since some commonalities in symbiosis regulation may exist between AM symbioses and endophyte-grass symbioses. Lastly, an overview on methods to study differential gene expression is given, followed by my research objectives.

\subsection{Life Cycle of Epichlö and Related Neotyphodium Endophytes}

Claviciptaceous endophytes of the genus Epichloë (order Hypocreales, phylum Ascomycota) and related asexual Neotyphodium species [reclassified from Acremonium 
sect. Albo-lanosa by Glenn et al. (1996)] form symbiotic associations with cool-season grasses of the Pooideae subfamily (Clay and Leuchtmann 1989; Schardl et al. 1997). Associations range from antagonistic (highly pathogenic) to mutualistic (beneficial), depending upon the relative importance of the sexual or asexual life cycle of the fungus (reviewed in Schardl 1996). Epichloë species that are highly antagonistic to their host grasses (also referred to as Type I by White 1988) cause reproductive sterilization of their host by the formation of an external sexual structure called a stroma (choke disease). Ectophytic stromata, containing the fungal sexual structures for reproduction and contagious spread, surround and abort host grass inflorescences (Chung and Schardl 1997a). These fungi are heterothallic and require spermatia to be transferred from stromata of an opposite mating type by feeding flies of the genus Botanophila (Bultman et al. 1998) to fertilize the female structures in the stroma. Meiotic ascospores (sexual spores) are forcibly ejected from perithicia that form embedded within the stromata after fertilization. Discharged ascospores may penetrate the stigmata of flowers or cut culms of neighbouring plants (Chung and Schardl 1997a; Western and Cavett 1959). For most of the grass life cycle, these antagonistic endophytes cause no symptoms since systemic growth is entirely intercellular with epiphytic growth occurring only with the onset of flowering. The highly antagonistic endophytes are typically only transmitted horizontally via ascospores since seeds are usually not infected.

Type II (White 1988) Epichlö̈ symbionts may be both horizontally (via ascospores) and vertically transmitted through seeds of infected plants (Sampson 1933). These Epichloë endophytes are particularly interesting since they may represent an evolutionary transition between the contagious and vertically transmitted endophytes. $E$. 
festucae is an example of an endophyte that tends to be in balanced symbiosis, since only a minority of tillers of the infected plant are choked (in the host red fescue, Schardl 2001), and the overall benefits bestowed upon its host appear to outweigh any small losses in grass reproduction (if these occur). E. festucae also appears to have a role in the evolution of a number of mutualistic Neotyphodium endophytes (Craven et al. 2001a; Schardl et al. 1994; Tsai et al. 1994).

The asexual Neotyphodium endophytes (Glenn et al. 1996) are truly endophytic as fungal hyphal growth is always intercellular, even during flowering time. These type III endophytes form only mutualistic relationships with their hosts and induce no symptoms. An external infective stage is completely lacking and they do not cause any disruption of host reproduction. The ovule of the developing host seed is ultimately infected by endophytic hyphae located in the intercellular spaces of the embryo (Freeman 1904, Philipson and Christey 1996, White et al. 1991). Seed transmission is particularly important for the type III endophytes since this is the only means of fungal propagation. Consequently, vertical transmission of these endophytes is extremely efficient and can approach $100 \%$. The developmental pathway for seed transmission begins when fungal hyphae invade the ovule primordium ensuring that the fungus is present during subsequent seed development. Hyphae proliferate during seed development to form an obvious mat between the aleurone and the seed coat. Generally, hyphae are intercellular, but occasionally intracellular hyphae for penetration of the embryo sac cell wall and for invasion of the embryonic shoot occur, processes that are vital for vertical transmission (Freeman 1904, Philipson and Christey 1986). In these instances, hyphae are always surrounded by an invagination of the host plasmalemma to retain host integrity (Philipson 
and Christey 1986) similar to intracellular penetration that occurs during rhizobium and arbuscular mycorrhizae symbioses with plant roots

\subsection{Growth of Epichlö̈/Neotyphodium Endophytes in their Host Grasses}

Hyphal growth of both Epichloë/Neotyphodium endophytes within their host grasses is highly regulated. Growth of hyphae is synchronized with leaf growth, since hyphal growth occurs rapidly during leaf growth, and ceases when leaf growth stops (Christensen et al. 2002). As a result, similar concentrations of hyphae are present in both young and old leaves. Surprisingly, although fungal hyphae stop growing in mature tissues, reporter-gene expression studies indicate that the fungus remains metabolically active (Herd et al. 1997, Spiering 2000). Metabolic activity would presumably be required for the continual production of bioprotective fungal secondary metabolites during the life span of the association.

Hyphae are typically distributed more abundantly in sheaths than in blades of vegetative tillers. Intercellular hyphae have a characteristic appearance in leaf sheaths, being seldom branched and in nearly all associations aligned parallel to the leaf axis (Fig. 1.1). No intracellular hyphae have been observed in the asymptomatic (mutualistic) associations (those that do not spread horizontally). Of significance is the observation that intercellular growth does not result in the surrounding cells producing any signs of a plant defense reaction (Christensen 1995), although some artificial associations (those involving fungi not naturally associated with the host grass) do show some signs of incompatibility (see section 1.4). 


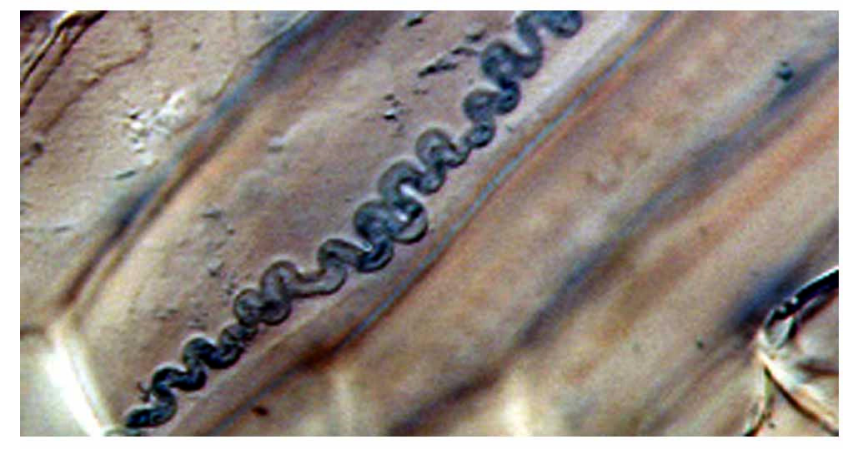

Figure 1.1. Characteristic Appearance of Intercellular Fungal Hyphae in Leaf Sheaths of Tall Fescue.

Aniline blue staining of $N$. coenophialum hyphae in peeled leaf sheaths of tall fescue plant 15 (Table 2.1) visualized by light microscopy (400X). Photograph courtesy of D.G. Panaccione and R.D. Johnson.

\subsection{Neotyphodium Endophytes are Often Interspecific Hybrids}

Neotyphodium endophytes are asexual and so classification based on a biological species concept cannot practically apply. However, their host associations and morphological characteristics all indicate their relatedness to Epichlö̈ species. Phylogenetic analysis based on molecular data has enabled these asexual endophytes to be classified and has revealed that many Neotyphodium endophytes appear to have arisen by interspecific hybridization. Analysis of the non-coding region of $\beta$-tubulin genes (tub2) showed the presence of multiple tub2 copies for several asexual Neotyphodium species and a single copy for each Epichloë species examined reflecting their haploid state (Schardl et al. 1994; Tsai et al. 1994; Moon et al. 2000; Craven et al., 2001a). Surprisingly, each of the multiple tub2 copies from the apparently hybrid Neotyphodium species grouped more closely with a tub2 gene from different Epichloë species rather 
than grouping the multiple $t u b 2$ genes with each other. The tall fescue endophyte $N$. coenophialum, for example, contains three tub2 genes that correspond to E. festucae, E. typhina and an E. baconii related fungus (Tsai et al. 1994), whereas N. siegelii, a rare endophyte of meadow fescue (Lolium pratense $=$ Festuca pratensis), is a hybrid of $E$. festucae and E. bromicola (Craven et al. 2001a). Similarly, many other asexual Neotyphodium endophytes have genes derived from different combinations of Epichlö̈ species (Craven et al. 2001a, 2001b; Moon et al. 2000; Schardl and Wilkinson 2000) indicating that they are interspecific hybrids of their sexual Epichlö relatives. These genetic hybrids are thought likely to have arisen through the parasexual process of hyphal anastomosis in doubly infected plants (Schardl et al. 1994; Schardl and Wilkinson 2000). Neotyphodium coenophialum has three ancestors and so has probably arisen from at least two hybridizations. In accordance with this hypothesis, these apparent hybirds have genome sizes nearly twice those of the Epichlö̈ spp. most closely related to their

ancestors as well as larger conidia (Craven et al. 2001a; Kuldau et al. 1999). Neotyphodium lolii, the common endophyte from perennial ryegrass appears to be one of the few Neotyphodium endophytes that is not a hybrid, but its relatedness to E. festucae is evident by its genetic similarity (Schardl et al. 1994).

\subsection{Endophyte-Host Specificity}

Host specificity appears to be typical of both the asexual Neotyphodium endophytes as well as the sexual Epichlö̈ endophytes. Mating tests have identified mating populations MP-I through to MP-IX of Epichlö̈ species (Schardl and Wilkinson 2000). Five of these are endemic to Eurasia and four to North America. All but one of 
these Epichlö̈ species exhibit host-specificity; the exception is E. typhina, which has a wide host range, although strains of E. typhina can be host specific (Chung and Schardl 1997b).

Novel associations of Neotyphodium/Epichlö̈ endophytes with grasses they are not known to infect in nature (obtained by the artificial inoculation of grass seedlings) have revealed the host specific nature of these endophytes. No adverse reactions occur in some novel associations. However, incompatibility reactions indicative of a plantdefense reaction can be observed in others. These reactions can include death of host cells (Christensen 1997), death of hyphae (Koga et al. 1993) and a high level of seedling mortality. Failure to establish novel associations results in necrosis at seedling inoculation points. These obvious defense reactions contrast with the apparent lack of a host defense in the natural associations.

\subsection{Fungal Secondary Metabolites}

The plant host receives various benefits from Epichloë/Neotyphodium endophyte infection, primarily protection from biotic and abiotic stresses (reviewed in Belesky and Malinowski 2000). Many of these benefits have been associated with the production of a diverse range of biologically active secondary metabolites produced by these endophytes in association with their grass hosts. There are four classes of well-defined fungal toxic alkaloids with proposed plant protective roles: the pyrrolopyrazine alkaloid, (peramine); ergot alkaloids; pyrrolizidines (lolines); and, indole-diterpenoids (lolitrems) (for excellent reviews see Porter 1994; Bush et al. 1997; Siegel and Bush 1997). Different combinations of these four classes of alkaloids are produced by individual endophytes in 
infected grasses, however, no more than three of these compounds have ever been found in one symbiotum. The endophyte $N$. coenophialum produces three classes of alkaloids in planta: ergot alkaloids (ergovaline), peramine, and lolines.

Secondary metabolite concentrations are affected by changes in plant growth conditions, and are sometimes increased during plant stress, suggesting that some changes in metabolite concentration may be associated with plant defense (Lane et al. 2000). Although all of these bioactive alkaloids are products of the fungal genome (Blankenship et al. 2001; Porter 1994), increasing evidence suggests that quantitative metabolite expression is also regulated by the plant host genome (Lane et al. 2000).

Ergot alkaloids are widespread in clavicipitaceous endophytes. In many endophyte-grass associations, the specific chemical composition and concentration of an ergot alkaloid can vary. In $N$. coenophialum-tall fescue associations, ergovaline is the predominant ergot alkaloid. Ergovaline also is thought to be the major factor linked to the toxic syndrome, "fescue toxicosis", in grazing livestock (Thompson and Stuedemann 1993), resulting in estimated annual losses of hundreds-of-millions of dollars to US agriculture. Symptoms of this toxicosis can be extremely serious and are affected by animal physiology and temperature extremes. Possible symptoms include loss of control of body temperature and water balance, loss of appetite, gangrene of limbs, and reduced lactation and fertility (Schardl and Phillips 1997). Ergovaline concentration in this association is affected by at least two environmental factors, nitrogen fertilization and soil water deficit (Siegel and Bush 1997). Concentrations of ergovaline as well as lolines were increased during water stress conditions, and ergovaline concentration alone was increased under high nitrogen levels (Arechavaleta et al. 1992). The plant genotype, 
tissue type and the season also can influence in planta ergot alkaloid concentrations. The same endophyte genotype introduced into different tall fescue genotypes can significantly alter alkaloid concentration (Hill et al. 1991). Ergot alkaloids in general have a low deterrence activity against aphids (Siegel et al. 1990).

Ergovaline is a member of the ergopeptine group that is synthesized nonribosomally by multifunctional enzyme complexes called peptide synthetases. Ergopeptines contain lysergic acid and three other amino acids that vary between each ergopeptine member. Knockout analysis of a peptide synthetase gene essential for ergovaline production (lpsA) from Neotyphodium sp. Lp1 resulted in the elimination of ergovaline in planta and did not adversely affect endophyte colonization of perennial ryegrass (Panaccione et al. 2001). The contribution of ergovaline to animal toxicity and its potential role in other endophyte-induced host enhancements such as nematode resistance can now be assessed in trials using the knockout ergovaline minus strain alongside the ergovaline producer strain under genetically identical backgrounds.

The saturated amino pyrrolizidine alkaloids, collectively known as lolines (mainly $\mathrm{N}$-formylloline and $\mathrm{N}$-acetylloline), are produced abundantly in endophyte-grass associations, and levels in meadow fescue associations have been reported to reach more than $2 \%$ of the plant's dry mass (Craven et al. 2001a). Although lolines may not be toxic to mammals, numerous reports suggest that they have strong insecticidal and feedingdeterrent properties (Bush et al. 1993; Dahlman et al. 1997; Riedell et al. 1991; Siegel et al. 1990, Wilkinson et al. 2000). Loline production is controlled by a single genetic locus in E. festucae (Wilkinson et al. 2000). Genes putatively associated with loline biosynthesis have been isolated from $N$. uncinatum and one of these genes cosegregates 
with the loline locus identified in E. festucae (Spiering et al. 2002). These alkaloids also may be involved in increasing plant competitiveness, since the growth of neighboring plants alongside loline producing $N$. uncinatum-infected meadow fescue is suppressed (Bush et al. 1997; Fletcher et al. 2000; Malinowski et al. 1997a, b).

Peramine is found in the majority of symbiota and is the only member of the pyrrolopyrazine class of alkaloids to be found in Epichloë/Neotyphodium infected grasses (Siegel et al. 1990). The primary activity of peramine is believed to be insect deterrence (Rowan 1993).

The lolitrems are indole-diterpenes produced mainly by $N$. lolii-perennial ryegrass associations and are well known for their tremorgenic activities associated with the disorder ryegrass staggers, a neurological disorder of sheep (Gallagher et al. 1984; Miles et al. 1992). These indole-diterpenes are found in several other fungi and the gene cluster from a Penicillium paxilli isolate that produces the indole-diterpene paxilline has been cloned and genetically analyzed (Young et al. 2001). Three clustered genes orthologous to those in the P. paxilli cluster also have been isolated from $N$. lolii and are therefore probably involved in lolitrem biosynthesis (Scott 2001).

\subsection{Host Responses to Endophyte Infection}

Epichlö̈ and Neotyphodium endophytes provide a competitive advantage to infected grasses presumably by the production of protective alkaloids as well as by inducing physiological changes in their host grass that enable the host grass to quickly adapt to a variety of challenging circumstances. Resistance to insect herbivores, nematodes, and fungal disease, as well as tolerance to drought and high temperatures may 
be attributable to alkaloid production (Arechavaleta et al. 1989; Bacon 1993; Clay and Cheplick 1989; Gwinn and Gavin, 1992; Latch 1993; Popay and Rowan 1994; Siegel et al. 1987; West 1994). Other effects of endophyte infection on the host plant involve osmotic adjustment, stomatal regulation, modification of root morphology, and alteration of nitrogen accumulation and metabolism (reviewed by Belesky and Malinowski 2000). Vegetative growth also may be enhanced by the production of fungal auxin-like compounds (De Battista et al. 1990; Porter et al. 1985). E+ tall fescue and meadow fescue grasses, but not perennial ryegrass, exhibit stomatal closure more rapidly than noninfected plants under water stressed conditions (Malinowski and Belesky 2000). Stomatal closure induced by water deficit may benefit plants by reducing water loss via transpiration (Turner 1986). Mechanisms for this adaptation are unknown, but have been hypothesized to occur through an endophyte biochemical signal or an altered hormonal status (Belesky et al. 1987; West et al. 1994). Potentially the endophyte may precondition the host grass to drought or other stresses by inducing an internal stress by its presence. E+ grasses induce a range of responses to water deficit that encompass drought tolerance, drought avoidance and recovery mechanisms. E+ plants can facilitate rapid re-growth upon the return of plentiful water supplies. Roots can rapidly uptake water, and physiological functions of tissue can be restored (West et al. 1994; Malinowski et al. 1997b). Although it is clear that these observed changes in host metabolism are directly influenced by the endophyte, it is unknown whether alkaloids or other fungal metabolites are responsible for all these changes. However, the widespread nature of $N$. coenophialum-infected tall fescue, in conjunction with its ability to successfully outcompete uninfected grasses in diverse environments, suggests that endophyte-infected 
grasses are at a natural selective advantage.

Our knowledge of the molecular signals involved in these grass-endophyte interactions still remains elusive. However, evidence that the endophyte is actively recognized by its host is provided from the following observations. Production of an antifungal phenolic compound, resveratrol, can occur in response to fungal infection by plants (Sylvia and Sinclair 1983). Powell et al. (1994) found that resveratrol concentration was higher in Neotyphodium infected than in uninfected tall fescue. Malinowski et al. (1998) later found that higher concentrations of phenolic-like compounds were present in all parts of Neotyphodium-infected tall fescue compared with uninfected tall fescue. The presence of chitinase, a pathogenesis-related protein, in endophyte-infected tall fescue (Roberts et al. 1992), in addition to phenolic compounds, suggests that endophyte-grass associations are not completely benign environments for the endophyte. Antifungal activity also has been detected in these endophyte associations (Christensen 1996) and protection against these plant compounds has been spectulated to occur through proteinase activity, since one is present in endophyte cell walls (Lindstrom and Belanger 1994). The host must recognize the endophyte to exert some control over fungal growth. The lack of any visible host defense response reaction suggests that either the endophyte can actively suppress certain plant defenses or can avoid the elicitation of them.

\subsection{Biotrophic Plant-Fungal Interactions}

Broadly, symbiosis refers to organisms living together and these interactions can be parasitic, commensal, or mutualistic. The most widespread symbiotic interactions are 
formed between plants and fungi and include biotrophic plant pathogens such as those that produce the mildew and rust diseases and mutualistic symbioses with endosymbionts such as arbuscular mycorrhizal fungi (AMF). Endophyte-grass symbioses are unusual in that these interactions span a spectrum of relationships encompassing antagonistic as well as balanced and mutualistic interactions (Schardl 2001). In nature, all of these symbiotic associations with plants are characterized as biotrophic because they rely on living plant tissue for growth.

Mutualistic relationships must be beneficial to both partners and cause no disease. Two such plant-microbe interactions that have been extensively studied (other than grassendophyte symbioses) are the intracellular plant root symbioses with AMF and nitrogenfixing bacteria (referred to as rhizobia). Of significance is the finding that recognition by the plant host of both of these endosymbionts requires common signalling components and the conservation of some signal transduction pathways (Hirsch and Kapulnik 1998; Kistner and Parniske 2002; Stougaard 2001). Evidence is provided from the number of common nodulin genes induced in both types of interactions as well as plant mutants that are defective in both symbioses.

The mutualistic symbiosis formed between AMF (Zycomycetes, Glomales; Morton and Benny 1990) and roots of terrestrial flowering plants are the most common. The symbiosis had its origins in the Devonian period during which time plants colonized land (Remy et al. 1994). Therefore this symbiosis is generally hypothesized to have assisted plants in the colonization of land (Pirozynski and Malloch 1975). AMF are ubiquitous soil fungi that are obligate biotrophs that form non-specific mutualistic symbioses in order to develop and complete their life cycle. 
Legumes form root nodule symbioses with nitrogen-fixing bacteria referred to as rhizobia. Ultimately, successful infection results in the development of a completely new plant organ, dinitrogen-fixing root nodules. Initiation of the nodulation process requires the exchange of signalling compounds between the plant host and bacterium and is hoststrain specific. Plant secreted flavonoids induce the synthesis of bacterial Nod factors (act as plant morphogens) required for host recognition (along with other components such as extracellular polysaccharides, lipopolysaccharides and secreted proteins). Intracellular invasion of the host is performed in a tightly controlled manner. Rhizobia invade in an infection thread formed from curled root hairs, enclosed in a host-derived peribacteroid membrane, until they are released into nodule cells for nodule development (Hirsch and Kapulnik 1998).

\subsection{Development of Biotrophic Interfaces}

A common feature of symbiotic associations is the development of specialized interfaces for nutrient transfer between symbionts. The interfaces are formed during invasion of the plant cell by various endosymbionts (such as AMF, biotrophic plant pathogens such as the rusts and smuts and the root nodule-forming bacteria, rhizobia) where it becomes surrounded by the plant membrane. In AMF associations with vascular flowering plants, colonization of the root is initiated by the formation of fungal appressoria on the root surface. After penetration of the root with coils and intercellular hyphae for spreading the infection, the fungus sends branches intracellularly within the cortex to produce highly branched structures called arbuscules. Two colonization patterns have been described that are influenced by the host plant and cell type (reviewed in 
Bonfante 2001; Smith and Smith 1997). An interface is formed between the arbuscule exclusively in plant root cortical cells whereas the other type of colonization morphology consists of extensive intracellular coils and is often produced in epidermis and exodermis cells (Bonfante and Genre 2000). The fine fungal structures of the arbuscule invaginate the plant plasma membrane (referred to as the peri-arbuscular membrane) resulting in the formation of a new apoplastic compartment. The symbionts are only separated by a thin interfacial matrix of plant origin and a minimal fungal cell wall. Both the intracellular and intercellular interfaces formed are assumed to function to allow a two-way exchange of signal molecules and nutrients. An interface between both symbionts is essential for the fungus, as it must obtain nutrients from its photoautotrophic partner. Carbon in the form of glucose is preferentially taken up and metabolized to trehalose and mobile lipids (Pfeffer et al. 1999). The mechanisms for carbon uptake by the fungus is unknown and may occur in the intercellular hyphae since these membranes, and not the arbuscular interface show high levels of ATPase activity that is likely required for the establishment of an active proton gradient (Harrison 1999). Nutrient transfer must be bidirectional at the interface in order that both symbionts receive nutrients-the basis for the mutualistic interaction. Evidence for bidirectional transfer has finally come from the identification of a plant phosphate transporter StPT3 from potato (Rausch et al. 2001). StPT3 was shown by in situ hybridization to be localized with cells containing arbuscules and is therefore presumably located in the plant derived periarbuscular membrane. Co-localization of a proton pump (H+-ATPase) suggests that energy to drive phosphate (P) uptake from the fungus via StPT3 is provided from the proton pump (Gianinazzi-Pearson et al. 2000). A phosphate transporter in the external hyphae of AMF participates in the active uptake of 
phosphorus from the soil (Harrison and van Buuren 1995), which is then transferred along many centimeters of hyphae for delivery to the arbuscules.

In the biotrophic pathogen/plant interactions, such as powdery mildews, the fungus infects the leaves via an appressorium. Penetration of the cell wall occurs and an interface is formed between a fungal structure termed a haustorium and the invaded leaf cell. The haustorium is completely surrounded by an extrahaustorial membrane, which is an invagination of the plasma membrane. A matrix of complex polysaccharides fills the intervening space between the haustorial wall and the extrahaustorial membrane (Mackie et al. 1991; Manners and Gay 1983). Transport across this interface contrasts with mutualistic associations in that nutrient flow is unidirectional towards the pathogen (Manners and Gay 1983; Smith and Smith 1989).

Unlike the other biotrophic interactions described above, grass-endophyte associations do not form obviously specialized structures to obtain nutrients. For the asymptomatic mutualistic endophyte-grass associations, no intracellular hyphae or haustoria have been observed and growth occurs entirely in the intercellular spaces where they obtain nutrients through unknown mechanisms. The apoplast separates the plant and fungal plasma membranes, but presumably enough photosynthates from the plant are released into the intercellular space to allow biotrophic growth of the endophyte since there is no evidence from ultrastructural studies that the host cell walls are enzymatically modified by action of nearby hyphae. There also are no signs of a plant defense reaction, which may in part be due to stealth (Christensen 1995; Koga et al. 1993). Hyphal penetration of young tissue is unlikely to occur by the production of extracellular pectic enzymes, since penetration appears to occur solely by physical pressure into existing 
spaces (Christensen et al. 2002). Little is known about the metabolic and structural interface between endophyte and host. Attachment of the endophyte hyphae to the host cell wall is likely to be important for establishing compatible interactions. Mucilage (intercellular matrix) is present at contact points between plant and fungal walls, and the contacting hyphal outer cell wall of some endophyte strains were fibrous (Christensen et al. 1997; Christensen et al. 2002). Additionally, hyphal cell walls were flattened at the point of contact, possibly to increase the nutrient absorption area. Subtle recognition changes in the host at hyphal contact points were occasionally indicated by the presence of small dense zones just inside plant cell walls. Additionally, chloroplasts within mesophyll cells were conspicuously absent from these points of contact (Christensen et al. 2002).

The question of how endophytes, while confined to the apoplastic space, acquire certain minerals and compounds essential for survival and for the production of secondary metabolites such as alkaloids, remains unanswered. Acquisition of sucrose as a carbon source is likely since sucrose is a major solute of the plant apoplast and the presence of cell wall invertase activity in E. festucae (Lam et al. 1994) implies the ability for conversion to hexoses. Both sucrose and hexoses are taken up by the endophyte, suggesting the presence of up-take mechanism, such as carriers (Lam et al. 1994). In addition to carbon sources, endophytes must acquire other essential elements, such as calcium, nitrogen, sulfur and phosphorus for proteins and other essential metabolites. A subtilisin-like proteinase is secreted by all Epichlö species analysed so far, suggesting a universal role possibly in the breakdown of plant cell wall proteins for metabolism or by causing host cell membranes to leak nutrients (Lindstrom and Belanger 1994; Reddy et 
al. 1996).

Phosphorus $(\mathrm{P})$ is apparently taken up by the endophyte since inorganic $\mathrm{P}$ has been reported to be stored in hyphae of $N$. coenophialum while associated with tall fescue seedlings, in a manner similar to that found for mycorrhizal fungi (Azevedo and Welty 1995). A study by Malinowski et al. (1998) showed that E+ grasses grown in low levels of $\mathrm{P}$, contained greater concentrations of $\mathrm{P}$ in roots and shoots than $\mathrm{E}$ - isolines. In subsequent studies, E+ plants, unlike their E- counterparts, exhibited at least one of two responses to $\mathrm{P}$ deficiency -- either altered root morphology (longer root hairs and smaller root diameters) and/or the release of phenolic-like chemicals into the rhizosphere (Malinowski and Belesky 1999; Malinowski et al. 1999). Interestingly, the response to P deficiency differed depending upon the genotype of the endophyte in E+ tall fescue, suggesting that mechanisms for $\mathrm{P}$ deficiency may be differentially expressed in a particular endophyte-tall fescue association. Perception of mineral stress signals such as $\mathrm{P}$ deficiency appear to be received by the endophyte, and a corresponding response was induced in the plant host to affect uptake of nutrients. However, the molecular signals underlying these endophyte-induced adaptation mechanisms have not been elucidated.

Notably, the response of AMF and grass endophytes to low phosphorus is different physiologically since endophyte hyphae are absent from roots, whereas AMF are restricted to roots where they form a hyphal extension (extra-radical mycelium) to physically search out inaccessible nutrients in the surrounding soil (Jakobsen et al. 1992).

\subsection{Regulation of Plant Defense Responses in Arbuscular Mycorrhiza}

Various types of intimate plant-microbe relationships can be established. These 
interactions can be pathogenic or mutualistic, but both types involve complex recognition events between the plant and its symbiont. Unlike mutualistic interactions, plantpathogenic interactions are detrimental to one of the two organisms involved. Either disease will develop in a compatible interaction, or a plant resistance response will be mounted in an incompatible interaction (reviewed by Somssich and Hahlbrock 1998). Two types of plant resistance responses can occur. A non-host resistance response is displayed by all plant species that respond to potential pathogens from other species, compared to the gene-for-gene host resistance response recognized by Flor (1971). The gene-for-gene response involves an interaction between the product of a resistance gene (R) and a complementary product of the corresponding pathogen avirulence (Avr) gene and results in pathogen containment. Despite these differences, the biochemical processes in both host and non-host resistance (a non-specific protective mechanism) are thought to be similar.

For the initiation of an effective plant defense response, potential invaders must be recognized. Elicitor molecules resulting from infection by microbes can be generated by chemical or physical damage to plant cell walls. Plant responses to pathogen attack involve the sudden release of active oxygen species, the activation of protein kinases, membrane bound enzymes, phospholipases, phosphatases and the production of signal molecules. These biochemical processes collectively induce complex signal transduction pathways to ultimately result in the transcriptional activation of defense-related genes and localized cell and tissue death. Rapid activation of these defenses in association with localized host cell death is called the hypersensitive response.

AMF are clearly recognized by their hosts since penetration of the root and 
intercellular growth results in plant-induced modifications as well as the induction of complex biochemical and cytological events. Although the mechanisms controlling these events are undefined at present, evidence suggests that, as in plant-pathogen interactions, induction as well as suppression of plant defense mechanisms play a crucial role in both AMF-colonization as well as host compatibility.

AMF that form incompatible associations with plants, or in $\mathrm{Myc}^{-}$mutants (that cannot form mycorrhizal associations), show that defense responses can be elicited. These responses involve a hypersensitive-like response (Allen et al. 1989). During the early stages of mycorrhiza formation, a number of defense-related components, including the accumulation of phytoalexins are reportedly activated (reviewed by Garcia-Garrido and Ocampo 2002). However, expression of these genes is usually weak and transient. This observation has led to the hypothesis that AMF can actively suppress a general plant defense response, or weak expression is due to the low capacity of the fungus to trigger such a response.

A number of defense genes (chitinases, $\beta$-1,3-glucanase, catalase, peroxidase, phenylpropanoid compounds) have been reported to be expressed in arbuscule-containing cells (Garcia-Garrido and Ocampo 2002). Potential roles for these genes in cells containing arbuscules may be to control the spread of hyphae and arbuscule formation in roots.

A possible mechanism to halt a plant defense reaction in response to AM symbioses might be to degrade the AMF produced elicitor molecule(s) or to prevent their release from plant cell walls. Lambais (2000) has proven that an AMF elicitor (from an extraradical mycelium extract) can induce a plant defense response, whereas intracellular 
fungal components could not. One interpretation of these results is that a factor exists in plants to breakdown fungal elicitor molecules. Other authors suggest that constitutive expression of plant chitinases in the early stages and the mycorrhizal-specific expression of chitinases in the later stages were responsible for elicitor degradation (Salzer et al. 2000; Salzer and Boller 2000).

AMF also produce very little plant cell wall degrading enzymes and the role of these enzymes is very selective and specific for fungal penetration thereby preventing elicitor formation (Garcia-Garrido et al. 2000).

The symbiotic genes (SYM) have fundamental roles in the establishment of both AMF and rhizobial colonization since a mutation in any of the SYM genes (SYM8, SYM9, SYM19, SYM30) blocks infection of either endosymbiont resulting in incompatibility and activation of plant defense, leading to resistance (Hirsch and Kapulnik 1998; Marsh and Schultze 2001; Parniske 2000). A mutation also disrupts the signal transduction cascade, implying that the symbiotic signal is no longer perceived by the plant. The SYM genes have therefore been hypothesized to either be involved in producing a negative regulator of a plant defense response, or inducing specific suppressors of the defense response by the endosymbionts (Gianinazzi-Pearson 1996).

Another mechanism to attenuate plant defenses could include the blockage of components of pertinent signal transduction pathways. Regulation of the plant defense response also may occur through alterations in plant hormones and imbalance of nutrients. Phosphate for example negatively regulates AMF root colonization and levels of plant hormones (ethylene, cytokinins) are altered in mycorrhizas (see Beyrle 1995 for a review). AMF can even produce plant hormones, but their exact roles in gene regulation 
are unclear (Barea and Azcon-Aguilar 1982).

\subsection{Methods to Study Differential Gene Expression}

A gene does not necessarily have to be up-regulated or down-regulated to have a critical role in specific biological processes. However, the screening for differentially expressed genes is an effective approach to investigate the molecular mechanisms of biological systems and has become one of the most important tools for gaining insights into gene-function. The development of sophisticated transcript profiling techniques has enabled researchers to study the expression of many genes in complex biological systems such as symbioses, in a single experiment.

Traditional screening methods, such as differential hybridization (Maniatis et al. 1982), in which the hybridization pattern of a cDNA library is compared between two labeled samples, were not very effective because the libraries were highly redundant and contained mostly abundant transcripts. With the advent of PCR, low abundance transcripts also could be amplified. One of the first techniques to utilize PCR was differential display (Liang and Pardee 1992). Short 5' arbitrary primers in conjunction with 3' anchored oligo(dT) primers were used to amplify cDNA fragments. These were separated on a denaturing polyacrylamide gel and autoradiographed for visualization. However, major disadvantages of this technique include a high incidence of false positives, low sensitivity (compared to more recent PCR techniques), and that the procedure is labor intensive (reviewed in Lievens et al. 2001). Improvements on this method yielding quantitative expression patterns include cDNA-amplified fragment length polymorphism (cDNA-AFLP) involving amplification with primers after 
restriction enzyme digestion and adaption ligation (Bachem et al. 1996). Other techniques such as representational difference analysis (RDA) combined the advantages of subtractive hybridization along with the power of PCR to create enriched pools of cDNA (Lisitsyn et al. 1993; Hubank and Schatz 1994). RDA is still biased towards the detection of abundant transcripts though and requires many rounds of subtraction. Suppressive subtractive hybridization ( $\mathrm{SSH}$ ), combined normalization of sequence abundance and subtraction during one hybridization step (Diatchenko et al. 1996). This procedure also utilizes the suppression PCR effect, which selectively suppresses amplification of cDNA sequences with identical adaptor sequences present on each end of ss cDNA during PCR. The ability of SSH to detect low abundance differentially expressed genes is advantageous because it can allow the identification of genes involved in signalling and signal transduction which may be essential regulatory components.

High-throughput methods for transcription profiling are serial analysis of gene expression (SAGE; Velculescu et al. 1995) and microarrays (Schena et al. 1995). These techniques combine the availability of sequence information generated through genome and EST projects (built by single-pass sequencing of random cDNAs; Adams et al. 1991) to quantitatively analyze thousands of genes at one time. For SAGE, the 3' end of each cDNA is tagged by a 9-11 bp DNA fragment generated by restriction digestion, amplified by PCR, ligated, concatenated and then cloned into a vector and sequenced. It is the frequency of each tag in the sequence that directly reflects the abundance of each mRNA in the tissue and the length of the tags are sufficient to unequivocally identity each gene. The expression of unknown genes can be obtained by SAGE, but the annotation of SAGE tags is based on pre-existing EST databases. 
For microarray analysis, thousands of clones are arrayed onto chips, or synthetic oligonucleotides can be synthesized in situ on silicon and hybridized with fluorescent probes (Lockhart et al. 1996). Subtracted cDNA pools prepared from SSH, RDA or differential display techniques, or unsubtracted cDNA preparations have been successfully used as probes to microarrays (Cho et al. 2001; Martin et al. 2001; Welford et al. 1998; Yang et al. 1999). For genome-wide studies of gene expression, these highthroughput techniques are ideal.

\subsection{Research Objectives}

The main objectives of this study are to:

1. Identify differentially expressed genes in the $N$. coenophialum-tall fescue association by suppressive subtractive hybridization (SSH).

2. Confirm differential gene expression of selected clones and further characterize clones of interest by obtaining full-length cDNA clones and /or genomic clones combined with the determination of gene copy number by genomic Southern blot analysis.

3. Examine the expression of selected differentially expressed genes in the following plant-fungal interactions:

a. In other endophyte-grass associations (tall fescue infected with $N$. siegelii, perennial ryegrass infected with $N$. lolii, and E. typhina; meadow fescue infected with $N$. siegelii, E. festucae and $N$. uncinatum versus endophytefree associations).

b. Mycorrhizal-infected, endophyte-free/endophyte-infected tall fescue 
compared with non-mycorrhizal, endophyte-free/endophyte-infected tall fescue.

c. Endophyte-free/endophyte-infected tall fescue with a compatible foliar pathogen (Pyricularia grisea) versus uninoculated endophytefree/endophyte infected tall fescue.

In chapter 2, differentially expressed genes were obtained by the preparation of two subtracted cDNA libraries by a PCR based cDNA subtraction procedure, suppressive subtractive hybridization (SSH; Diachenko et al.1996). Both up- and down-regulated transcripts were identified by the differential screening of forward and reverse subtracted SSH libraries respectively. Confirmation of differential gene expression for the majority of cDNA clones was carried out using semi-quantitative/quantitative RT-PCR. In addition, the two fungal clones obtained by $\mathrm{SSH}$ were shown by northern analysis to be up-regulated in planta. Southern hybridization of both fungal clones also was performed and their corresponding genomic clones were obtained.

In chapter 3, the expression of selected differentially expressed plant genes in various tall fescue associations were studied by northern analysis. Southern analysis also was carried out for three of these plant genes for the determination of copy number. Expression analyses of selected tall fescue and fungal genes were extended to other plantfungus interactions. Gene expression data were collected from related endophyte-grass interactions, the effect of colonization by other fungi that form mutualistic associations, AMF (Glomus clarum and Glomus etunicatum), as well as the influence of a compatible foliar pathogen, Pyricularia grisea. 
Finally, in chapter 4 , the results are summarized and their significance discussed. 


\section{CHAPTER 2: IDENTIFICATION OF DIFFERENTIALLY EXPRESSED GENES IN THE MUTUALISTIC NEOTYPHODIUM COENOPHIALUM-TALL FESCUE INTERACTION}

\section{$2.1 \quad$ INTRODUCTION}

Tall fescue (Lolium arundinaceum = Festuca arundinacea , Darbyshire 1993), an agronomically important forage grass, is typically associated with a mutualistic asexual fungus Neotyphodium coenophialum. Plant colonization is endophytic and symptomless, with fungal growth confined to the intercellular spaces and fungal dissemination dependent upon vertical, maternal transmission through infected host seed. The endophyte partner enhances its host's fitness by improving nutrient acquisition, and by providing protection from various abiotic and biotic stressors such as insect herbivores, nematodes, pathogenic fungi, drought, and high temperatures. I used suppressive subtractive hybridization (SSH) to identify differentially expressed genes in $N$. coenophialum and tall fescue associated with $N$. coenophialum. Genes that are upregulated and down-regulated in endophyte-infected tall fescue as compared to endophyte-free tall fescue were identified, as well as were two novel fungal genes that are up-regulated in planta. Analyses of genes with altered transcription in grassendophyte symbiotic associations should aid in understanding the fundamental processes of establishment and maintenance of mutualistic symbioses, as well as provide insight into genes important for the documented endophyte enhanced plant improvements.

Plants have developed mutualistic symbioses with diverse organisms for their 
mutual benefit. The symbiosis formed between seedborne Neotyphodium Glen et al. endophytes (phylum Ascomycota, class Hypocreales, family Claviciptaceae) and their cool-season grass hosts (family Poaceae) represent a widespread type of mutualism. In the United States, tall fescue is associated with $N$. coenophialum in about $95 \%$ of pastures. Other important Neotyphodium endophytes include N. lolii, and N. uncinatum, which colonize perennial ryegrass (Lolium perenne L.) and meadow fescue (Lolium pratense Huds.), respectively. Prominent examples of other plant-fungus symbiotic relationships include the mutualistic association between phosphate-acquiring arbuscular mycorrhizal fungi (AMF; Glomales, Zygomycota) with the roots of the majority of terrestrial plants, ectomycorrhizal fungi (both basidomycetes and ascomycetes) with a narrower range of plant species (gymnosperms or woody angiosperms) (Smith and Read 1997), and that of nitrogen fixing soil bacteria (collectively known as rhizobia) with legumes. Just as AMF and rhizobia play a pivotal role in the health of their plant partners, Neotyphodium endophytes provide their grass partners with an array of fitness improvements (Schardl and Phillips 1997) which overall provide endophyte-infected grasses with a competitive advantage over endophyte-free grasses. In return, nutrition is provided from the apoplastic space where endophyte growth is confined. Unlike AMF or rhizobia, Neotyphodium endophytes are exclusively vertically transmitted through infected host seeds (Philipson and Christey 1986), often at nearly 100\% efficiency (Siegel et al. 1984). These fungal endophytes reside within the aerial parts of the grass hosts and, due to their strictly asexual lifestyle, Neotyphodium endophytes depend on host seed production for dispersal and, therefore, on host survival for their continued existence. 
A defensive mutualism aptly describes Neotyphodium endophyte-grass relationships (Clay 1988), where infected grasses are afforded protection from insect herbivores (Clay and Cheplick 1989; Latch 1993; Popay and Rowan 1994; Siegel et al. 1987), nematodes (Elmi et al. 2000; Kimmons et al. 1990), and some fungal pathogens (Gwinn and Gavin, 1992); as well as tolerance of drought and high temperatures (Arechavaleta et al. 1989; Bacon 1993; West 1994). The widespread nature of $N$. coenophialum-infected tall fescue and high infection frequency of vegetative tillers and seeds (asexual transmission), in conjunction with its ability to successfully out compete uninfected grasses in diverse environments (Bush et al. 1997) suggests that endophyteinfected grasses are at a natural selective advantage. Other effects of endophyte infection on the host plant involve osmotic adjustment, stomatal regulation, modification of root morphology, enhanced uptake of minerals and alteration of nitrogen accumulation and metabolism (Belesky and Malinowski, 2000; Malinowski et al. 1999; Malinowski and Belesky, 2000). Vegetative growth also may be enhanced by the production of fungal auxin-like compounds (De Battista et al. 1990; Porter et al. 1985), and seed production and germination is increased (Clay 1987; Rice et al. 1990), along with increased shoot growth and tillering (Clay 1987; Hill et al. 1991; Read and Camp 1986).

Some of the benefits received by the plant in partnership with its fungal endophyte have been linked with the production of a diverse range of fungal secondary metabolites (Bush et al. 1997; Porter 1994; Siegel and Bush 1997), which are produced under the control of both host and fungal genomes, and also are influenced by the environment. Many of the biologically active secondary metabolites produced by Neotyphodium endophytes in association with their grass hosts are toxic alkaloids. Concentrations of 
these secondary metabolites are affected by changes in plant growth conditions and are sometimes increased during plant stress, suggesting that some changes in metabolite concentration may be associated with plant defense (Lane et al. 2000). Although all these alkaloids are products of the fungal genome, accumulating evidence suggests that quantitative metabolite expression also is regulated by the plant host genome (reviewed in Lane et al. 2000).

Ergot alkaloids produced in many endophyte-grass associations are toxic to mammalian herbivores. In $N$. coenophialum-tall fescue associations ergovaline is hypothesized to be the major factor linked to the toxic syndrome, 'fescue toxicosis', in grazing livestock (Thompson and Stuedemann 1993), resulting in estimated losses of up to US \$1 billion each year to US agriculture. Two other classes of alkaloids also are produced in $N$. coenophialum-infected tall fescue. The abundant pyrrolizidine (loline) alkaloids, and the pyrrolopyrazine, (peramine) have both been shown to enhance insect resistance (Dahlman et al. 1997; Rowan 1986; Rowan 1993; Siegel and Bush 1997; Wilkinson et al. 2000). Although it is clear that the observed changes in host metabolism are directly influenced by the endophyte, it is unknown whether alkaloids or other fungal metabolites are responsible for all these changes.

A thorough understanding of the interactions that occur between a plant and its fungal symbiont remain elusive. To move towards a better understanding of the molecular regulation of these processes in endophyte-grass symbioses, I used suppression subtractive hybridization ( $\mathrm{SSH}$ ) to identify differentially expressed genes in the $N$. coenophialum-tall fescue interaction. $\mathrm{SSH}$ is a sensitive and efficient method for generating differentially regulated cDNA probes and libraries, and has been very 
successfully used in identifying genes that are transcribed at higher or lower levels in different tissues or developmental stages (Beyer et al. 2001; Grenier et al. 2002; Osherov et al. 2002; Pnueli et al. 2002; Spiering et al. 2002; Voiblet et al. 2001; Xiong et al. 2001). Unlike other subtractive hybridization techniques, SSH permits one to detect both high and low abundance transcripts by incorporating a normalization step to more approximately equalize sequence abundance during one hybridization step. Using this technique, I identified 27 plant genes that are differentially expressed in endophyteinfected versus endophyte-free tall fescue. This same approach revealed two fungal genes that are up-regulated in infected tall fescue. The expression pattern of 12 different plant genes in infected tall fescue and endophyte-free tall fescue were analyzed using a semi-quantitative RT-PCR method. Competitive PCR was used to quantify the differential expression of one tall fescue gene and was used to quantitatively compare the expression of one fungal gene in planta versus in culture conditions. The expression and distribution pattern of both up-regulated fungal genes also was assessed by northern blot analysis. The potential function of these genes, as indicated by database searches, provides novel information about the tall fescue-endophyte symbiosis.

\subsection{MATERIALS AND METHODS}

\subsubsection{Biological Materials}

The fungal isolate used in this study, Neotyphodium coenophialum strain e19 (ATCC90664), was isolated from endophyte infected-grass leaf tissues (from plant 19, described below) on potato dextrose agar (PDA; Difco Laboratories, Detroit, Michigan, 
USA) as described by Moon et al. (2002). Fungal mycelium was then transferred onto fresh PDA plates and incubated at $22^{\circ} \mathrm{C}$. Mycelium from new growth was ground in 400 $\mu l$ of PD broth and used to inoculate $50 \mathrm{ml}$ of PD broth. Cultures were incubated at $22^{\circ} \mathrm{C}$ with rotary shaking $(100 \mathrm{rpm})$ for approximately 2 weeks. Mycelium was harvested by vacuum filtration through Whatmann No. 1 filter paper and used fresh for RNA extractions or stored at $-80^{\circ} \mathrm{C}$ for subsequent fungal DNA extractions. The fungal isolate was maintained on PDA at $22^{\circ} \mathrm{C}$.

All plants and their fungal symbionts used in this study are listed in Table 2.1. Grasses were grown from seed and maintained in the greenhouse at Lexington, Kentucky. The plants used for the SSH procedure were tall fescue [Lolium arundinaceum (Schreb) Darbysh. = Festuca arundinacea Schreb.] cultivar KY31 (6X) infected by its natural endophyte $N$. coenophialum (E+ plant, plant 15) (Siegel et al. 1990, where it is listed as plant code 16) and an endophyte free tall fescue cultivar KY31 (6X) (E- plant, plant 14, source P. Burrus).

The endophyte status of the grasses used in the SSH subtraction were confirmed in a PCR reaction with $N$. coenophialum-specific primers ( $\beta$-tubulin, Table 2.2), and also by staining peeled leaf sheaths with aniline blue followed by microscopy. 


\section{Table 2.1. Grass-Endophyte Associations Used in Study}

\begin{tabular}{|c|c|c|c|c|}
\hline Plant no. & Grass species and cultivars & Fungal endophyte & Fungal strain & Reference \\
\hline & Lolium arundinaceum & & & \\
\hline 19 & GI-320 (Johnstone) & Neotyphodium coenophialum & e19 (ATCC 90664) & Siegel et al (1990)/Schardl \\
\hline 18 & GI-320 (Johnstone) & endophyte minus & & Siegel et al (1990)/ \\
\hline 15 & KY31 & Neotyphodium coenophialum & e19 & Siegel et al (1990) \\
\hline 14 & KY31 & endophyte minus & & Siegel et al (1990) \\
\hline $4179-3$ & KY31 & Neotyphodium coenophialum & e19 & this study/Schardl \\
\hline 48 & Mustang & Neotyphodium coenophialum & $\mathrm{e} 48$ & this study/Schardl \\
\hline 47 & Mustang & endophyte minus & & this study/Siegel \\
\hline $347-1$ & KY31 & Neotyphodium coenophialum & $\mathrm{e} 15$ & this study/Schardl \\
\hline 66 & DBC & endophyte minus & & this study/Bacon \\
\hline \multirow[t]{2}{*}{$4180-7$} & Seine & endophyte minus & & this study/Hignight \\
\hline & Lolium perenne & & & \\
\hline 266 & Gator & Neotyphodium lolii & e265 & this study/Schardl \\
\hline 85 & Gator & Epichloe typhina & e8 & Siegel et al (1990) \\
\hline \multirow[t]{2}{*}{86} & Gator & endophyte minus & & Siegel et al (1990)/Schardl \\
\hline & Lolium pratense & & & \\
\hline 952 & Predix & Neotyphodium uncinatum & e167 & Carvel et al. (2001a)/Schardl \\
\hline 955 & Predix & Neotyphodium siegelii & e915 (ATCC 74483) & Craven et al (2001a)/Schardl \\
\hline 629 & Predix & Epichloe festucae & e682 (CBS102476) & Wilkinson et al. (2000)/Schardl \\
\hline 953 & Predix & endophyte minus & & Wilkinson et al. (2000)/Schardl \\
\hline
\end{tabular}


Table 2.2. PCR Primers

\begin{tabular}{|c|c|c|}
\hline CLONE & FORWARD PRIMER & REVERSE PRIMER \\
\hline ACTIN & CGCCATCCAGGCTGTGCTTTC & CCAGCTCCTGTTCATAGTCAAG \\
\hline TFF2 & GGATGAAGATCTTAGGCAGA & GCATACATGCCCGGGTCA \\
\hline TFF6 & CAGGGTAACTTGGGAAACCA & TTCCTAACAGCTCTTGTGGA \\
\hline TFF17 & ATCCAGAGGCTCGGCCAGCA & CACCCTGCAGAAGCAGTTCA \\
\hline TFF24 & CCAGTGACCAACAGCAGAGAT & ACAGGAACTCTCTGCACCCTG \\
\hline TFF26 & GTAGGAGTGCCATTCCTCCA & GAAGACACCTCGTGCTCCTA \\
\hline TFF31 & CGGGCAGGTTTGTAATCGTA & CAAAAAGGCGGAAAAGACAC \\
\hline TFF32 & ACCAGAGAGAATGCGAAAGG & ACTGGAGGAATCCTCAATAC \\
\hline TFF38 & TCCGCAGCAGCACTTGTAATA & CGGGCAGGTACTAACACAAAT \\
\hline TFF41 & ATACTTGTGCCTTACAATGGC & TACGGGACACCGTAGAGCTT \\
\hline TFR044 & CGCTCCAAGGCTACTCGTCA & GGAGTGGTGTCAACATGCAA \\
\hline TFR47 & GCAAGAGCTTGTCTGGTCTC & TGGACTTCTATAACAAGTGG \\
\hline TFR53 & ACATGATGCTCAAGGGCAAG & GGAAAATTGATCCCTCTTTACTGA \\
\hline Nc12 & AGTCTGGCTAGCAAGAAG & TTGCCTCCGGAACCACCA \\
\hline $\mathrm{Nc} 25$ & TTCCTATGTAATCGAGTTGCC & ACATTCCCAAGTCTCACACA \\
\hline$\beta$-TUB & TTCAAACCGGTCAGTGCG & GAGATCGACGAGGACAGC \\
\hline \multirow[t]{2}{*}{ Mi-Nc12 } & \multicolumn{2}{|c|}{ AGTCTGGCTAGCAAGAAGCTTGCCTTGGGTCATCAT } \\
\hline & \multicolumn{2}{|c|}{ TTGCCTCCGGAACCACCACATGATCCCCGACATCTG } \\
\hline \multirow[t]{2}{*}{ Mi-TFF41 } & \multicolumn{2}{|c|}{ TACGGGACACCGTAGAGCTTCGCCATCCAGGCTGTGCTTTC } \\
\hline & \multicolumn{2}{|c|}{ GGTACAGGAGCCTGGACAGTCCAGCTCCTGTTCATAGTCAAG } \\
\hline
\end{tabular}




\subsubsection{Preparation of Subtracted cDNA Libraries by Suppression Subtractive Hybridization (SSH)}

Total RNA was extracted from symbiotic tall fescue- $N$. coenophialum, and separately from each of the free-living partners by application of the Plant RNeasy Kit (Qiagen, Valencia, CA, USA). RNA from tall fescue was only extracted from the pseudo-stem region of the plant (approximately $3-4 \mathrm{~cm}$ from the soil line) since this tissue contains the highest amount of endophyte in infected grasses. Total RNA integrity was verified by electrophoresis in a $1.0 \%$ agarose gel in $0.5 \mathrm{x}$ TBE $(44.5 \mathrm{mM}$ Tris- $\mathrm{HCl}$, $44.5 \mathrm{mM}$ boric acid and $1.25 \mathrm{mM} \mathrm{Na} 2$ EDTA) buffer. Poly(A) RNA was enriched from total RNA by oligo-dT chromatography (Qiagen Oligotex mRNA mini kit).

The forward subtracted library was prepared from $1.8 \mu \mathrm{g}$ of poly(A) RNA from the tall fescue- $N$. coenophialum association and served as the source of the tester cDNA in the SSH procedure. Driver cDNA for the control population was prepared from freeliving tall fescue and free-living $N$. coenophialum (obtained from growing endophyte out of leaf sheaf onto PDA and sub-cultured once). Endophyte-free tall fescue poly(A) RNA $(1.8 \mu \mathrm{g})$ and $7.2 \mathrm{ng}$ of $N$. coenophialum poly(A) RNA were pooled as template in the preparation of driver cDNA to give a 1:250 ratio of tall fescue cDNA to endophyte cDNA. The amount of poly(A) RNA from axenically grown endophyte added to the driver was based on competitive PCR results obtained from analysis of endophyteinfected tall fescue genomic DNA. This analysis showed that $N$. coenophialum contributed approximately $1 / 500$ th of the total symbiotium DNA (results not shown). If fungal cDNAs expressed in culture were not added to the driver cDNA in the forward subtraction, all fungal genes expressed in planta regardless of their role in the symbiosis 
could have been isolated.

The reverse subtraction was performed with $1.8 \mu \mathrm{g}$ of poly(A) RNA from endophyte-free tall fescue as the source of tester cDNA. The driver cDNA was prepared from $1.8 \mu \mathrm{g}$ of poly(A) RNA from tall fescue associated with N. coenophialum.

SSH was then performed on the above tester and driver poly(A) RNA pairs by application of the PCR Select cDNA subtraction kit (Clontech, Palo Alto, CA, USA; Diachenko et al. 1996) according to the manufacturer's instructions but with the following modifications. Double-stranded tester and driver cDNA populations were digested with $D p n$ II in addition to digestion with $R s a$ I, the enzyme recommended by the manufacturer. Digestion with Rsa I alone produced fragment sizes that were too large for effective hybridization. All prescribed phenol-chloroform extractions were replaced by purifying samples with the QIAquick PCR Purification Kit (Qiagen). When required, samples were concentrated with Microcon YM-30 columns (Millipore). Following two hybridizations of each tester and driver cDNA pair, differentially expressed sequences were amplified in the first PCR primed from oligonucleotide P1 (Clontech PCR-select cDNA subtraction kit) with the following modifications. DyNAzyme EXT polymerase (0.5 U; MJ Research, Watertown, MA, USA) was added to the reaction mix after the mixture was eqilibrated to $75^{\circ} \mathrm{C}$ for $1 \mathrm{~min}$ (to simulate a hot start). An initial incubation step at $75^{\circ} \mathrm{C}$ for 5 min was performed to extend the adaptors, followed by 30 cycles of $94^{\circ} \mathrm{C}$ for $30 \mathrm{~s}, 62^{\circ} \mathrm{C}$ for $30 \mathrm{~s}$ and $72^{\circ} \mathrm{C}$ for $1.5 \mathrm{~min}$. A secondary PCR amplification to enrich for differentially expressed cDNAs was carried out with the following PCR conditions of 10 cycles of $94^{\circ} \mathrm{C}$ for $30 \mathrm{~s}, 67^{\circ} \mathrm{C}$ for $30 \mathrm{~s}$ and $72^{\circ} \mathrm{C}$ for $1.5 \mathrm{~min}$. The subtracted cDNA PCR products from both the forward and reverse subtraction were 
purified with the PCR purification kit (Qiagen) and then cloned into pBluescript (Stratagene, La Jolla, CA, USA) that had been digested with the enzymes Not I and Eag $I$, sites for which are present in the adapter sequences of the PCR products.

\subsubsection{Differential Screening of Subtracted cDNA Libraries}

The cloned forward and reverse subtracted cDNA libraries were transformed into E. coli DH5 alpha cells by electroporation. One-third of the entire ligation reaction for each library was electroporated in each of three separate transformation experiments to generate a sufficient number of colonies for each library. Colonies from the forward and reverse subtracted libraries were lifted onto uncharged nylon membranes (Roche) and screened by colony hybridization (following the manufacturer's protocol) with the forward and reverse subtracted cDNA libraries as probes. Colonies were selected from the forward library if strong hybridization occurred with the forward SSH probe, but not with the reverse probe. The opposite criteria were used for selecting colonies from the reverse subtracted library.

Preparation of the forward and reverse SSH probes were carried out as described by Diatchenko et al. (1999). Essentially, the adaptor sequences from the ends of the library clones were removed by restriction enzyme digestion and the purified products were labelled with digoxigenin (DIG) by random-priming as described in the DIG manual (Roche-Boehringer, Indianapolis, IN, USA).

The cDNA dot blot method was based on the method described by Diatchenko et al. (1999), except that the cDNA inserts were amplified directly from a colony by PCR (primed with primers N1 and N2R in the Clontech PCR-select cDNA subtraction kit). 
cDNA dot blots were performed in duplicate.

\subsubsection{Sequence Analysis}

Plasmid DNA was isolated by application of the QIAprep Spin Miniprep Kit (Qiagen). Sequencing was performed with the ABI Prism BigDye Terminiator cycle sequencing ready reaction kit (PE Biosystems, Foster City, CA, USA) and analyzed on an ABI 310 automated sequencer (PE Biosystems) at the University of Kentucky, Lexington, Kentucky. Reactions were primed from any of the following oligonucleotide primers that anneal to cloning vector sequences (such as universal M13 forward and reverse primers, T7 and T3 primers). Sequence data were edited with the assistance of SEQUENCHER (version 3.1.1) program for Macintosh. Vector sequence was trimmed manually and in conjunction with VecScreen, a BLAST-based algorithm for detection of vector sequences.

Comparison of DNA sequences obtained from the SSH clones to other sequences present in the NCBI (National Center for Biotechnology Information) database, were performed with the BlastX algorithm (Altscul et al. 1997). If an insignificant or no match was obtained from any of these sequences, BlastN and tBlastX searches also were performed. Additionally, specific searches were conducted to EST sequences at NCBI.

\subsubsection{Semi-Quantitative RT-PCR}

Total RNA (10 $\mu \mathrm{g})$ was treated with DNase I (Amplification grade, Invitrogen, life technologies, Carlsbad, CA, USA) to remove single and double-stranded DNA following the manufacturer's instructions. First strand cDNA was synthesized from 
approximately $1 \mu \mathrm{g}$ of DNase I-treated RNA by treatment with Superscript II RNase HReverse Transcriptase (Invitrogen). Reactions were primed with an Oligo(dT) $)_{15}$ primer following the manufacturer's instructions. The resulting cDNA served as a template for PCR amplification. PCR conditions were optimized (typically by altering the number of PCR cycles) for each gene specific primer pair (listed in Table 2.2) to ensure amplification of a product was within the linear range of the PCR. Prior to amplification with gene-specific primers, serially diluted cDNA samples were equalized in a PCR reaction primed from oligonucleotides designed to the housekeeping gene actin (Table 2.2; accession number AY194227) from tall fescue. In addition, the same cDNA samples were analyzed to check both putative up-regulated and down-regulated cDNA clones as an extra control for cDNA normalization.

\subsubsection{Competitive RT-PCR}

Competitive RT-PCR was based on a modification of the quantitative PCR (qPCR) method described by Groppe and Boller (1997). Mimic DNA molecules (generation is described below) were purified by GELase Agarose Gel-Digesting Preparation (Epicentre Technologies, Madison, WI) following the manufacturer's instructions and quantified based on $\mathrm{A}_{260}$ readings. cDNA for RT-PCR experiments was synthesized as described in the semi-quantitative method section.

For equalizing cDNA synthesized from E- and E+ plants, an actin mimic DNA molecule was constructed from tall fescue genomic DNA by PCR from primers (actin primers, Table 2.2) specific to the tall fescue actin housekeeping gene (accession number AY194227). qPCR amplification reactions contained either E- or E+ plant cDNA, 10- 
fold dilutions of the actin mimic DNA molecule (from $10 \mathrm{pg}$ to $1 \mathrm{ag}$ ), and final concentrations of the following reagents: 1x Taq DNA Polymerase 10x Buffer containing $15 \mathrm{mM} \mathrm{MgCl}_{2}$ (Promega, Madison, WI), $200 \mu \mathrm{M}$ of each dNTP, $1 \mu \mathrm{M}$ each of actin primers, and $0.05 \mathrm{U}$ of Taq DNA Polymerase (Promega). Amplification conditions were an initial denaturation at $95^{\circ} \mathrm{C}$ for 2 min followed by 30 cycles of $94^{\circ} \mathrm{C}$ for $30 \mathrm{~s}, 64^{\circ} \mathrm{C}$ for $30 \mathrm{~s}$ and $72^{\circ} \mathrm{C}$ for $1 \mathrm{~min}$, with a final extension of $72^{\circ} \mathrm{C}$ for $5 \mathrm{~min}$. Amplification of the actin mimic product gave a product of $370 \mathrm{bp}$, whereas amplification of the cDNA actin product yielded a 290 bp product.

For the quantitative analysis of clone TFF41, a mimic DNA molecule designed to have primer binding sites for amplification of TFF41, was constructed from tall fescue genomic DNA by PCR primed with Mi-TFF41 primers (Table 2.2), in which the 5 '-most nucleotides provided primer annealing sites for amplification of clone TFF41, and the remaining nucleotides prime amplification of the actin gene from tall fescue. PCR was performed on equalized cDNA from E- and E+ plants as described above, except PCR was primed with primers specific to clone TFF41 (TTF41 primers, Table 2.2), and dilutions of TFF41-mimic DNA molecule were added to generate a mimic product of 410 bp and a cDNA specific product of $264 \mathrm{bp}$. Amplification conditions were an initial denaturation at $95^{\circ} \mathrm{C}$ for 2 min followed by 32 cycles of $94^{\circ} \mathrm{C}$ for $30 \mathrm{~s}, 60^{\circ} \mathrm{C}$ for $30 \mathrm{~s}$ and $72^{\circ} \mathrm{C}$ for $1 \mathrm{~min}$, with a final extension of $72^{\circ} \mathrm{C}$ for $5 \mathrm{~min}$.

The $\beta$-tubulin mimic DNA molecule was constructed from Neotyphodium sp. Lp1 genomic DNA by PCR amplification from primers ( $\beta$-TUB primers, Table 2.2$)$ specific to the $\beta$-tubulin gene from Neotyphodium sp. FaTG-2 (tub2-1) (accession number L06963). PCR was performed on cDNA from E+ plant and $N$. coenophialum as 
described above, except PCR was primed with $\beta$-tubulin specific primers ( $\beta$-TUB primers, Table 2.2), and dilutions of the $\beta$-tubulin mimic molecule were added to produce a mimic product of $367 \mathrm{bp}$ and a cDNA specific product of $189 \mathrm{bp}$. Amplification conditions were an initial denaturation at $95^{\circ} \mathrm{C}$ for 2 min followed by 30 cycles of $94^{\circ} \mathrm{C}$ for $30 \mathrm{~s}, 55^{\circ} \mathrm{C}$ for $30 \mathrm{~s}$ and $72^{\circ} \mathrm{C}$ for $1 \mathrm{~min}$, with a final extension of $72^{\circ} \mathrm{C}$ for $5 \mathrm{~min}$.

For the quantitative analysis of fungal clone Nc12, a mimic DNA molecule designed to have primer binding sites for amplification of Nc12, was constructed from $N$. coenophialum genomic DNA by PCR primed with Mi-Nc12 primers (Table 2.2), in which the 5'-most nucleotides provide primer annealing sites for Nc12 clone specific primers (Nc12 primers, Table 2.2), and the remaining nucleotides prime amplification of an internal sequence of the Nc12 clone for generating the mimic DNA molecule. PCR was performed on equalized cDNA from E+ plant (15) and $N$. coenophialum as described above, except the PCR was primed with primers specific to clone $\mathrm{Nc} 12$ (Nc12 primers, Table 2.2), and dilutions of the Nc12-specific mimic DNA molecule were added to generate a mimic product of $182 \mathrm{bp}$ and a cDNA-specific product of $277 \mathrm{bp}$. Amplification conditions were an initial denaturation at $95^{\circ} \mathrm{C}$ for 2 min followed by 30 cycles of $94^{\circ} \mathrm{C}$ for $30 \mathrm{~s}, 54^{\circ} \mathrm{C}$ for $30 \mathrm{~s}$ and $72^{\circ} \mathrm{C}$ for $1 \mathrm{~min}$, with a final extension of $72^{\circ} \mathrm{C}$ for $5 \mathrm{~min}$.

\subsubsection{Screening of Lambda ZAP II cDNA Libraries}

A lambda ZAP II cDNA (Stratagene, La Jolla, CA, USA) library of culture grown N. coenophialum (ATCC 90664), and a lambda ZAP II cDNA (Stratagene) library of tall fescue associated with $N$. coenophialum (ATCC 90664) were kindly provided by 
Christopher Schardl and Huei-fung Tsai. Phage were plated and lifted onto uncharged nylon membranes (Roche). The membranes were hybridized at $65^{\circ} \mathrm{C}$ in standard hybridization buffer [5x SSC, $0.1 \%$ N-lauroylsarcosine, $0.02 \%$ SDS (sodium dodecyl sulfate) and $1 \%$ Blocking reagent (Roche)]. The culture grown $N$. coenophialum library was hybridized with a forward SSH probe (prepared and labelled with DIG as described in 2.2.3). The N. coenophialum-tall fescue library was hybridized with a probe prepared by labeling a SSH clone (25) with DIG during PCR amplification with primers specific to clone 25 as described in the DIG manual (Roche). After hybridization, filters were washed at room temperature twice for 5 min each in $2 \mathrm{x} \mathrm{SSC}(1 \mathrm{x}$ SSC is $0.15 \mathrm{M} \mathrm{NaCl}$ plus $0.015 \mathrm{M}$ trisodium citrate) and $0.1 \% \mathrm{SDS}$, followed by two washes at $65^{\circ} \mathrm{C}$ for 15 min each in $0.1 \mathrm{x}$ SSC and $0.1 \%$ SDS. DIG-labelled probe was detected by chemiluminescence (CSPD or CDP-star) following the manufacturer's (Roche) recommendations. Selected plaques obtained after three rounds of screening were converted to pBluescript phagemids by treatment with ExAssist Interference-resistant helper phage (Stratagene) according to the manufacturer's single-clone excision protocol. Plasmid DNA was isolated with a QIAprep Spin Miniprep Kit (Qiagen) from single colonies selected on LB agar with ampicillin.

\subsubsection{Southern Blot Hybridization}

Fungal genomic DNA was isolated by the method of Yoder (1988) and plant genomic DNA was isolated with the DNeasy plant mini kit (Qiagen). Restriction digests were carried out with $5 \mu \mathrm{g}$ of DNA according to the manufacturer's instructions (New England Biolabs, Beverly, MA, USA) and electrophoresed in a $0.8 \%$ agarose gel. 
Fractionated DNA was then transferred to a Zeta-Probe GT blotting membrane (Bio-Rad, Hercules, CA, USA) by capillary transfer under alkaline conditions (Read and Mann, 1985). DNA for probe labeling was generated by PCR amplification from gene specific primers (primer sequences are given in Table 2.2). PCR fragments were then gel purified by either GELase Agarose Gel-Digesting Preparation (Epicentre Technologies, Madison, WI, USA) following the manufacturer's instructions or by the freeze-squeeze method (described below). Gel fragments were soaked $5 \mathrm{~min}$ in $300 \mathrm{mM}$ Na-acetate, $10 \mathrm{mM}$ TrisHCl $\mathrm{pH} 8$, and $10 \mathrm{mM}$ EDTA, blotted dry and put into a 0.5-ml tube (containing a plug of glass wool and a small hole in the bottom) nested within a 1.5-ml microcentrifuge tube and incubated at $-80^{\circ} \mathrm{C}$ for 20 mins. The frozen gel fragment was then centrifuged 5-10 min at room temperature through the glass wool and the resulting eluate was ethanol precipitated. Gel purified fragments from either method were then further purified using the QIAquick PCR Purification Kit (Qiagen). Probes were random primed labeled with $\left[\alpha^{32} \mathrm{P}\right] \mathrm{dCTP}$ by treatment with High Prime (Roche) as described in the manufacturer's instructions. Unincorporated labeled nucleotides were removed by passing the reaction mixtures through Probe Quant G-50 Micro columns (Amersham Biosciences, Piscataway, NJ, USA) following the supplier's instructions.

Fungal Southern blots were hybridized at $65^{\circ} \mathrm{C}$ in $0.25 \mathrm{M}$ sodium phosphate, $\mathrm{pH}$ 7.2 and 7\% SDS (sodium dodecyl sulfate) overnight. Membranes were washed twice at $65^{\circ} \mathrm{C}$ for $30-60$ mins in $20 \mathrm{mM}$ sodium phosphate, $\mathrm{pH} 7.2+5 \% \mathrm{SDS}$; followed by two additional washes at $65^{\circ} \mathrm{C}$ for $30-60$ mins each in $20 \mathrm{mM}$ sodium phosphate, $\mathrm{pH} 7.2+1 \%$ SDS. 


\subsubsection{Northern Blot Analysis}

Total RNAs $(15 \mu \mathrm{g})$ were separated by electrophoresis on a $1.0 \%(\mathrm{w} / \mathrm{v})$ agarose gel containing 0.6 $\mathrm{M}$ formaldehyde in 1x MOPS (3-[N-morpholino] propanesulfonic acid) buffer (20 mM MOPS, $5 \mathrm{mM}$ sodium acetate, and $1 \mathrm{mM}$ EDTA; $\mathrm{pH}$ 7.0). RNA was then transferred to a Zeta-Probe GT blotting membrane (Bio-Rad) in 10x SSC (1.5 $\mathrm{M} \mathrm{NaCl}$ and $0.15 \mathrm{M}$ trisodium citrate, $\mathrm{pH}$ 7.0) by standard procedures (Sambrook et al. 1989) and dried at $80^{\circ} \mathrm{C}$ for $2 \mathrm{hr}$. Hybridization was performed in formamide-containing buffer (50 ml formamide, $25 \mathrm{ml} 0.5 \mathrm{M}$ sodium phosphate ( $\mathrm{pH} 7.2$ ), $1.46 \mathrm{~g} \mathrm{NaCl}, 7.0 \mathrm{~g}$ SDS and water to $100 \mathrm{ml}$ ) at $42^{\circ} \mathrm{C}$ overnight. Probes were prepared and labeled as described for Southern blotting. Filters were washed successively at room temperature twice for 10 min each in $2 x \mathrm{SSC}$ ( $1 \mathrm{x} \mathrm{SSC}$ is $0.15 \mathrm{M} \mathrm{NaCl}$ plus $0.015 \mathrm{M}$ trisodium citrate) and $0.1 \%$ SDS and then in $0.5 \times$ SSC and $0.1 \%$ SDS. If background radiation (measured with a Muller-Geiger counter) on parts of the membrane unlikely to contain RNA were still several times above background radiation levels, a final wash was conducted in $0.1 \mathrm{x}$ SSC and $0.1 \%$ SDS at $50^{\circ} \mathrm{C}$.

\subsection{RESULTS: IDENTIFICATION OF DIFFERENTIALLY EXPRESSED cDNA CLONES}

Two subtracted cDNA libraries (forward and reverse) were created by SSH to identify differentially expressed genes in the tall fescue- $N$. coenophialum symbiosis. The forward subtracted library enriched for differentially expressed genes in the 'tester' cDNA population. The 'tester' in this case contained cDNA derived from tall fescue in association with its fungal endophyte $N$. coenophialum (E+ tall fescue) to isolate genes 
up-regulated in the symbiosis. To subtract out any plant or fungal genes not regulated in the symbiosis, such as general housekeeping genes, 'driver' cDNA derived from endophyte-free tall fescue and saprophytically grown $N$. coenophialum was used as the subtractive partner in the forward subtraction. The reverse subtraction which was prepared from opposite tester and driver cDNA pairs, enriched for genes expressed at a higher level in endophyte-free tall fescue (E- tall fescue), which has now become the 'tester' cDNA population in the reverse subtraction. Genes isolated from the reverse library are expected to be down-regulated in E+ tall fescue.

Total subtracted cDNA obtained from either the forward and reverse subtraction were cloned into pBluescript (Stratagene) to obtain cloned libraries of each subtraction. Approximately 430 and 280 colonies from the forward and reverse subtracted cDNA libraries, respectively, were obtained by transformation and then screened initially by colony dot blot hybridization to identify false positives. Duplicate colony dot blots of each subtracted library were hybridized individually with probes made from total subtracted cDNA from either the forward subtraction (forward cDNA probe), or from the reverse subtraction (reverse cDNA probe). Colonies -67 and 30 from the forward and reverse subtracted libraries, respectively, were selected based on the intensity of the differential hybridization signals. These selected cDNA clones were then re-screened by cDNA dot blot analysis (screened with the same forward and reverse cDNA probes) to improve the sensitivity of the differential screen. A representative cDNA dot blot is shown in Fig. 2.1. Seventeen cDNA clones were identified as putatively up-regulated in E+ tall fescue based on stronger hybridization to the forward cDNA probe over the reverse probe. From the reverse library, 12 clones were identified as putatively down- 
regulated cDNAs in $\mathrm{E}+$ tall fescue based on stronger hybridization to the reverse cDNA probe. These putatively differentially expressed cDNA clones were sequenced and similarities and proposed gene functions were assigned if a significant match $\left(\mathrm{P}(\mathrm{N})<10^{-}\right.$ $\left.{ }^{5}\right)$ was obtained to other sequences present in the NCBI database as a result of BLAST analyses (Altscul et al. 1997) (Table 2.3 and 2.4). Fifteen out of 29 clones had no significant similarity to any other sequences in the database, although some did have matches to EST databases. Some of these clones probably represent novel genes, but as many of the clones obtained by SSH were short and contained mostly 3' non-coding region, there was a reduced chance of finding significant homologies to other sequences present in the database.

The redundancy of each library was low since only two clones (TFR53, a putative PR-10 homolog and TFR021, a putative $S$-adenosylmethionine decarboxylase precursor) were identified twice from the reverse library and none were identified more than once from the forward library. 


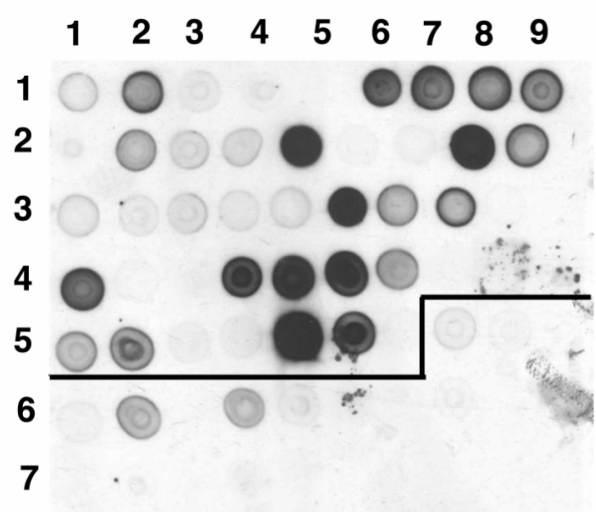

Forward cDNA probe

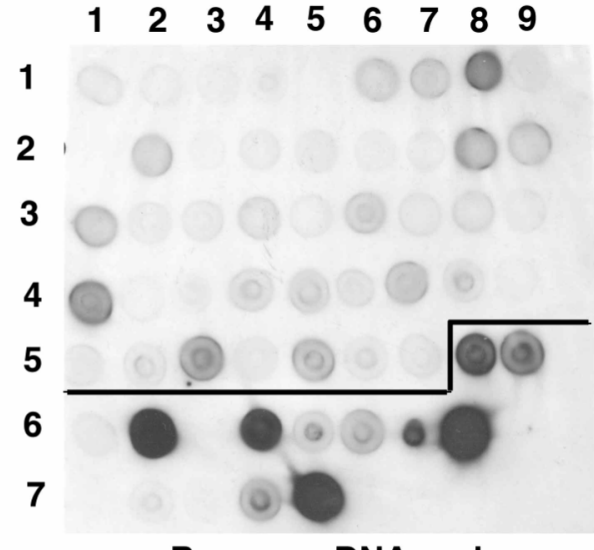

Reverse cDNA probe

\section{Figure 2.1 Duplicate cDNA Dot Blots}

Forward and reverse subtracted cDNA clones were spotted onto duplicate nylon filters and hybridized with either total cDNAs from the forward subtracted library (forward cDNA probe), or with total cDNAs from the reverse subtracted library (reverse cDNA probe). Clones from the forward subtracted library were spotted above the line and reverse library clones were spotted below. 
Table 2.3. Genes Putatively Up-Regulated in the Tall Fescue- $N$. coenophialum Symbiosis

\begin{tabular}{|c|c|c|c|c|c|}
\hline $\begin{array}{l}\text { GenBank } \\
\text { accession no. }\end{array}$ & $\begin{array}{l}\text { Clone ID } \\
\text { (bp) }\end{array}$ & Length & Organism & Homology & $\begin{array}{l}\text { Protein matches } \\
\% \text { identity/E values }\end{array}$ \\
\hline CA820676 & TFF2 & 457 & Plant & putative RNA binding protein, A. thaliana, AC007519 & $64 \% / 3 e-33$ \\
\hline CA820677 & TFF6 & 473 & Plant & hypothetical protein 1087, XY8029 & $79 \% / 8 \mathrm{e}-42$ \\
\hline CA820678 & TFF7 & 380 & Plant & no significant hit in database & \\
\hline \multirow[t]{2}{*}{ CA820679 } & TFF9 & 432 & Plant & GDP-dissociation inhibitor protein, & \\
\hline & & & & O.sativa, AF016897-1 & $84 \% / 3 e-09$ \\
\hline CA820680 & TFF14 & 304 & Plant & no significant hit in database & \\
\hline CA820681 & TFF17 & 608 & Plant & putative protein A. thaliana, AL031394 & $81 \% / 2 \mathrm{e}-26$ \\
\hline CA820682 & TFF24 & 500 & Plant & putative RNA binding protein, O.sativa, AC091811 & $59 \% / 6 e-24$ \\
\hline CA820683 & TFF25 & 203 & Plant & metallothionein protein, O. sativa, U77294 & $62 \% / 0.006$ \\
\hline \multirow[t]{2}{*}{ CA820684 } & TFF26 & 505 & Plant & herbicide safener binding protein, & \\
\hline & & & & Zea mays, AF033496 & $58 \% / 5 e-20$ \\
\hline CA820685 & TFF28 & 510 & Plant & polyadenylate-binding protein (Nicotiana) & $73 \% / 4 \mathrm{e}-28$ \\
\hline CA820686 & TFF31 & 353 & Plant & no significant hit in database & \\
\hline CA820687 & TFF32 & 505 & Plant & putative ABC transporter, A. thaliana, NM_128248 & $72 \% / 2 \mathrm{e}-65$ \\
\hline CA820688 & TFF38 & 230 & Plant & no significant hit in database & \\
\hline \multirow[t]{2}{*}{ CA820689 } & TFF41 & 271 & Plant & omega-3 fatty acid desaturase FAD7, & \\
\hline & & & & T.aestivum, D43688 & $91 \% / 8 \mathrm{e}-24$ \\
\hline CA820690 & TFF45 & 240 & Plant & no significant hit in database & \\
\hline CA820691 & $\mathrm{Nc} 25$ & 203 & Fungus & no significant hit in database & \\
\hline CA820692 & $\mathrm{Nc} 12$ & 455 & Fungus & no significant hit in database & \\
\hline
\end{tabular}


Table 2.4. Genes Putatively Down-Regulated in the Tall Fescue- $N$. coenophialum Symbiosis

\begin{tabular}{|c|c|c|c|c|c|}
\hline $\begin{array}{l}\text { GenBank } \\
\text { accession no. }\end{array}$ & Clone ID & $\begin{array}{l}\text { Length } \\
\text { (bp) }\end{array}$ & Organism & Homology & $\begin{array}{l}\text { Protein matches } \\
\% \text { identity/E values }\end{array}$ \\
\hline A820693 TFR044 & 470 & Plant & \multicolumn{2}{|c|}{ no significant hit in database } & \\
\hline \multirow[t]{2}{*}{ CA820694 } & TFR45 & 280 & Plant & chlorophyll A-B binding protein of LHCII & \\
\hline & & & & type III precursor, H. vulgare, X63197 & $98 \% / 2 \mathrm{e}-24$ \\
\hline CA820695 & TFR47 & 510 & Plant & putative aminopeptidase, A. thaliana, AC011622 & $84 \% / 6 e-69$ \\
\hline CA820696 & TFR049 & 224 & Plant & no significant hit in database & \\
\hline CA820697 & TFR49-2 & 332 & Plant & no significant hit in database & \\
\hline CA820698 & TFR50 & 428 & Plant & no significant hit in database & \\
\hline CA820699 & TFR51 & 349 & Plant & no significant hit in database & \\
\hline CA820700 & TFR53 & 357 & Plant & pathogen-related protein, O.sativa, AF416604 & $64 \% / 3 \mathrm{e}-05$ \\
\hline CA820701 & TFR57 & 170 & Plant & no significant hit in database & \\
\hline CA820702 & TFR58 & 189 & Plant & no significant hit in database & \\
\hline \multirow[t]{2}{*}{ CA820703 } & TFR021 & 387 & Plant & $S$-adenosylmethionine decarboxylase precursor, & \\
\hline & & & & T.aestivum, AF117660 & $77 \% / 6 e-13$ \\
\hline CA820704 & TFR031 & 130 & Plant & no significant hit in database & \\
\hline
\end{tabular}

\subsection{RESULTS: CONFIRMATION OF DIFFERENTIALLY EXPRESSED PLANT GENES BY SEMI-QUANTITATIVE AND COMPETITIVE RT- PCR}

To validate the SSH results, the expression of 9 putatively up-regulated plant cDNA clones (from the forward subtracted library) and 3 putatively down-regulated plant-derived cDNA clones (from the reverse subtracted library) were compared by semiquantitative RT-PCR (primers are listed in Table 2.2) of RNA isolated from E+ and Etall fescue. Although a quantitative measurement of the difference in gene expression between endophyte infected and uninfected grass could not be accurately assessed, I could reproducibly show for each clone whether gene expression was higher or lower in E+ tall fescue compared to E- tall fescue. All 12 clones analyzed showed the expected 
differential pattern of gene expression, although no cDNA clones displayed a complete on/off pattern of expression (Fig. 2.2). Semi-quantitative RT-PCR also was performed with clones TFF9, TFR45, TFR57, TFR58 and TFR021, but results were inconclusive (results not shown). In several cases, the number of cycles required to reliably amplify the transcript were greater than that required for the tall fescue housekeeping gene actin, indicating that the SSH technique can identify both high and low abundance messages. In order to test if differential gene expression was not due to variation in plant genotypes between endophyte infected and uninfected tall fescue plants, relative mRNA abundance of genes for clones TFF2, TFF17, TFF26, TFF32, TFF41, TFR044, TFR47 and TFR53, was measured in additional tall fescue cultivars (plants 18 and 19; see biological materials for description) infected and uninfected with endophyte. All of the SSH clones produced similar gene expression patterns to those obtained from the original tall fescue E+ and E- cultivars.

To confirm the semi-quantitative RT-PCR results, and to quantify the difference in expression observed between E+ and E- tall fescue for one clone (TFF41) that was apparently strongly up-regulated in E+ tall fescue (Fig. 2.2), E+ and E- tall fescue cultivars (Plants 19 and 18) different from those originally used for SSH library subtraction (Fig. 2.3) were analyzed by quantitative (competitive) RT-PCR. Results showed that this gene is up-regulated in E+ tall fescue by at least 1000 fold, suggesting an important role for this gene in the association. 


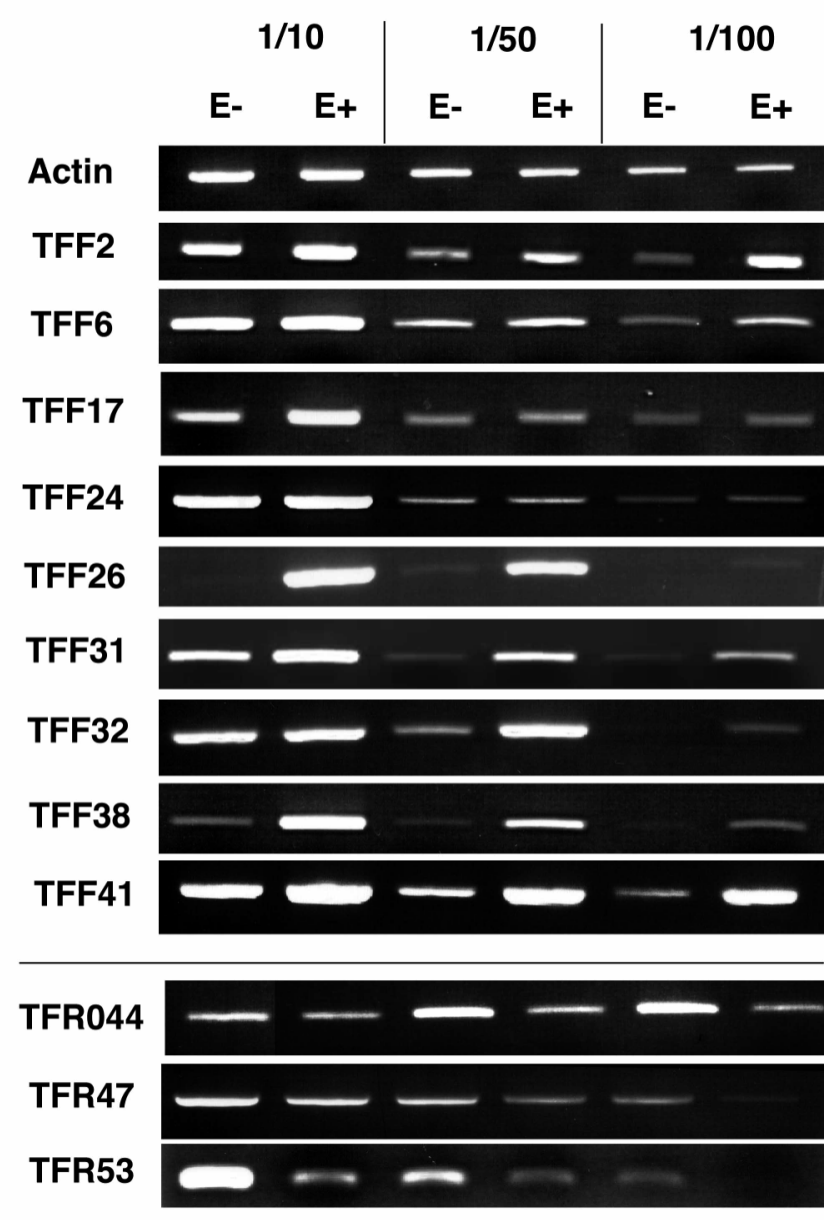

Figure 2.2. Semi-Quantitative RT-PCR Analysis of Differentially Expressed Clones Semi-quantitative RT-PCR analysis was performed with serial dilutions $\left(1 / 10^{\text {th }}, 1 / 50^{\text {th }}\right.$ and $1 / 100^{\text {th }}$ ) of cDNA from endophyte free-tall fescue (E-) and from endophyte-infected tall fescue (E+). To check for equal amounts of E- and E+cDNA samples, a housekeeping gene from tall fescue, actin (accession number AY194227) also was amplified from the diluted cDNA samples. Forward library clones are designated TFF, whereas the reverse library clones are designated TFR. 


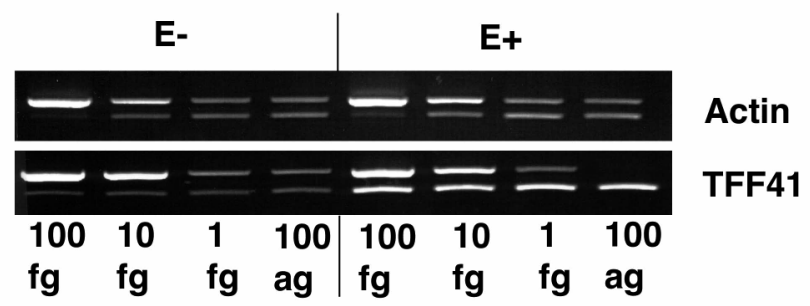

Figure 2.3. Quantitative RT-PCR Analysis of Clone TFF41

Equalization of endophyte-free tall fescue (E-) and endophyte-infected tall fescue (E+) cDNA by amplification of the actin gene (accession number AY194227) from tall fescue is shown at the equivalence point (representing equal mimic and specific gene amplification) of $1 \mathrm{fg}$. The upper band in the actin lane represents amplification of the competing mimic DNA molecule (designed to contain competing primer binding sites for actin) added at set concentrations from $100 \mathrm{fg}$ to $100 \mathrm{ag}$. The lower band represents the specific amplification of actin from E- or E+ cDNA. In lane TFF41, the upper band represents the specific amplification of TFF41 from E- or E+ cDNA, while the lower band represents amplification of the mimic DNA molecule (designed to contain competing primer binding sites for TFF41 amplification). An equivalence point at $100 \mathrm{ag}$ is shown for E- cDNA and an equivalence close to $100 \mathrm{fg}$, but clearly above $10 \mathrm{fg}$ is shown for E+ cDNA. 


\subsection{RESULTS: IDENTIFICATION OF DIFFERENTIALLY EXPRESSED FUNGAL TRANSCRIPTS}

Clone TFF25 was obtained by the differential screening of cDNA dot blots (described above). PCR amplification from primers spanning the insert of clone TFF25 did not result in the amplification of a product from either plant or fungal genomic DNA. The presence of a GATC site in the middle of the clone suggested that 2 different cDNA inserts of $203 \mathrm{bp}$ each were ligated together. One of these inserts had similarity by BlastX analysis to a metallothionein type II gene from rice, and was designated TFF25 (Table 2.2), whereas the other insert (from here on in designated Nc25, Table 2.2) contained no matches to any sequences present in the NCBI database or to the Magnaporthe grisea or Neurospora crassa genome sequencing projects at the Whitehead Institute Center for Genome Research (http://wwwgenome.wi.mit.edu). Screening of an endophyte-infected tall fescue cDNA library was carried out to obtain more sequence of each insert. cDNA clones corresponding to each insert were obtained and primers were then specifically designed for the amplification of genomic PCR products. Clone TFF25 was confirmed to be derived from a plant-derived metallothionein transcript by PCR and was differentially expressed (results not shown, see section 3.3.4), and clone Nc25 was found to be fungal in origin. Genomic PCR products of clone Nc25 were obtained from fungal endophytes $N$. coenophialum (strain e19; accession number AY191830) and $N$. lolii (strain Lp19; accession number AY191831). An alignment of the genomic PCR products amplified with Nc25 specific primers from both endophytes is shown in Fig. 2.4. The consensus sequence obtained from the alignment of N. coenophialum (e19) Nc25 genomic and cDNA sequences (given in Fig. 2.4) finds a statistically significant 
BlastX match (9e-05) to a putative guanidine nucleotide exchange factor from Plasmodium falciparum. The match to Nc25 occurs only over a 92 amino acid region, from a total of 2606 amino acids. The putative guanidine nucleotide exchange factor from $P$. falciparum is similar to the $P$. falciparum guanidine nucleotide exchange factor pfrcc1 over a region of 1338 amino acids at $97.6 \%$ identity (9.6e-190). The match to Nc25 is outside the region of greatest similarity to pfrcc1, and given that $\mathrm{Nc} 25$ does not appear to encode any conserved domains for RCC1 proteins, the possibility that $\mathrm{Nc} 25$ encodes such a protein is therefore very unlikely. Clone Nc25 appears to encode an extremely repetitive protein. Nc25 from $N$. coenophialum (e19) encodes a protein consisting of 4 repeating units of the following 28 amino acids: VDGDDVQEGDKLAKRPNRKIRYSGADL (allowing for conservative substitutions). The $N$. lolii $\mathrm{Nc} 25$ homologue is highly similar to the $\mathrm{Nc} 25$ gene from N. coenophialum, but only contains 2 repeating units instead of four. An entire ORF of 132 amino acids is predicted for $N$. coenophialum $\mathrm{Nc} 25$, versus 79 amino acids for the $N$. lolii homologue. A peculiar feature of this gene is the presence of an intron with conserved fungal splice sites in the 3' non-coding region (nucleotides are written in lowercase in Fig. 2.4). The Nc25 cDNA clone from $N$. coenophialum was obtained by screening a lambda ZAPII cDNA library of $N$. coenophialum-infected tall fescue (accession number CA820705). This cDNA clone has this intron sequence spliced out, indicating that the intron is functional. Typically, translation of fungal genes occurs at the first AUG triplet, unless the first AUG codon has a weak Kozak or consensus sequence (CNNNCA(A/C)NATGGC; Jon et al. 1993) for initiation of translation (Kozak 1991). The consensus sequence for the first ATG, has an exceptionally well conserved Kozak sequence (CATTCACC $\underline{A T G C A), ~ a n d ~}$ 
other possible AUG codons all contained weak consensus sequences, indicating that the first AUG codon is the most likely codon for initiation of translation.

The 614-bp genomic PCR fragment from N. coenophialum was used as a probe to Southern blots of N. coenophialum genomic DNA (Fig. 2.5A) and to endophyte-free tall fescue genomic DNA (not shown). No hybridization signals were detected to endophytefree tall fescue DNA confirming that the Nc25 transcript is fungal. Hybridization signals obtained to the fungal Southern blot indicate that there is only one copy of this gene present in the genome of $N$. coenophialum. None of the restriction enzymes used for DNA digestion cut within the 614-bp genomic DNA probe used for hybridization. The presence of one band with the restriction enzyme BamHI therefore indicates one copy of this gene. Two bands are present in the HindIII digest, but the upper band is most likely a partial since hybridization with the original SSH clone (25) which contained one HindIII site only gave the same two hybridization bands, indicative for one copy. The high molecular weight DNA did not cut well with $X b a \mathrm{I}$, so additional bands present are most likely to be partials.

All but one cDNA clone obtained from the forward or the reverse cDNA libraries (except for $\mathrm{Nc} 25$ mentioned above) were ascertained to be plant in origin by either PCR using gene specific primers to endophyte-free tall fescue DNA (results not shown), and/or by a significant match to a plant DNA sequence present in the NCBI databases (see Table 2.3 and 2.4). However, it was still possible that the forward library contained other fungal cDNA clones not identified by the previous differential cDNA screens. The forward cDNA probe was therefore used to screen an available culture-derived $N$. coenophialum lambda ZAP II (Stratagene) cDNA library to search for fungal genes up- 
regulated in planta. Despite the fact that many genes expressed in planta may not be expressed in culture, this screen identified another fungal cDNA clone that was represented in the library three times. Sequence analysis of these three cDNA sequences revealed no ambiguity at the DNA level. This fungal clone was named Nc12, and the sequence obtained was found to have no significant matches to any protein or DNA sequence in the NCBI databases. I also found no matches to either the M. grisea or N. crassa genome sequencing projects (Whitehead Institute Center for Genome Research), indicating that clone Nc12 represents a novel gene with perhaps a specialized function.

A 277-bp fragment was amplified from clone $\mathrm{Nc12}$ and used as a probe to a Southern blot of $N$. coenophialum (strain e19) DNA (Fig. 2.5B). None of the restriction enzymes used for DNA digestion cut within the probe sequence. Therefore, the presence of more than one hybridization signal in each lane (containing genomic DNA digested with a different restriction enzyme), suggests that this gene is either present in more than one copy, or is part of a gene family (since sequence ambiguities were not found among the three different $\mathrm{Nc} 12$ cDNA clones obtained). Using primers specific to the Nc12 transcript, I amplified a 365-bp PCR product from genomic N. coenophialum (strain e19) DNA. Sequence analysis and alignment of this genomic PCR fragment with the cDNA Nc12 clones revealed the presence of an 88-bp intron (results not shown). No other sequencing differences between the Nc12 cDNA and Nc12 genomic DNA clones were found. 


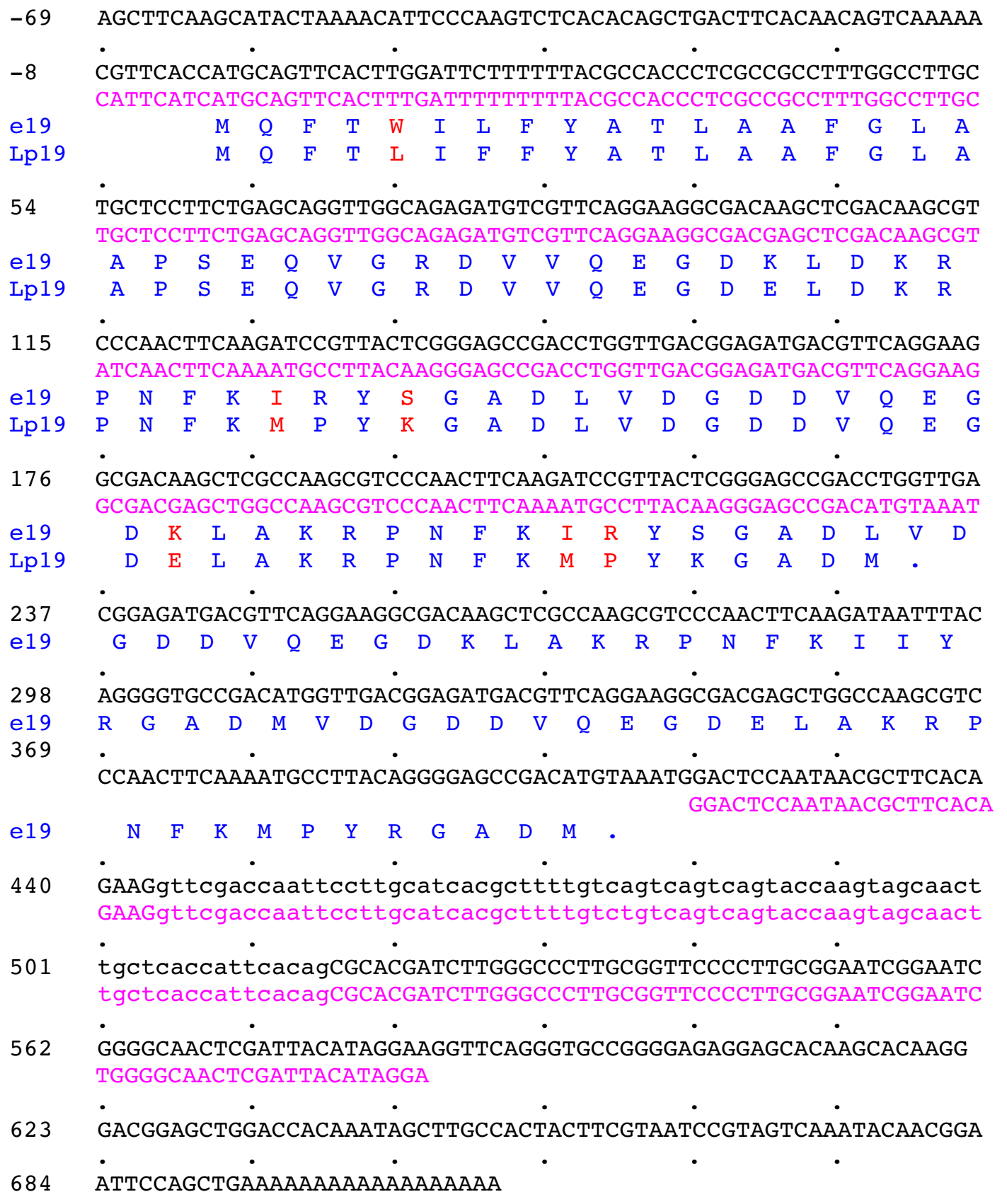

\section{Figure 2.4. Alignment of $N$. coenophialum and $N$. lolii $\mathbf{N c 2 5}$ Fungal Sequences}

Nucleotide sequence of $\mathrm{Nc} 25$ from N. coenophialum (e19) is given in black (top line), whereas the nucleotide sequence from $N$. lolii (Lp19) is given underneath in pink. Identical amino acids from each fungus are aligned below the nucleotide sequence, with non-identical amino acids highlighted in red. The one putative intron is distinguished by lowercase print. 
A

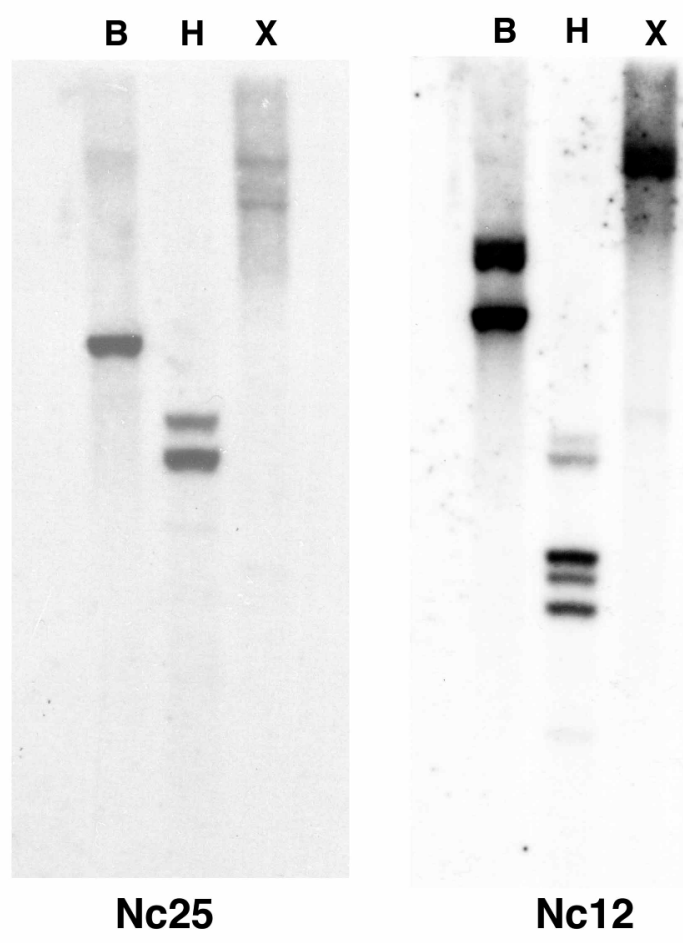

B

Nc12

Figure 2.5A \& B. Southern Blot Analysis of Fungal Clones Nc25 and Nc12

A, Southern blot hybridization using a 614 bp genomic DNA fragment from Nc25 as a probe. B, Southern blot in A re-probed with a 277bp cDNA fragment from Nc12. Lanes $\mathrm{B}, \mathrm{H}$ and $\mathrm{X}$ represent BamHI, HindIII and $\mathrm{XbaI}$ digested genomic DNA from $N$. coenophialum (e19) respectively. 


\subsection{RESULTS: IN PLANTA EXPRESSION OF FUNGAL TRANSCRIPTS Nc12}

AND Nc25

To determine if fungal transcripts $\mathrm{Nc} 12$ and $\mathrm{Nc} 25$ are up-regulated in planta, a northern blot of RNA extracted from E+ tall fescue $(15,19$, Table 2.1), E- tall fescue (18, 14, Table 2.1) and culture-grown N. coenophialum (e19) were probed individually with gene-specific probes (Fig. 2.6). Hybridization of a 614-bp fragment from $N$. coenophialum genomic DNA amplified with $\mathrm{Nc} 25$ specific primers to E+ tall fescue RNA samples $(15,19)$, gave a strong signal, showing that $\mathrm{Nc} 25$ is highly expressed in planta. However, no hybridization signal could be detected when this same probe was incubated with fungal RNA obtained from saprophytically grown cultures, suggesting that $\mathrm{Nc} 25$ is not expressed (or barely expressed) under culture conditions. Expression of Nc25 could therefore be important during symbiosis with its host grass tall fescue. The same northern blot was re-probed with a 277-bp cDNA fragment from clone Nc12. Low expression of this gene during in vitro saprophytic growth (e19) compared with dramatic gene expression during in planta conditions $(15,19)$ shows that $\mathrm{Nc} 12$ also is significantly up-regulated in planta.

Nc25 has an ORF of $694 \mathrm{bp}$ and is therefore expected to encode a small protein. The Nc12 ORF is partial at the 5'end, but based on northern blot experiments (that enabled the comparison between $\mathrm{Nc} 12$ and $\mathrm{Nc} 25$ transcript sizes), $\mathrm{Nc} 12$ produces a marginally smaller transcript than $\mathrm{Nc} 25$, and also is therefore expected to encode a small protein. 


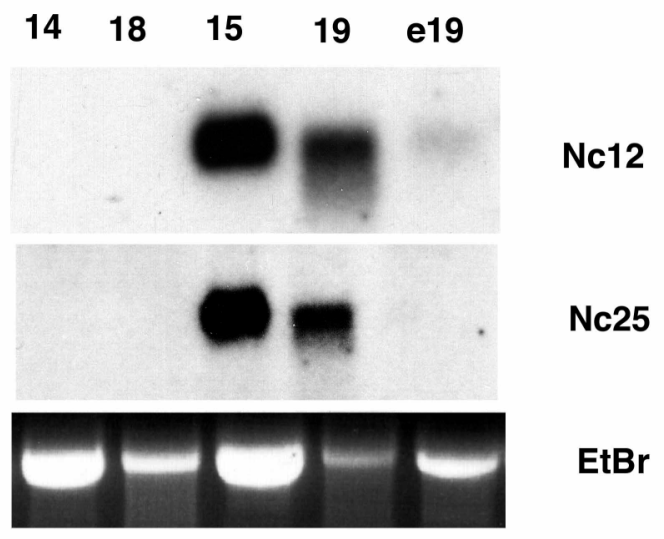

Figure 2.6. Fungal Clones Nc12 and Nc25 are Up-Regulated In Planta

Northern blot of pseudo-stem total RNA $(15 \mu \mathrm{g})$ from endophyte-free tall fescue plants 14, 18; endophyte-infected tall fescue plants 15, 19; and total RNA from cultured endophyte e19; hybridized with either Nc12, or Nc25 probes. EtBr, ethidium bromide stained rRNA to indicate RNA loading. 
To further analyze the expression and distribution of the $N$. coenophialum $\mathrm{Nc} 12$ and Nc25 transcripts in planta, probes specific to each transcript were individually hybridized to northern blots of tall fescue (Fig. 2.7A), perennial ryegrass and meadow fescue (Fig. 2.7B) symbiotic with different endophytes (see Table 2.1 for plant and endophyte descriptions). Both $\mathrm{Nc} 12$ and $\mathrm{Nc} 25$ gave extremely strong hybridization signals when hybridized with the two $\mathrm{E}+(N$. coenophialum strain e19) tall fescue symbiota (genotypes 4179-3, 15). Similarly, tall fescue associated with $N$. coenophialum strain e48 (48) and tall fescue associated with $N$. coenophialum strain e15 (347-1) (Fig. 2.7A) had abundant mRNA for these two fungal genes. The expression of these genes is remarkably high considering that the fungal endophyte represents only a small fraction of the total symbiotum biomass (fungal genomic DNA is estimated to be approximately $1 / 500^{\text {th }}$ of the plant genome). No signals were obtained to any of the endophyte-free grasses $(14,47,66,4180-7,86,953)$, as expected.

The Nc12 transcript was expressed at a lower level in meadow fescue associated with $N$. uncinatum (952), meadow fescue associated with $N$. siegelii (955) and meadow fescue associated with E. festucae (629) (Fig. 2.7B), compared to its levels in $N$. coenophialum-infected tall fescue. This was in contrast to the extremely high levels obtained with the Nc25 transcript to all of the meadow fescue associations. Strikingly, two hybridization signals occurred with the Nc25 transcript to meadow fescue associated with either endophyte $N$. siegelii (955) or $N$. uncinatum (952).

Hybridization of Nc12 to perennial ryegrass associated with N. lolii (266) was noticeably low compared to the intense signal obtained in perennial ryegrass associated with E. typhina (85), whereas hybridization of $\mathrm{Nc} 25$ resulted in strong signals to both 
perennial ryegrass-endophyte associations $(266,85)$. The $\mathrm{Nc} 25$ homologue present in $N$. lolii gave a slightly smaller transcript size than the $N$. coenophialum transcript, and the $E$. typhina homologue (85) gave a similar sized transcript to the E. festucae $\mathrm{Nc} 25$ homologue (629).

From these results we can deduce that homologues of the N. coenophialum $\mathrm{Nc12}$ and $\mathrm{Nc} 25$ transcript are present in the endophytes E. festucae, N. siegelii, N. lolli, $N$. uncinatum, and E. typhina, and that this endophyte gene is expressed during symbiosis with their respective grass hosts. With the Nc12 transcript, the same size transcript was found in all grass-endophyte associations, whereas with the $\mathrm{Nc} 25$ transcript there was much variation in transcript size and number, presumably resulting from the presence of different numbers of unit repeats. The two bands present in the meadow fescue associations $(952,955)$ most likely represent two Nc25 homologues, potentially one from each of its Epichlö̈ ancestors. 
A
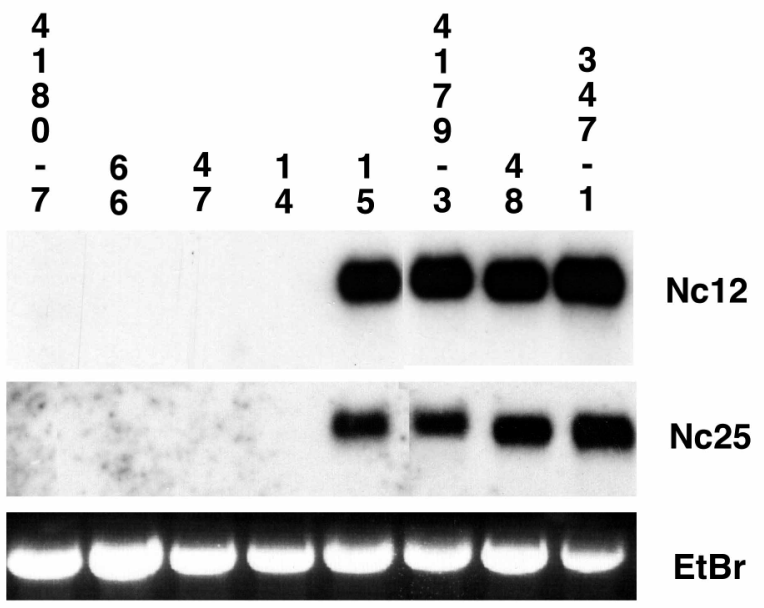

B

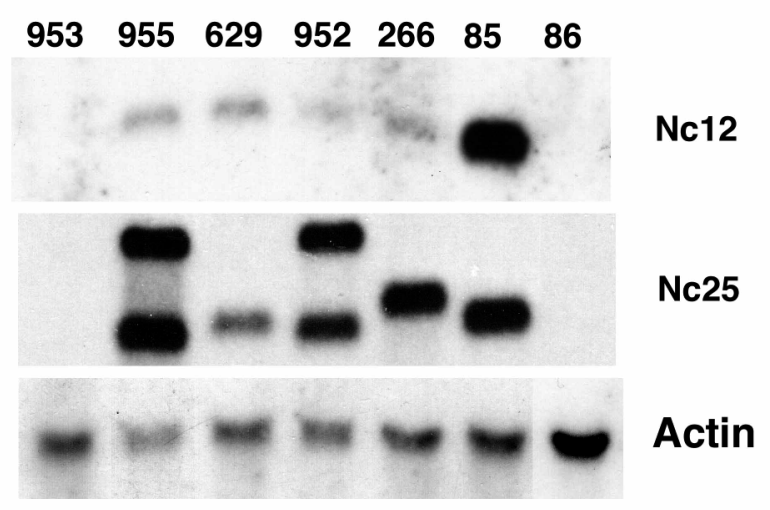

Figure. 2.7. Northern Analysis of Nc12 and Nc25 in other Endophyte-Grass Associations

A, Northern blot of pseudo-stem total RNA (15 $\mu \mathrm{g})$ from endophyte-free tall fescue cultivars $(4180-7,66$, $47,14)$ and $N$. coenophialum-infected tall fescue cultivars $(15,4179-3,48,347-1)$ hybridized with $\mathrm{Nc} 12$ or $\mathrm{Nc} 25$ probes. EtBr, ethidium bromide stained ribosomal RNA to indicate RNA loading. B, Northern blot of pseudo-stem total RNA (15 $\mu \mathrm{g}$ ) from meadow fescue associated with $N$. uncinatum (952), meadow fescue associated with $N$. siegelii (955) meadow fescue associated with $E$. festucae (629), endophyte free meadow fescue (953), perennial ryegrass associated with $N$. lolii (266), perennial ryegrass in association with $E$. typhina (85) and endophyte-free perennial ryegrass (86) hybridized with $\mathrm{Nc12}$, Nc25 and with the tall fescue actin gene (accession number AY194227) as a control for RNA loading. 
A quantitative (competitive) PCR assay was developed to quantify the difference in gene expression of $\mathrm{Nc12}$ in planta versus in culture conditions (Fig. 2.8). A housekeeping gene, $\beta$-tubulin [amplified from Neotyphodium sp. Lp1 (tub2-1), $\beta$-TUB primers, Table 2.2] was used to normalize the amount of cDNA from infected plant and culture-grown $N$. coenophialum. Fungal cDNA derived from in vitro cultures had to be diluted considerably relative to $\mathrm{E}+$ tall fescue symbiotum cDNA to result in equal mimic and cDNA product concentration (at $1 \mathrm{fg}$ ). This was expected since fungal biomass in planta was estimated to be approximately $1 / 500^{\text {th }}$ (this study and Panaccione et al. 2001) of the total DNA. This technique showed that the fungal gene Nc12 is up-regulated approximately 1000 fold in planta. The presence of this clone in a lambda ZAP II cDNA library prepared from cultured endophyte also indicated that it is expressed in culture. Accordingly, expression of the Nc12 transcript in culture was about 10-fold higher than expression of the fungal $\beta$-tubulin gene. 


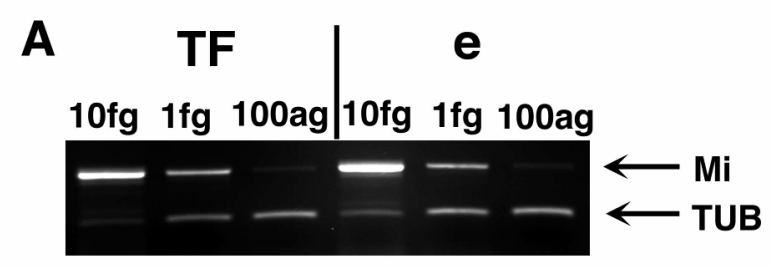

B

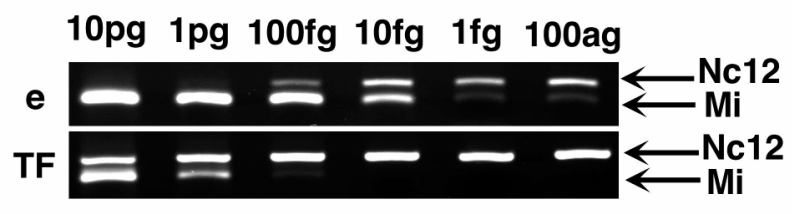

Figure 2.8. Quantitative RT-PCR Analysis of Nc12

A, Equalization of endophyte-infected tall fescue (TF) and cultured endophyte (e) cDNA is shown at the equivalence point (representing equal mimic and specific amplification of a Nc12 PCR fragment) of $1 \mathrm{fg}$. Mi indicates amplification of a competing mimic molecule (engineered to contain $\beta$-tubulin primer binding sites) at the mimic DNA concentrations of $10 \mathrm{fg}, 1 \mathrm{fg}$ and $100 \mathrm{ag}$. TUB indicates the specific amplification of a portion of the $\beta$-tubulin gene from e19 and E+ TF cDNA. B, Nc12 indicates the specific amplification of $\mathrm{Nc} 12$ from e and TF cDNA. Mi indicates amplification of the mimic DNA molecule (designed with Nc12 competing primer binding sites) at mimic DNA concentrations from $10 \mathrm{pg}$ to $100 \mathrm{ag}$. A mimic point close to $10 \mathrm{fg}$ is shown for e cDNA, in contrast to a mimic point of approximately $10 \mathrm{pg}$ for TF cDNA. 


\subsection{DISCUSSION}

This is the first report describing the identification of plant and fungal differentially expressed genes in an endophyte-grass symbiosis. By using the SSH technique, both up and down-regulated genes were identified from the important tall fescue- $N$. coenophialum association. Differential screening of the subtracted libraries identified 29 cDNA clones in total that were either putatively up-regulated or downregulated in tall fescue symbiotic with its fungal endophyte. Sequencing of these clones and analysis of the data by blast algorithms revealed that approximately half had no significant matches to any of the sequences present in the NCBI database (Altscul et al. 1997). Twelve plant cDNA clones were selected for further analysis and were confirmed to be differentially expressed by semi-quantitative RT-PCR (Fig. 2.2). Additionally, one of these plant cDNA clones (TFF41), with strong homology to an A. thaliana $\omega-3$ fatty acid desaturase FAD7 gene (Table 2.3), was shown to by quantitative RT-PCR be upregulated by approximately 1000 fold in E+ tall fescue (Fig. 2.3). Two novel fungal transcripts ( $N c 12$ and $N c 25)$ also were identified (Table 2.3). Northern analysis of $N c 12$ and $N c 25$ has confirmed that both fungal genes are highly up-regulated in planta (Fig. 2.6) and hence may play important roles in the association. As neither of these genes has any significant similarity to sequences in the NCBI database, or other EST databases, it is currently impossible to postulate on their roles. Further characterization (involving functional and structural analyses) of $N c 12$ and $N c 25$ should prove to be highly revealing as to the roles they play in endophyte-grass symbioses.

Of the clones that matched sequences in the NCBI database, several had potential 
functions with interesting implications for grass-endophyte associations. Clone TFF32 has strong similarity to A. thaliana genes putatively encoding ATP-binding cassette (ABC) transporters, as well as to ABC transporters of the PDR-5 group (Table 2.3). These proteins are proposed to be involved in the detoxification of herbicides and fungicides, as well as the transport of plant defense compounds (Davies and Coleman 2000). Expression studies of the PDR-5-like ABC transporter SpTUR2 from Spirodela polyrrhiza (Smart and Fleming 1996) in Arabidopsis suggests that SpTUR2 functions to transport the antifungal diterpene sclareol out of plant tissue, thereby conferring resistance to sclareol (van den Brule et al. 2002). A PDR-5-like protein from Nicotiana plumbaginifolia also may transport the diterpene sclareolide (Jasinski et al. 2001). In rice an $\mathrm{ABC}$ transporter gene also has been isolated from a SSH study to identify early immediate defense genes (Xiong et al. 2001). This gene was confirmed to be induced by both bensothiadiazole (BTH; a functional analog of salicylic acid) and by the blast fungus Pyricularia grisea (Xiong et al. 2001). Both of these reports implicate plant ABC transporters as important for the transport of plant-defense compounds. In the $N$. coenophialum-tall fescue association, the endophyte produces a number of bioactive alkaloids in planta [such as pyrrolizidine (loline), peramine and ergovaline alkaloids; Thompson and Stuedemann, 1993; Dahlman et al. 1997; Rowan 1986; Rowan 1993; Siegel and Bush 1997; Wilkinson et al. 2000] that have anti-herbivory effects resulting in the protection of both symbiont partners. However, as these alkaloids specifically affect neurotransmission, these alkaloids are unlikely to be toxic to the plant host, suggesting that the endophyte produces an unknown toxin in planta that the tall fescue putative $\mathrm{ABC}$ transporter may provide resistance to. 
TFF41 exhibits high similarity to both A. thaliana FAD7 and FAD8 genes (Table 2.3). These two genes encode two distinct chloroplast omega 3 fatty acid desaturases ( $\omega$ 3FAD) that are localized in the plastid membranes. The $\omega-3 \mathrm{FAD}$ enzyme converts dienoic fatty acids [linoleic acid (18:2) and hexadecanoic acid (16:2)] to trienoic fatty acids [a-linolenic acid (18:3) and hexadecatrienoic acid (16:3)]. FAD7 appears to have a role in regulating the levels of trienoic acid during leaf maturation, whereas FAD8 is predominately involved in lipid desaturation at low temperatures (Gibson et al. 1994) and its up-regulation has been correlated to increased tolerance of plants to low and freezing temperatures. However in maize, $Z m F A D 7$ is down-regulated by low temperature and ZmFAD8 is increased at low temperature (Berberich et al. 1998). The amount of trienoic fatty acids in plastid lipids not only affects tolerance of plants to the cold, but also affects the ability of the photosynthetic machinery to tolerate high temperatures. Silencing of both $F A D 7$ and $F A D 8$ genes in Arabidopsis (resulting in lower levels of plastid trienoic fatty acids) enabled these transgenic plants to tolerate higher temperatures (Murakami et al. 2000). In addition, the rates of photosynthesis and growth were increased at moderately high temperatures in this study. However, in Arabidopsis only expression of FAD8 changes in response to ambient temperatures.

The most abundant trienoic fatty acid is linolenic acid, a precursor of the plant growth regulator, jasmonic acid (JA), which in turn is involved in wound-induced gene activation in plants. In potato, the expression of a plastid-localized $\omega$-3FAD induced by wounding preceded the expression of a JA-inducible gene $\operatorname{pin} 2$ (proteinase inhibitor II), implying that expression of this gene may be required to supply the linolenic acid substrate for JA synthesis (Martin et al. 1999). Observations of the wound-responsive 
expression of the Arabidopsis FAD7 gene indicates that wound activation of FAD7 is mediated via the octadecanoid pathway in roots and by a jasmonate-independent pathway in leaves (Nishiuchi et al 1997). A plastid-localized $\omega$-3FAD identified from Parsley (Petroselinum crispum) was highly localized at fungal infection sites and rapidly and transiently induced by a fungal elicitor suggesting it may have a role in defense-related signaling (Kirsch et al. 1997).

In summary, $\omega-3 \mathrm{FAD}$ enzymes appear to be involved in a number of responses in plants: temperature, wound-response and plant-pathogen interactions. If the expression of TFF41 is endophyte-induced, then levels of trienoic fatty acids would be increased in the plastids of infected tall fescue. Whether this is to provide tolerance to temperature [tall fescue infected with endophyte is more drought tolerant (Arechavaleta et al. 1989; Bacon 1993; West 1994], an increase in the signaling molecule jasmonic acid, or for some other reason requires further investigation.

The up-regulated sequence represented by clone TFF26 exhibits significant sequence similarity to plant O-methyltransferases (OMT) that methylate phenolic compounds such as catechol, flavonoids and lignin precursors. The most significant BlastX match (Table 2.3) was to an herbicide safener-binding protein, SafBA from Maize (Zea mays L.) (Scott-Craig et al. 1998). The primary structure of this protein suggests it is an OMT, however it lacks a highly conserved amino acid motif present in all other known OMTs. SafBA binds a herbicide safener, dichloroacetamide safener (Saf), that is used to protect crops against injury from chloroacetanilide and thiocarbamate herbicides. Although clone TFF26 has the highest similarity to SafBA, a putative OMT, TFF26 may well function as an OMT that is involved in other cellular processes, of which there are 
many, depending upon the substrate targeted for methylation. The next highest matches to TFF26 from OMT proteins in the NCBI database were those encoding enzymes for the methylation of lignin precursors [catechol O-methyltransferase from barley $\left(6 \mathrm{e}^{-14}\right)$, an OMT (ZRP4) from Maize (Held et al. 1993) $\left.\left(6 \mathrm{e}^{-13}\right)\right]$, followed by OMTs with flavonoid substrates [a flavonoid 7-O-methyltransferase from Hordeum vulgare $\left(7 \mathrm{e}^{-13}\right)$ ]. Lignin, one of the major components of plant cell walls alters during plant development and is influenced by environmental factors (reviewed in Whetten et al. 1998). The phenylpropanoid pathway that provides the lignin-building blocks is induced by pathogens and participates in cell wall reinforcement to restrict pathogen ingress (Nicholson and Hammerschmidt 1992; Kauss et al. 1993; Dixon and Paiva 1995). Although the presence of endophyte is beneficial to tall fescue, endophyte growth may need to be restricted to avoid damage to the plant. Hypothetically, expression of this putative OMT during symbiosis could be to confine the endophyte (to the apoplast) just as pathogen growth is restricted during plant-pathogenic interactions, or increased accumulation of the products of this enzyme may have a role in providing resistance to pathogens as discussed below.

In plants, there are several hundred O-methylated flavonoids that play various roles. They can also have important roles in plant defense as precursors of antimicrobial secondary metabolites (phytoalexins) that are induced by microbial attack (Dakora et al. 1996; Edwards and Dixon 1991). Commonalities between plant-pathogen and plantsymbiotic interactions on the molecular level have been suggested and so the expression of this putative OMT gene in a symbiosis may be an example. Other possible functions for a plant OMT in the tall fescue-endophyte interaction may be in the production of a 
signal molecule, since O-methylated flavonoids have a signaling role in the rhizobiumlegume symbiosis by inducing Nod factors (Long 1989). Flavonoids also have been postulated to participate in plant-fungal communication in mycorrhizal interactions as well (Vierheilig et al. 1998). However, as maize mutants lacking flavonoids can still be mycorrhizal these molecules may not be essential signals (Becard et al. 1995). Since specific flavonoids are produced in E+ big bluegrass (Poa ampla) (where they were toxic to insects; Ju et al. 1998), these compounds could be involved in communication between the two symbionts or even increased resistance to insects. An OMT was similarly induced in the Eucalyptus globulus-Pisolithus tinctorius ectomycorrhiza symbiosis (Voiblet et al. 2001), further supporting the suggestion that OMTs may play a role during symbiosis.

Three of the up-regulated sequences (clones TFF2, TFF6, TFF24) were highly similar to different putative RNA binding proteins from A. thaliana (Table 2.3). A similar RNA binding protein was induced in rice infected by the blast fungus Magnaporthe grisea (Xiong et al. 2001). Only a few RNA-binding proteins have been studied in plants, compared to those from other eukaroytes. However, several reports have recently implicated RNA-binding proteins in hormone signaling and plant development (Fedoroff 2002). In eukaryotes, RNA-binding proteins participate in a surprising number of different functions, and so the presence of an RNA binding domain in a protein is a poor predictor of function. RNA proteins also are instrumental in the asymmetric distribution of proteins within a cell. This role is essential for the functioning of highly specialized cells such as neurons and is at the core of mechanisms for the development of a multi-cellular organism from a single cell. TFF6 may be involved in the formation of specialized cells since it also has significant BLAST matches to a ventral 
neuron-specific protein 1 (NOVA1) from Mus musculus (3e -5) and Homo sapiens (5e$05)$.

An RNA-binding protein complex mediates the light-regulated translation of chloroplast mRNAs, including those encoding the chlorophyll apoproteins. One of the RNA binding proteins involved in this function belongs to the poly(A) binding protein (PABP) family (Yohn et al.1998). A poly(A) binding protein also was up-regulated in E+ tall fescue (clone TFF28, Table 2.3) and proteins of this class are universally involved in translational stimulation (Gray et al. 2000). With over 200 putative RNA-binding proteins in the Arabidopsis genome, and the potential importance of these proteins in plant morphogenesis and cellular regulation, our understanding of the function of these proteins in plants will be highly enlightening.

TFF09 is a putatively up-regulated clone with high similarity to Rab GDP dissociation inhibitor proteins (GDI) (Table 2.3). These proteins play a central role in vesicular trafficking, by regulating the nucleotide states and cellular localizations of Rab proteins, a family of small GTPases. Vesicular trafficking is important for the intracellular transport of proteins in eukaroytes. In plants, these proteins may have a pivotal role upstream of defense responses to pathogens. Evidence for this comes from the finding that Rab-GDI proteins from rice were up-regulated early in response to fungal-elicitor treatment, as well as by salicylic acid, $\mathrm{H}_{2} \mathrm{O}_{2}$, or abscisic acid (Kim et al. 1999). The elucidation of the role this gene may play in symbiosis will therefore be interesting.

$T F F 25$, isolated from the lambda ZAP II library had the highest BLAST match to a metallothionein-like protein, type II from rice $\left(4 \mathrm{e}^{-5}\right)$. Metallothioneins (MT) are defined 
as low-molecular weight cysteine-rich proteins that bind heavy metals and are classified into types I, II and III. Plant MTs appear to have multiple, poorly understood functions in the cell (Robinson et al. 1993). They have been implicated in heavy-metal metabolism, stress tolerance, senescence, response to viral infection, sucrose starvation, microsporogenesis, the hypersensitive response and wounding (Birch et al. 1999; Buchanan-Wollaston 1994; Butt et al. 1998; Charbonnel-Campaa et al. 2000; Chen et al. 2000; Hsieh et al. 1996; Whitelaw et al. 1997). In the actinorhizal nitrogen-fixing symbiosis, a type I MT was highly expressed in roots and in nitrogen-fixing nodules and was hypothesized to play a role in metal ion transport and homeostasis (Laplaze et al. 2002). In two separate studies using serial analysis of gene expression (SAGE) to profile transcripts in the barley mildew pathogen Blumeria graminis (Thomas et al. 2002) and in rice seedlings (Matsumura et al. 1999), the most abundant transcript was a putative metallothionein in ungerminated conidia, germinated conidia and appressoria in the $B$. graminis study and a metallothionien (type II) in the rice study.

One of the down-regulated sequences (clone TFR53) putatively encodes a pathogenesis-related 10 (PR-10) protein (Table 2.4). PR proteins are defined as plant proteins that are induced in pathological or related situations (van Loon et al. 1994). They have been classified into 14 families (PR-1-14) mainly based on sequence relationships. PR-10 proteins are typically part of a gene family, with members often differentially regulated. Proteins of the PR-10 class are found in various species of the plant kingdom, including both dicots and monocots. Members of the PR-10 family include common allergens, such as the major birch pollen allergen Betv1 (Breiteneder et al. 1989). The biological functions of PR-10 proteins are unknown, although there is accumulating 
evidence that at least some act as ribonucleases (Bantignies et al. 2000; Moiseyev et al. 1994, 1997; Swoboda et al. 1996). This possibility is supported by the demonstration of in vitro ribonuclease activity for a cotton PR-10 protein and for PR-10c of birch (Koistinen et al. 2002; Zhou et al. 2002). The absence of signal peptides or membranebinding domains, suggests that they are intracellular proteins located in the cytosol (Matton and Brisson 1989; Somssich et al. 1988; Warner et al. 1992). There is evidence for PR-10 involvement in general plant defense mechanisms, since induction of PR-10 proteins occur after pathogen or elicitor treatment (Lo et al. 1999; McGee et al. 2001; Somssich et al. 1988), wounding (Warner et al. 1992; Warner et al. 1993) and other environmental stresses (Awade et al. 1991; Dubos and Plomion 2001; Moons et al. 1997). $P R-10$ also is induced by the plant hormones abscisic acid and methyl jasmonate (Moons et al. 1997; Wang et al. 1999). Other members of this gene family are invoked during plant development processes such as dormancy and nodule development with tissue specificity expression (Gamas et al. 1998; Pnueli et al. 2002; Poupard et al. 2001).

MtN13 from M. truncatula encodes a protein structurally related to the PR-10 family that is not pathogen-induced in leaves, but solely expressed during nodule development (Gamas et al. 1998). MtN13 may therefore represent a nodulation-specific defense gene functioning to protect the root nodule from pathogenic infections. Interestingly, there is another member of the PR-10 family present in M. truncatula $(M t P R-10-1)$ that is constitutively expressed in roots, and is pathogen-inducible in leaves. The expression of two yellow lupine (Lupinus luteus) PR-10-related proteins (L1PR10.1A and PR-10.1B), was inhibited during symbiosis with Bradyrhizobium sp. (Lupinus) (in young and mature root nodules) but both genes were constitutively expressed in roots 
(Sikorski et al. 1999). In senescent nodules, a return to high PR-10 transcript and protein levels was observed. The authors conclude that certain defense mechanisms are likely to be suppressed to allow for critical events such as the recognition of a micro-symbiont and therefore suppression of a defense protein like PR-10 in symbiotic tissues could be necessary for symbiosis establishment and development. Alternatively, PR-10 suppression could be under a developmentally regulated process, unrelated to plant defense, a possibility that is supported by the up-regulation of $M$. trancatula nodulinspecific PR proteins (MtN13) during nodulation. It is of high interest that in both the tall fescue- $N$. coenophialum mutualistic interaction and in the lupine-rhizobium symbiosis, a PR-10-like protein is down-regulated.

The down-regulated sequence, clone TFR47 showed highest similarity to a putative aminopeptidase from A. thaliana (Table 2.4) as well as to aminopeptidase $\mathrm{N}$ proteins from microorganisms (for example; Pseudomonas syringae pv. syringae, Pseudomonas fluorescens, Pseudomonas aeruginosa and Microbulbifer degradans) when analyzed by a BlastX search. Yamauchi et al. (2001) characterized a plant aminopeptidase $\mathrm{N}$ from cucumber that acts as a metalloprotease and cleaves $\mathrm{N}$-terminal alanine from artificial substrates.

Another down-regulated clone TFR45, putatively encodes a Type III chlorophyll a-b binding protein of the light harvesting complex II (Table 2.4). These proteins bind to the pigment molecules (chlorophyll a and $\mathrm{b}$, and some carotenoids) of the lightharvesting complexes I and II to capture and transfer light energy to the photosynthetic reaction centers in both photosystem I and II (Jansson 1994). Other chlorophyll a-b binding proteins also have been isolated from other differentially expressed gene studies. 
Infection by the mollicute, Spiroplasma citri in Catharanthus roseus (periwinkle) plants, also reduced expression of the periwinkle chlorophyll a-b binding protein (JagoueixEveillard et al. 2000). A transcript putatively encoding a chlorophyll a-b binding protein was also isolated from non-dormant legume (Retama raetam) plants and was upregulated under severe stress conditions (Pnueli et al. 2002). Chlorophyll a-b binding proteins were abundantly expressed in two different plant pathogen-related EST projects: infection of wheat and rice by the fungal pathogens Fusarium graminearum and Magnaporthe grisea, respectively (Kruger et al. 2002; Rauyaree et al. 2001). The functions of these proteins in these interactions is, however unknown.

A further down-regulated sequence, clone TFR021, putatively matches an $S$ adenosylmethionine decarboxylase (SAMDC) enzyme (Table 2.4). SAMDC is a key enzyme in polyamine biosynthesis for the production of spermidine and spermine (from putrescine), which are essential for all cells. Polyamines are involved in senescence and morphogenesis in plants and in responses to abiotic stresses (reviewed in Walters 2000) but their precise mechanisms of action are unknown. Polyamine concentrations also are dramatically affected by fungal and viral infection. Polyamine levels with a corresponding increases in the polyamine biosynthetic enzymes including SAMDC, were found to increase in barley leaves infected by the powdery mildew fungus, Blumeria graminia f. sp. hordei (Walters et al. 1985; Walters and Wylie 1986). Methyl jasmonate (MJ) treatment of barley leaves also increased the activity of the polyamine biosynthetic enzymes leading to reduction in powdery mildew infection on untreated second leaves, along with associated increases of plant defense enzyme activities such as phenylalanine ammonia lysase (PAL) and peroxidase (Walters et al. 2002). Overexpression of SAMDC 
in japonica rice under salt stress conditions increased levels of polyamines and plant biomass, responses which are postulated to contribute to salt stress tolerance (Roy and $\mathrm{Wu}, 2002$, in press). This gene also has been implicated in the tolerance of wheat to salinity and drought ( $\mathrm{Li}$ and Chen 2000). SAMDC also has been isolated as an abundant EST in the wheat- $F$. graminearum interaction (Kruger et al. 2002).

A number of alkaloids can be produced by $N$. coenophialum in association with it host tall fescue. The loline alkaloids (saturated 1-aminopyrrolizidine with an ether bridge) are produced abundantly in this association (Porter 1994). They are fungal in origin since lolines are produced by the endophyte $N$. uncinatum in axenic culture (Blankenship et al. 2001). Whether the down-regulation of SAMDC (an essential enzyme in polyamine biosynthesis) in endophyte-infected tall fescue has any relation to the production of the fungal pyrrolizidine alkaloids is unknown, but it is interesting that the polyamine spermidine is a unique precursor for the formation of the necine base moiety of senecio pyrrolizidine alkaloids in plants (Ober and Hartmann 1999).

We had expected to find other fungal transcripts specifically expressed during the symbiosis (i.e., up-regulated in planta). The chance of finding fungal genes, particularly lowly expressed ones, is hindered, since approximately $0.2 \%$ or less of the total symbiotum DNA is derived from endophyte DNA (this study and Panaccione et al. 2001). The lack of differentially expressed fungal genes may also have been due to the set up of the forward subtraction procedure that required an equivalent amount (as in planta) of culture grown fungal cDNA to be added as 'driver' cDNA (along with endophyte-free tall fescue cDNA) to subtract out fungal (and plant) genes not symbiotically regulated. Although the appropriate amount of fungal cDNA to add as part 
of the 'driver' cDNA was calculated by competitive PCR (see section 2.2 Materials and Methods), if too much culture derived cDNA was added, fungal genes expressed in planta as well as in culture may have been subtracted out.

In summary, a number of interesting genes have been identified by SSH (Table 2.3 and 2.4). Based on their sequence identity to genes in the NCBI database, we have been able to speculate on their possible functional roles in the symbiosis. The knowledge of these differentially expressed genes will allow us in the future to make targeted approaches to confirm their hypothetical functions. A number of unknown genes also have been identified, including two endophyte genes expressed at exceptionally high levels in planta. Most of the unknown tall fescue and the two fungal genes identified in this study are likely to have novel functions and may play unique roles in endophytegrass associations. However, some of these unknown genes may still be identified in other plant-microbe interactions once more EST and genome projects are undertaken and the sequence information released to the public. Our research has enabled the identification of both plant and fungal genes that may play vital roles in the tall fescue- $N$. coenophialum symbioses. Further studies to delineate the functions of these differentially expressed genes may allow some of the elusive mechanisms that control symbiosis development and function to be revealed. 


\section{CHAPTER 3: $\quad$ EXPRESSION ANALYSIS OF TALL FESCUE AND ENDOPHYTE GENES IN OTHER GRASS-ENDOPHYTE}

\section{ASSOCIATIONS AND THE EFFECTS OF FUNGAL INFECTION BY MYCORRHIZAL FUNGI AND PYRICULARIA GRISEA}

\subsection{INTRODUCTION}

Grasses have evolved to form symbiotic associations with fungi. Of particular significance are the widespread associations formed between cool-season grasses (subfamily Pooideae) and fungal endophytes from the family Clavicipitaceae (order Hypocreales, phylum Ascomycota) (Clay and Leuchtmann 1989, Schardl et al. 1997). Grass endophytes of the genus Epichloë form a variety of symbiotic relationships with their hosts that range from pathogenic to mutualistic, depending on the importance of the sexual or asexual life cycle of the fungus (reviewed in Schardl, 1996). In contrast, the related asexual Neotyphodium endophytes [reclassified from Acremonium sect. Albolanosa by Glenn et al. (1996)] are truly endophytic as their entire life cycle is limited to the intercellular spaces of their grass host. These associations are systemic and nonpathogenic, and many or all can be considered mutualistic since both symbiont and host benefit from the interaction. In exchange for carbon, the fungal endophyte primarily appears to provide protective benefits against herbivory and parasitism, as well as to induce plant physiological changes for enhanced nutrient uptake and improved drought tolerance (Arechavaleta et al. 1989; Bacon 1993; Belesky and Malinowski 2000; Malinowski et al. 1999; West 1994). The mechanisms by which endophyte-infected grass 
plants adapt to various biotic and abiotic stresses are poorly understood, as is the molecular nature of the symbiosis. Agriculturally important and well-studied Neotyphodium endophytes include $N$. coenophialum, $N$. lolii, and $N$. uncinatum, which colonize the cool-season grasses tall fescue (Lolium arundinaceum $=$ Festuca arundinacea; Darbyshire 1993), perennial ryegrass (Lolium perenne L.) and meadow fescue (Lolium pratense (Huds.) Darbysh.=Festuca pratensis Huds.), respectively.

To begin to investigate the molecular basis for the mutually beneficial $N$. coenophialum-tall fescue interaction, differentially expressed genes were identified by the preparation of two subtracted cDNA libraries by a PCR based cDNA subtraction procedure, suppressive subtractive hybridization (SSH; Diachenko et al. 1996) (Chapter 2 of this thesis). Up-regulated transcripts were obtained from the forward cDNA subtracted library generated by a subtraction of tall fescue- $N$. coenophialum symbiotum cDNA (tester) with cDNA from uninfected tall fescue supplemented with saprophytically grown N. coenophialum (driver). To obtain down-regulated transcripts, a reverse cDNA library was prepared by a subtraction of uninfected tall fescue cDNA (tester) with tall fescue- $N$. ceonophialum symbiotum cDNA (driver). Twenty-seven tall fescue genes and two fungal genes were identified as differentially expressed in the tall fescue- $N$. coenophialum interaction (Table $2.3 \& 2.4$ ). A subset of these genes was chosen to further analyze their potential involvement in other plant-fungal interactions.

We hypothesized that some of these differentially expressed genes may be unique to grass-endophyte symbioses in general, whereas others may be differentially regulated only in this particular partnership between $N$. coenophialum and its host tall fescue. For example, these differentially expressed genes may be part of an intimate signalling 
exchange essential for the establishment and maintenance of grass-endophyte symbioses, or they may solely be involved in various endophyte-induced fitness enhancements bestowed upon its host grass. In this chapter, I describe the analysis of expression of a subset of $N$. coenophialum-tall fescue symbiois-associated genes in other endophytegrass associations (perennial ryegrass infected with $N$. lolii, or E. typhina; meadow fescue infected with $N$. siegelii, E. festucae and $N$. uncinatum), to determine if they are differentially regulated in these grass-endophyte associations.

We also hypothesized that some of these differentially expressed genes could be involved in other plant-fungal interactions, whereas others may be unique to mutualistic interactions. Partially overlapping genetic requirements for the symbiotic interaction of legumes with the nitrogen-fixing rhizobia during root nodule formation and with arbuscular mycorrhizal fungi (AMF) have been elucidated from other studies. Evidence is provided from the number of common genes essential for both types of interactions (referred to as SYM genes) as well as plant mutants that are defective in both symbioses (van Rhijn et al. 1997; Parniske 2000; Marsh and Schultz 2001; Stougaard 2001). A breakthrough in understanding the molecular dialog between symbiont partners occurred with the recent discovery that one of the common SYM genes is a novel receptor likekinase essential for the recognition of both bacterial and fungal symbionts (Stracke et al. 2002). However, divergent regulatory mechanisms also are present between rhizobiainduced root nodules and mycorrhiza. Similar classes of chitinases were induced in response to both nodulation and pathogen infection, but the induction of a mycorrhizaclass of chitinases occurred only in response to AMF colonization (Salzer et al. 2000). In bacteria, similar mechanisms of pathogenesis and symbiosis also exist for the successful 
colonization of a niche, such as quorum sensing and the two-component regulatory system (Hentschel et al. 2000).

To address the above questions, the expression of a subset of genes was studied in both E- and E+ tall fescue infected with either a compatible fungus, Pyricularia grisea that causes gray leaf spot in perennial ryegrass (Farman 2001), or infected with AMF (Zygomycota, Order Glomales). The association formed between AMF and the roots of terrestrial flowering plants is widespread and highly beneficial to both partners. In contrast, $P$. grisea is a well-characterized plant pathogen primarily of agriculturally significance as the causal agent of rice blast and gray leaf spot of ryegrass and tall fescue.

Primarily, I was interested in the response at the transcriptional level of endophyte-free tall fescue to the formation of a successful mycorrhiza establishment. Endophyte-infected tall fescue also was inoculated with AMF, but it was anticipated that gene expression results from a tripartite association (involving AMF, a fungal endophyte and host plants) might be more difficult to interpret. In addition, Chu-chou et al. (1992) reported that the presence of $N$. coenophialum in tall fescue inhibited the formation of mycorrhizal interactions. This study also will address whether colonization by the AMF Glomus clarum and Glomus etunicatum is inhibited in E+ tall fescue.

In this chapter, gene expression studies of five up-regulated plant genes (cDNA clones TFF41, TFF32, TFF26, TFF25 and TFF24) and two fungal genes (cDNA clones $\mathrm{Nc} 25$ and $\mathrm{Nc12}$ ), together with one down-regulated gene (cDNA clone TFR53) are described. 


\subsection{METHODS AND MATERIALS}

\subsubsection{Plant Material}

Grasses and their fungal symbionts used in this study are listed in Table 3.1. Grasses were grown from seed and maintained in the greenhouse at Lexington, Kentucky.

\section{Table 3.1. Grass-Endophyte Associations Used in Study}

\begin{tabular}{|c|c|c|c|c|}
\hline Plant no. & Grass species and cultivars & Fungal endophyte & Fungal strain & Reference \\
\hline & Lolium arundinaceum & & & \\
\hline 19 & GI-320 (Johnstone) & Neotyphodium coenophialum & e19 (ATCC 90664) & Siegel et al (1990)/Schardl \\
\hline 18 & GI-320 (Johnstone) & endophyte minus & & Siegel et al (1990)/ \\
\hline 15 & KY31 & Neotyphodium coenophialum & e19 & Siegel et al (1990) \\
\hline 14 & KY31 & endophyte minus & & Siegel et al (1990) \\
\hline $4179-3$ & KY31 & Neotyphodium coenophialum & e19 & this study/Schardl \\
\hline 48 & Mustang & Neotyphodium coenophialum & $\mathrm{e} 48$ & this study/Schardl \\
\hline 47 & Mustang & endophyte minus & & this study/Siegel \\
\hline $347-1$ & KY31 & Neotyphodium coenophialum & e15 & this study/Schardl \\
\hline $4180-7$ & Seine & endophyte minus & & this study/Hignight \\
\hline \multirow[t]{2}{*}{4122} & KY31 & Neotyphodium siegelii & e915 (ATCC 74483) & Craven et al (2001a)/Schardl \\
\hline & Lolium perenne & & & \\
\hline 266 & Gator & Neotyphodium lolii & e265 & this study/Schardl \\
\hline 85 & Gator & Epichloe typhina & e8 & Siegel et al (1990) \\
\hline \multirow[t]{2}{*}{86} & Gator & endophyte minus & & Siegel et al (1990)/Schardl \\
\hline & Lolium pratense & & & \\
\hline 952 & Predix & Neotyphodium uncinatum & e167 & Carvel et al. (2001a)/Schardl \\
\hline 955 & Predix & Neotyphodium siegelii & e915 (ATCC 74483) & Craven et al (2001a)/Schardl \\
\hline 629 & Predix & Epichloe festucae & e682 (CBS102476) & Wilkinson et al. (2000)/Schardl \\
\hline 953 & Predix & endophyte minus & & Wilkinson et al. (2000)/Schardl \\
\hline
\end{tabular}




\subsubsection{Northern Blot Analysis of Endophyte-Grass Associations}

Total RNAs $(15 \mu \mathrm{g})$ were separated by electrophoresis on a $1.0 \%(\mathrm{w} / \mathrm{v})$ agarose gel containing 0.6 $\mathrm{M}$ formaldehyde in 1x MOPS (3-[N-morpholino] propanesulfonic acid) buffer (20mM MOPS, $5 \mathrm{mM}$ sodium acetate, and $1 \mathrm{mM}$ EDTA; $\mathrm{pH}$ 7.0). RNA was then transferred to a Zeta-Probe GT blotting membrane (Bio-Rad) in 10x SSC (1.5 M $\mathrm{NaCl}$ and $0.15 \mathrm{M}$ trisodium citrate, $\mathrm{pH}$ 7.0) according to standard procedures (Sambrook et al. 1989) and dried at $80^{\circ} \mathrm{C}$ for $2 \mathrm{~h}$. Hybridization was performed in formamidecontaining buffer [50 ml formamide, $25 \mathrm{ml} 0.5 \mathrm{M}$ sodium phosphate ( $\mathrm{pH} 7.2), 1.46 \mathrm{~g}$ sodium chloride, $7.0 \mathrm{~g}$ SDS and water to $100 \mathrm{ml}$ ] at $42^{\circ} \mathrm{C}$ overnight. Probes were prepared and labeled as described for Southern blotting (primer sequences are given in Table 3.2). Filters were washed successively at room temperature twice for $10 \mathrm{~min}$ each in 2x SSC (1x SSC is $0.15 \mathrm{M} \mathrm{NaCl}$ plus $0.015 \mathrm{M}$ trisodium citrate) and $0.1 \% \mathrm{SDS} ; 0.5 \mathrm{x}$ SSC and $0.1 \%$ SDS. A final wash was performed in $0.1 \mathrm{xSC}, 0.1 \%$ SDS at $50^{\circ} \mathrm{C}$.

\subsubsection{Southern Blot Hybridization}

Plant genomic DNA was isolated with the DNeasy plant mini kit (Qiagen). Restriction endonuclease digests of DNA were carried out with $10 \mu \mathrm{g}$ of DNA according to the manufacturer's instructions (New England Biolabs, Beverly, MA, USA) and electrophoresed in $0.8 \%$ agarose gels. Size-separated DNA was then transferred from the gel to Zeta-Probe GT blotting membranes (Bio-Rad, Hercules, CA, USA) by capillary transfer under alkaline conditions (Read and Mann 1985). DNA for probe labeling was generated by PCR amplification from gene specific primers (primer sequences are given 
in Table 3.2). PCR fragments were then gel purified with GELase Agarose GelDigesting Preparation (Epicentre Technologies, Madison, WI, USA) following the manufacturer's instructions. Gel purified fragments were then further purified by treatment with the QIAquick PCR Purification Kit (Qiagen). Probes were random primelabeled with $\left[\alpha^{32} \mathrm{P}\right] \mathrm{dCTP}$ using High Prime (Roche) as described in the manufacturer's instructions. Unincorporated labeled nucleotides were removed by chromatography over Probe Quant G-50 Micro columns (Amersham Biosciences, Piscataway, NJ, USA) following the supplier's instructions.

Southern blots were hybridized at $65^{\circ} \mathrm{C}$ in $0.25 \mathrm{M}$ sodium phosphate, $\mathrm{pH} 7.2$ and $7 \%$ SDS (sodium dodecyl sulfate) overnight. Membranes were washed twice at $65^{\circ} \mathrm{C}$ for $30-60 \mathrm{~min}$ in $20 \mathrm{mM}$ sodium phosphate, $\mathrm{pH} 7.2,5 \%$ SDS; followed by two additional washes at $65^{\circ} \mathrm{C}$ for 30-60 min each in $20 \mathrm{mM}$ sodium phosphate, $\mathrm{pH} 7.2,1 \%$ SDS.

Table 3.2. PCR Primers

\begin{tabular}{lll}
\hline CLONE & FORWARD PRIMER & REVERSE PRIMER \\
\hline ACTIN & CGCCATCCAGGCTGTGCTTTC & CCAGCTCCTGTTCATAGTCAAG \\
TFF24 & CCAGTGACCAACAGCAGAGAT & ACAGGAACTCTCTGCACCCTG \\
TFF25 & ACATTCCCAAGTCTCACACA & CTTCAAGATAATTTACAGGGGT \\
TFF26 & GTAGGAGTGCCATTCCTCCA & GAAGACACCTCGTGCTCCTA \\
TFF32 & ACCAGAGAGAATGCGAAAGG & ACTGGAGGAATCCTCAATAC \\
TFF41 & ATACTTGTGCCTTACAATGGC & TACGGGACACCGTAGAGCTT \\
TFR53 & ACATGATGCTCAAGGGCAAG & ACAGTTGTCACCTCACACAG \\
Nc12 & AGTCTGGCTAGCAAGAAG & TTGCCTCCGGAACCACCA \\
Nc25 & TTCCTATGTAATCGAGTTGCC & ACATTCCCAAGTCTCACACA \\
$\beta-$ TUB & TTCAAACCGGTCAGTGCG & GAGATCGACGAGGACAGC
\end{tabular}




\subsubsection{Inoculation of Tall Fescue with Arbuscular Mycorrhizal Fungi (AMF)}

The potting medium for all treatments consisted of a field soil collected locally supporting meadow fescue and a sandy loam soil (Lily series) with a 2:1 (v/v) addition of a quartzite sand (average grain size $=0.9 \mathrm{~mm})$. The two soils were mixed $1: 1(\mathrm{v} / \mathrm{v})$ and steam sterilized at $80^{\circ} \mathrm{C}$ twice for one hour separated by a 24 -hr cooling period). Filtrate from the field soil (after passage through a sieve with $10 \mu \mathrm{m}$ openings) was added 1:20 $(\mathrm{v} / \mathrm{v})$ to sterilized media and mixed thoroughly to reintroduce native soil microflora minus mycorrhizal fungi. The soil was adjusted to $\mathrm{pH} 6.0$ with lime and separated into two batches, one unamended with phosphorus and the other with $30 \mathrm{mg} \mathrm{kg}^{-1} \mathrm{P}$ added. Two treatments were applied to the unamended soil: (i) inoculum of Glomus clarum CL883A and Glomus etunicatum UT316, which consisted of chopped contents of stored pot cultures of the International Culture Collection of Arbuscular Mycorrhizal Fungi (INVAM) at West Virginia University (Morton et al. 1993) and (ii) chopped contents of pot cultures grown without mycorrhizal fungi. Inocula were thoroughly mixed 1:10 (v/v) with sterile soil. The pot culture medium lacking mycorrhizal fungi was applied in the same proportions to the $\mathrm{P}$-amended soil. All soil treatments were placed in 4 x $21 \mathrm{~cm}$ cone-tainers $^{\mathrm{TM}}$ (Stuewe and Sons, Inc., Corvallis, Oregon). E+ (plant 19) and E- (plant 18) tall fescue were seeded into ten cone-tainers of each soil treatment (-M-P, $+\mathrm{M}-\mathrm{P}$, $\mathrm{M}+\mathrm{P})$.

Between 7 and 10 seedlings germinated per cone-tainer. Plants were grown in a greenhouse with natural and fluorescent lighting (14-hr photoperiod, 160-225 $\mu \mathrm{mol} \mathrm{m} \mathrm{m}^{-2} \mathrm{~s}^{-1}$ photon flux density at pot level) and room temperatures ranging from 19 to $26 \mathrm{C}$ during 
the growth period. At 9 weeks, pseudo-stems, leaves and roots for RNA extraction were harvested, flash-frozen in liquid nitrogen and stored at $-80^{\circ} \mathrm{C}$ until required. Roots from one plant of each treatment also were stained to assess amount of mycorrhizal colonization.

\subsubsection{Microscopic Detection of AMF-Colonization}

Sections of roots were placed in capsules and stained by boiling in $10 \% \mathrm{KOH}$ for 5 mins, followed by 5 rinses in water. The roots were then covered in $2 \% \mathrm{HCl}$ for 5 mins, drained and immediately incubated in boiling $0.05 \%$ trypan blue for 5 mins. Root capsules were then rinsed well in water before checking colonization by microscopy.

\subsubsection{Gene Expression Studies of AMF-Infected Tall Fescue}

Approximately $10 \mu \mathrm{g}$ of total RNA extracted from each plant type was analysed by northern analysis. This procedure is described in section 3.2.2. For semi-quantitative and competitive RT-PCR, RNA was converted into cDNA as described in section 2.2.5. Quantification of TFF41 expression by competitive RT-PCR was performed as described in section 2.2.6.

\subsubsection{Pyricularia grisea Fungal Isolates}

A list of the fungal isolates used in this study is presented in Table 3.3. Cultures of the $P$. grisea isolates were kindly provided on oatmeal agar by Mark Farman (Valent et al. 1986). 
Table 3.3. Pyricularia grisea isolates used in this study

\begin{tabular}{lllll}
\hline Isolate & Host & Place of isolation & Year & Collector/source \\
\hline LpKY97-1 & Perennial ryegrass & Golf Course, Lexington, KY, & 1997 & P. Dernoeden \\
LpOH1 & Perennial ryegrass & OH & 1997 & J. Rimelspach \\
\hline
\end{tabular}

\subsubsection{Inoculation of tall fescue with $P$. grisea isolates}

Inoculations of tall fescue with $P$. grisea were performed as described by Smith and Leong (1994). Spore suspensions were made by spreading $5 \mathrm{ml}$ of gelatin $(0.2 \%)$ onto culture plates with gentle rubbing. Spores were then filtered through cheesecloth and the procedure repeated to obtain the remaining spores. Spores were then counted on a hemocytometer under a microscope. To inoculate endophyte free (E-, plant 18) and endophyte-infected (E+, plant 19) tall fescue, approximately $1 \times 10^{5}$ spores $/ \mathrm{ml}$ of $0.2 \%$ gelatin was sprayed onto leaves in a total volume of $10 \mathrm{ml}$. Control E- and E+ plants were sprayed with $10 \mathrm{ml}$ of $0.2 \%$ gelatin only. Plants were loosely sealed in bags and incubated for 24 hours in a growth chamber. After 24 hours, bags were slowly opened. Stems and leaves were harvested at 24, 48 and 72 hours. The remaining stems and leaves on the harvested plants were incubated until disease symptoms developed.

\subsubsection{Northern Analysis of P. grisea Infected Tall Fescue}

Approximately $15 \mu \mathrm{g}$ of RNA extracted from stems and leaves of both E- and E+ plants inoculated with LpOH1, LpKY97-1A, or $0.2 \%$ gelatin were analysed by northern analysis. This technique is described in section 3.2.2. 


\subsection{RESULTS: ANALYSIS OF TALL FESCUE AND N. COENOPHIALUM GENE EXPRESSION IN DIFFERENT GRASS-ENDOPHYTE ASSOCIATIONS}

\subsubsection{Northern Analysis of the Putative Tall Fescue PR-10 gene (clone TFR53)}

Semi-quantitative RT-PCR had previously confirmed that TFR53, putatively encoding a PR-10-like protein (Table 2.4), was down-regulated in tall fescue symbiotic with the fungal endophyte $N$. coenophialum in comparison to endophyte-free tall fescue (Fig. 2.2). If the presence of $N$. coenophialum in tall fescue was actively causing down-regulation of the tall fescue $P R-10$ gene, other grasses in association with Neotyphodium endophytes also may demonstrate a similar response. In an attempt to further analyze the affects of endophyte association with tall fescue upon $P R-10$ expression, and to analyze the potential importance of this gene in other endophyte-grass associations, RNA from tall fescue, perennial ryegrass and meadow fescue with or without their respective fungal endophytes (Table 3.1) was analzed on northern blots probed with the 3' region of the putative $P R-10$ gene (Figs 3.1A, 3.1C, 3.2).

Expression of $P R-10$ (TFR53) was shown to be down-regulated in three different tall fescue cultivars (plants $4179,19,15$ ), all of which form an association with the endophyte $N$. coenophialum (strain e19) when compared to two endophyte-free tall fescue cultivars (plants 18 and 14) (Fig 3.1A). These results therefore support the previous semi-quantitative RT-PCR experiments on expression of $P R$ - 10 . In contrast, tall fescue artificially infected with $N$. siegelii (4122) showed very high levels of $P R-10$ 
expression relative to uninfected plants 18 and 14 . Meadow fescue is the natural host for $N$. siegelii, and so the high expression of $P R-10$ in tall fescue may indicate that tall fescue is a less compatible host for this endophyte.

Expression of $P R-10$ was observed in other tall fescue endophyte-free cultivars and other tall fescue associations (Fig 3.1C). High levels of $P R-10$ occurred in endophyte-free plant 4180-7 (Seine) as anticipated. However, very low levels of $P R-10$ were expressed in endophyte-free plant 47 (Mustang) compared with the corresponding endophyte-infected plant 48 (Mustang), indicating that $P R-10$ is up-regulated in this E+ tall fescue cultivar (Mustang). Lower levels of $P R-10$ expression occurred in the other endophyte-infected plants 4179-3 (KY31), and 347-1 (KY31), relative to the E- tall fescue plants 4180-7 (KY31) and 14 (KY31). Levels of $P R-10$ in these E+ tall fescue cultivars were, however, higher in comparison to plant 15 (E+) used in the SSH study (which showed basal expression levels).

In figure 3.2, homologues of $P R-10$ are strongly expressed in perennial ryegrass associated with $N$. lolii (266), moderately in perennial ryegrass associated with E. typhina (85), and weakly in endophyte-free perennial ryegrass (86), suggesting that downregulation of $P R-10$ does not occur in endophyte-infected perennial ryegrass (or at least in association with these fungi). No $P R$-10-like homologue could be detected in the meadow-fescue associations under low stringency hybridization $\left(37^{\circ} \mathrm{C}\right)$ and wash conditions, raising the possibility that a gene homologous to $P R-10$ might either be absent, not expressed in meadow fescue or the gene may be too divergent to detect with this probe. Since $P R-10$ genes are fairly ubiquitous, and are often present as gene families, it seems likely that $P R-10$ gene homologue(s) would be present in meadow 
fescue. In addition, the chances of detecting other members of the $P R-10$ family in meadow fescue were reduced since much of the probe (212 of $298 \mathrm{nt})$ is from the 3'noncoding sequences of the tall fescue gene.

The copy number of $P R-10$ also was analyzed by Southern blot hybridization. These results indicate that more than one copy is present in tall fescue (Fig. 3.3). It is interesting to note the high expression of $P R-10$ in tall fescue infected with $N$. siegelii versus the absence of $P R-10$ expression in meadow fescue plant 955 , infected with $N$. siegelii.

\subsubsection{Northern Analysis of the Putative Tall Fescue $A B C$ Transporter Gene (Clone TFF32)}

Clone TFF32, putatively encoding a PDR-5 like ABC transporter (Table 2.3), was previously shown to be up-regulated in a $N$. coenophialum-tall fescue symbiotum (plant 15, cv KY31) in comparison to endophyte-free tall fescue (plant 14, cv KY31) when analyzed by semi-quantitative RT-PCR (Fig. 2.2). Northern analysis was used to investigate the expression of the putative tall fescue PDR-5 like ABC transporter gene in different cultivars of tall fescue in association with their fungal endophytes or as endophyte-free grass (Figure 3.1B, 3.1C). Compared to the relevant endophyte-free controls, expression of the $A B C$ (TFF32) gene was clearly up-regulated in tall fescue in association with $N$. siegelii (4122) and in tall fescue associated with different $N$. coenophialum strains (plants 4179, 19, 15, 48, 347-1). The lone exception was endophyte-infected plant 4179-3 (cv KY31), which showed a relatively low level of expression compared to the endophyte-free controls [14 (cv KY31); 18 (cv GI-320 
Johnstone)]. In comparison, low expression of the $A B C$ gene occurred in endophyte-free tall fescue grasses (plants $18,14,4180-7,47,14$ ) as shown previously. Despite the one exception, the overall trend was consistent with the idea that the symbiotic association of tall fescue with its fungal endophytic partner has resulted in an up-regulation of the tall fescue putative $A B C$ gene.

Homologues of the tall fescue $A B C$-like gene also were present in the related grasses meadow fescue and perennial ryegrass (Fig. 3.2). No differential gene expression was apparent in the meadow fescue samples, as weak hybridization was seen throughout. In perennial ryegrass, the $A B C$ homologue appeared to be up-regulated in endophyte-free perennial ryegrass (plant 86), in comparison to the two endophyte-infected grasses (266 \& 85). This apparent discrepancy between tall fescue and perennial ryegrass is an interesting observation that cannot be explained without further experiments.

\subsubsection{Northern Analysis of Clone TFF24, Putatively Encoding an RNA-binding Protein}

TFF24 was isolated from the forward SSH library and was confirmed to be upregulated in E+ tall fescue by semi-quantitative RT-PCR (Fig. 2.2). Sequence information suggests it encodes an RNA-binding protein (Table 2.3). To determine if TFF24 is differentially expressed in other endophyte-free tall fescue cultivars and tall fescue associations with different strains of the fungal endophyte $N$. coenophialum, TFF24 was used as a probe to a Northern blot (Fig. 3.1C). Northern analysis showed that TTF24 is up-regulated in tall fescue associated with $N$. coenophialum strain e19 (plant 15, cv KY31), and in tall fescue associated with $N$. coenophialum strain e48 (plant 48, cv 
Mustang) in comparison to their relative tall fescue endophyte free cultivars 14 (KY31) and 47 (Mustang). The two E+ and E- plants used for the SSH subtraction (15, E+ and 14, E-), clearly showed the expected differential pattern of gene expression, confirming the screening process used for selecting differentially expressed clones. However, expression of TFF24 in E+ tall fescue plant 347-1 (KY31) infected with N. coenophialum strain e15 was low (but is under loaded) compared to the matching endophyte-free cultivar (14, KY31). Therefore, the expression of TFF24 does not appear to be universally up-regulated in endophyte-infected tall fescue.

\subsubsection{Northern analysis of clone TFF25, putatively encoding a metallothionein protein}

Northern analysis was used to investigate the expression of the TFF25 transcript [with a putative match to type II metallothionein (MT) gene], using a TFF25 specificcDNA fragment (obtained from screening a lambda ZAP II cDNA tall fescue-endophyte infected library) as a probe (Fig. 3.1C). Expression of TFF25 was up-regulated in tall fescue plant 15 (cv KY31), that forms an association with $N$. coenophialum strain e19, and similarly to tall fescue (plant 48, cv mustang) associated with $N$. coenophialum strain e48. Correspondingly low expression occurred in the relevant endophyte-free control plants 14 (KY31) and 47 (Mustang). Endophyte-free plant 4180-7 (cv Seine) had relatively low levels of MT mRNA accumulation compared to other E+ plants $(15,4179$ 3, 48) as expected (Fig. 3.1C). 
A

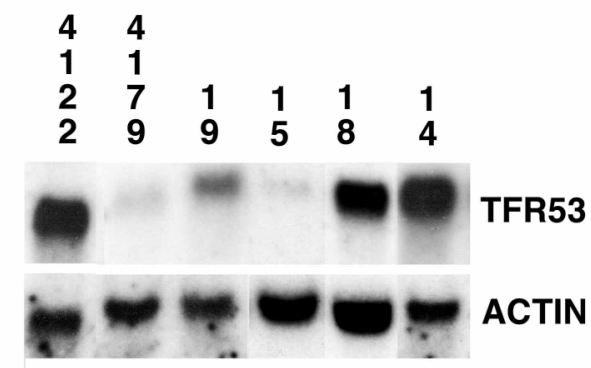

B

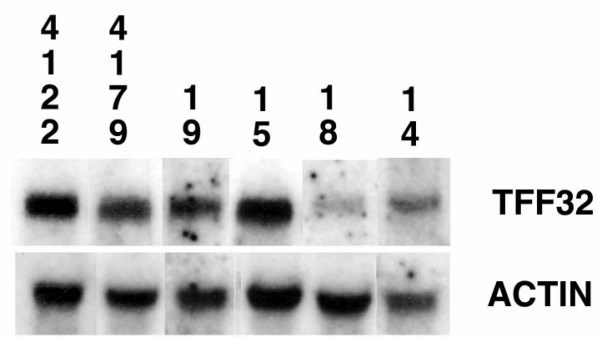

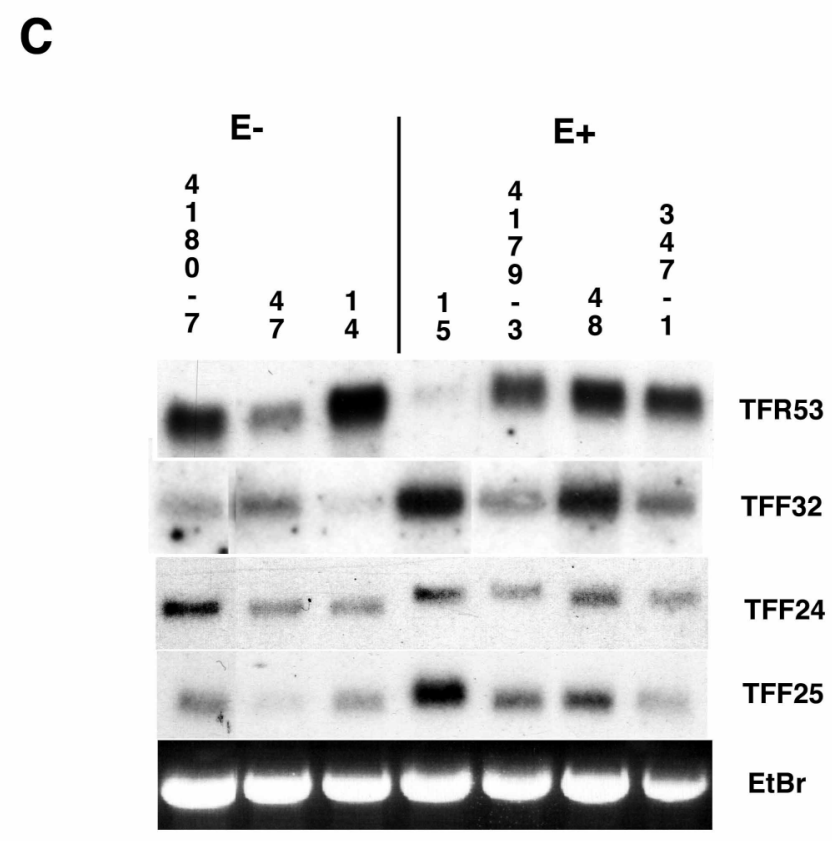

Figure 3.1. Northern Analysis of Tall Fescue Genes

A \& B. Northern blot of pseudo-stem total RNA $(15 \mu \mathrm{g})$ from endophyte-free tall fescue $(14,18) N$. coenophialum-infected tall fescue $(15,19,4179)$ and $N$. siegelii-infected tall fescue (4122). (A) hybridized with clone TFR53 and tall fescue actin gene (accession number AY194227) as a control for RNA loading, (B) hybridized with clone TFF32 and actin probe. (C) Northern blot of total RNA $(15 \mu \mathrm{g})$ extracted from the pseudo-stem region of N. coenophialum-infected tall fescue cultivars [E+; 15 (cv KY31), 4179-3 (cv KY31), 48 (cv Mustang), 347-1 (cv KY31)] and endophyte-free tall fescue cultivars [E-; 4180-7 (cv Seine), 47 (cv Mustang) 14 (cv KY31)] hybridized with TFR53, TFF32, TFF24, TFF25 probes. EtBr, ethidium bromide-stained ribosomal RNA to indicate RNA loading. 


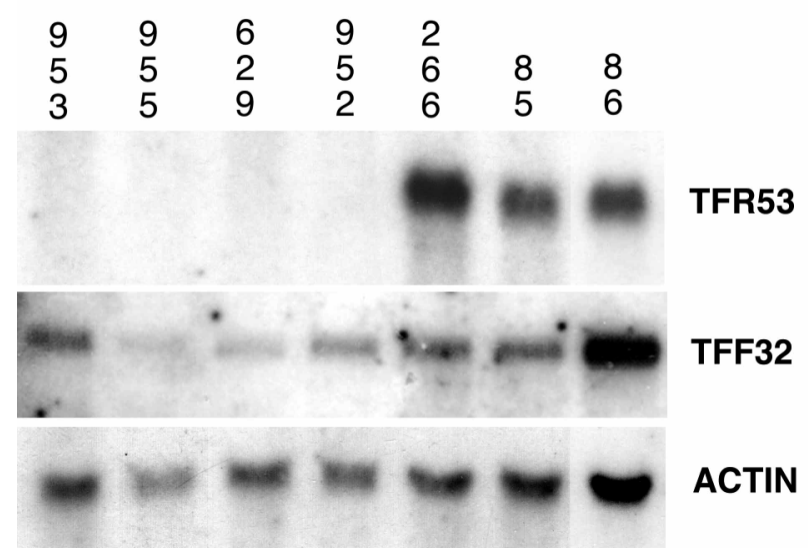

Figure 3.2. Northern analysis of TFR53 and TFF32 in related grasses perennial ryegrass and meadow fescue

Northern analysis of TFR53 and TFF32 transcripts in total RNA (15 $\mu \mathrm{g})$ extracted from pseudo-stems of endophyte-free meadow fescue (953), meadow fescue infected with $N$. uncinatum (952), E. festucae (629), N. siegelii (955), perennial ryegrass infected with $N$. lolii (266), E. typhina (85) and endophyte-free perennial ryegrass (86). RNA loading is indicated by actin (accession number AY194227) hybridization. 


\subsubsection{Transcripts not detected by Northern Analysis}

Although the differential expression of a number of SSH cDNA clones had been confirmed by semi-quantitative RT-PCR, northern analysis was attempted for a number of selected transcripts to allow further analysis of gene expression in other endophytegrass associations. As the SSH subtraction procedure yielded subtracted cDNA clones of a small size (see Tables $2.3 \& 2.4$ ), many of the subtracted clones were unsuitable for making radioactive probes for northern hybridization. However, a number of clones in addition to those above that had a cDNA insert size greater then 250 bp were amenable to northern analysis. Hybridization of cDNA clones TFF2, TFF6, TFF26, TFF41, TFR044 to total RNA gels of tall fescue-endophyte grass associations, resulted in either no detectable signal or very faint signals. A likely reason for the lack of any hybridization signal was because these genes were expressed in tall fescue at levels too low for detection by this method.

\subsubsection{Southern Analysis}

Clones TFR53, TFF32 and TFF41 were analyzed by Southern blotting to estimate gene copy number as well as to confirm the genomic origin of these cDNA clones. E- tall fescue was digested with three different restriction enzymes and hybridized with specific cDNA probes from TFR53, TFF32 and TFF41 (Fig. 3.3). Hybridization with each cDNA specific probe showed that there was more than one copy of each gene present in tall fescue. 
TFR53

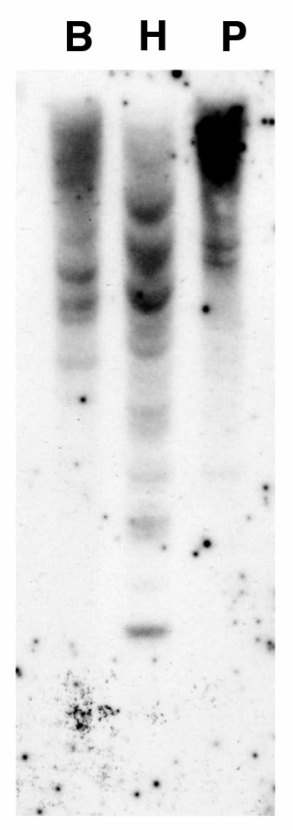

TFF32

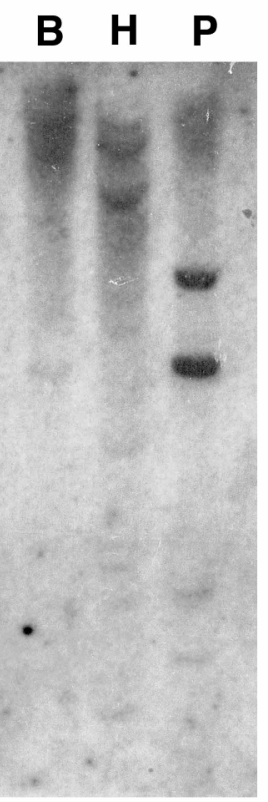

TFF41

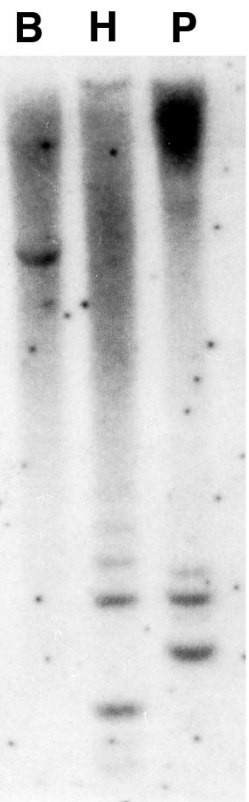

Figure 3.3. Southern Analysis of Tall Fescue Clones TFR53, TFF32, and TFF41.

Southern blot hybridization of genomic DNA from endophyte-free tall fescue (18) with ${ }^{32} \mathrm{P}$-labeled cDNA probes from TFR53, TFF32, and TFF41. DNA was digested with $\mathrm{B}$, Bam HI, H, HindIII and P, PstI. 


\subsection{RESULTS: EFFECT OF INFECTION WITH ARBUSCULA MYCORRHIZAL FUNGI GLOMUS CLARUM AND G. ETUNICATUM ON EXPRESSION OF SYMBIOSIS-RELATED GENES}

Infection of tall fescue plants with arbuscular mycorrhizal fungi (AMF) was undertaken to see how another fungal micro-symbiont affects expression of selected tall fescue and endophyte genes. Since plants for this experiment were harvested at 9 weeks for assessment, the opportunity for analyzing gene expression in young tall fescue plants, versus mature ones also was presented. Leaves and roots also were examined in addition to the previously examined pseudo-stem region, where endophyte colonization is the highest. Roots were important to examine since AMF only colonize this tissue.

\subsubsection{Infection of Tall Fescue with AMF}

E+ and E- tall fescue seeds were sown in identical soil, that either contained AMF G. clarum and G. etunicatum (M+), or was free of AMF inoculum and thus remained uninfected (M-). In addition, some E+ and E- tall fescue seeds were grown in soil containing additional phosphorus $(\mathrm{P}+)$, as a control for transcriptional changes that might be induced by enhanced phosphorus uptake in $\mathrm{M}+$ plants rather than by AMF infection alone. Plants were harvested at 9 weeks of age and checked for AMF colonization. Plant phenotypic differences were apparent at harvesting, with $\mathrm{M}+$ plants producing a greater number of vegetative tillers that were generally longer than those of M- plants. Plants grown with added phosphorus appeared similar to the AMF infected plants. Roots and leaves from each plant type are shown in Fig. 3.4. Sections of roots were stained for AMF detection by microscopy (Fig. 3.5). In E+M+ tall fescue plants, mycorrhizal fungus 
colonization and spores were observed, whereas in E-M+ tall fescue plants, AMF colonization of roots was observed, but no spores were detected. In the roots of both E+M- and E-M- plants, AMF were not detected by root staining as expected. Percent mycorrhizal colonization was calculated and found to be approximately $48 \%$ for $\mathrm{E}+\mathrm{M}+$ tall fescue and approximately $51 \%$ for E-M+ tall fescue. Therefore, dual colonization by G. clarum and G. etunicatum of both E+ and E- tall fescue was very similar, indicating that AMF colonization was not inhibited by the presence of $N$. coenophialum in tall fescue. 


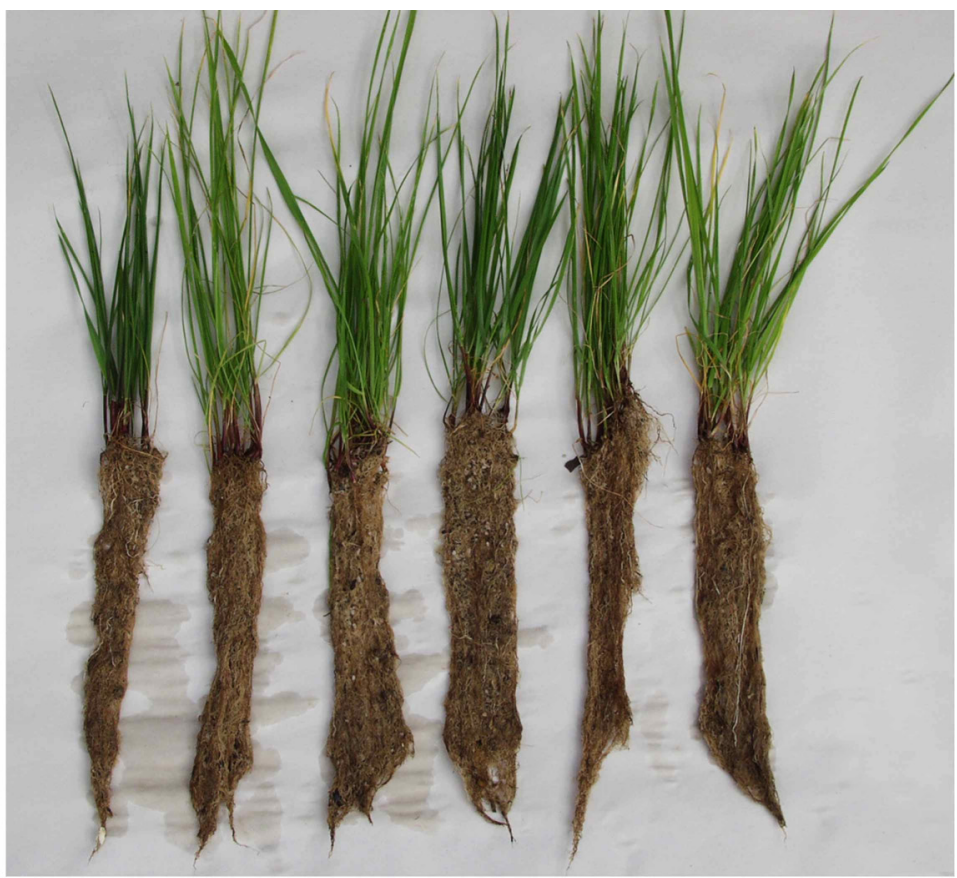

$E+M-E+M+P+E+M-E-M-E-M+P+E-M-$

Figure 3.4. Appearance of Tall Fescue Plants Colonized by Arbuscular Mycorrhiza Phenotypic effects of AMF colonization of endophyte infected (E+) and endophyte free (E-) tall fescue plants. Mycorrhizal infected (M+), non-mycorrhizal (M-) and phosphorus treated plants $(\mathrm{P}+)$ are shown at 9 weeks. 


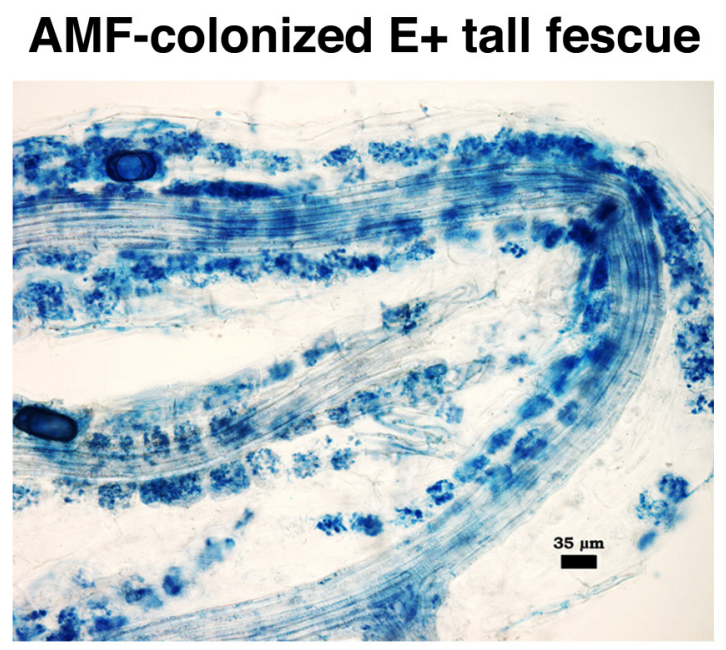

\section{AMF-colonized E- tall fescue}

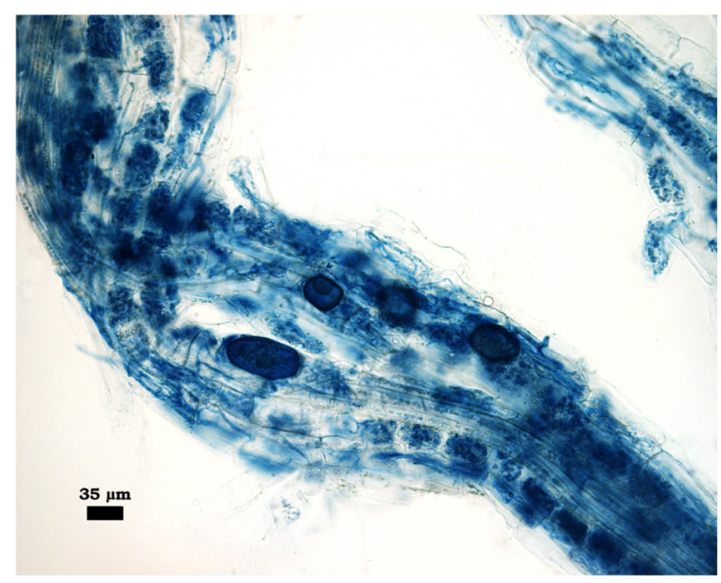

Figure 3.5. Sections of Roots Stained for AMF colonization by Microscopy Sections of endophyte infected (E+) and endophyte free (E-) tall fescue roots are shown stained for AMF colonization at 9 weeks. 


\subsubsection{Affect of AMF-Colonization on the Expression of a Putative Tall Fescue PR- 10 gene (TFR53)}

TFR53, putatively encoding a PR-10 protein (Table 2.4), was shown to be expressed abundantly in all pseudostem preparations, and was slightly down-regulated in E+ tall fescue pseudostems (E+M-) (Fig 3.6A). This was quite different to the dramatic down-regulation that occurred in mature stems (see northern blot results in Fig. 3.1A) and the reduced level of repression may be attributed to the difference in the age of the plants used in both experiments. The stronger down-regulation of this tall fescue transcript in older E+ tall fescue plants, suggests that $P R-10$ could be developmentally regulated.

$P R-10$ expression appeared to be similar in E- tall fescue stems with or without AMF infection, and no significant change in $P R-10$ expression was observed in mycorrhizal infected, E+ tall fescue $(\mathrm{E}+\mathrm{M}+)$ stems, although it is possible that $P R-10$ was weakly down-regulated (however, this slight difference may be due to RNA loading differences) (Fig. 3.6A).

$P R-10$ expression in roots was slightly down-regulated in E+ tall fescue (E+M-)

compared with E- tall fescue (E-M-), although expression was overall very weak (Fig. 3.6A). AMF infection of either E- or E+ tall fescue did not seem to significantly alter $P R$ 10 gene expression in roots.

$P R-10$ also was expressed in leaves, but was constitutively expressed in all samples irrespective of endophyte or mycorrhizal infection (Fig. 3.6B). Overall, expression of $P R-10$ in stems, leaves or roots does not appear to be significantly affected by association with AMF. 


\subsubsection{Expression of a Putative Tall Fescue $A B C$ Transporter Gene (TFF32) in AMF-Colonized Tall Fescue}

The expression of clone TFF32, putatively encoding an ABC transporter (Table 2.3), was fairly similar between pseudostem preparations from E+ and E- tall fescue (Fig. 3.6A). This was surprising since in previous experiments using mature stems, the putative tall fescue $A B C$ gene was found to be up-regulated in E+ tall fescue (Fig. 3.1B). AMF infection also did not seem to have any significant affect on $A B C$ gene expression in pseudostems. Expression of $A B C$ was not detected in leaves (results not shown), but weak expression was detected in roots (Fig. 3.6A). Expression of TFF32 is possibly higher in $\mathrm{E}+\mathrm{M}+$ roots, since this RNA sample is under-loaded compared to the others (compare to actin results), showing a possible up-regulation of this gene in response to AMF infection. Otherwise, in roots as in pseudostems, TFF32 expression did not appear to be altered in response to AMF infection.

\subsubsection{Analysis of TFF25 and Nc25 Gene Expression}

The probe for this experiment was prepared by random-labeling a PCR product obtained from a SSH clone (25) with radioactivity. As we were unaware at this time that it actually contained two inserts ( Nc25 a novel fungal gene, and TFF25, a tall fescue putative metallothionein gene), this complex probe was hybridized to a Northern blot of stems, leaves and roots extracted from E+ and E- tall fescue, either infected with mycorrhizae $(\mathrm{M}+)$ or not infected with mycorrhizae (M-) (Figs. 3.6A \& B). Two transcripts were detected in $\mathrm{E}+$ tall fescue irrespective of mycorrhizal infection $(\mathrm{E}+\mathrm{M}+$ 
and $\mathrm{E}+\mathrm{M}-$ ). The upper transcript represents expression of the fungal gene $\mathrm{Nc} 25$, whereas the lower band represents expression of the plant gene TFF25. Expression of Nc25 was weak in stems of E+ tall fescue, and was not detected at all in roots (Fig. 3.6A). In mature tall fescue, expression of Nc25 in stems was extremely high (Fig. 2.7A, B). This dramatic difference in expression observed between mature and 9 week old stems could possibly be due to developmental programming or to differences in endophyte colonization. Expression of TFF25 (MT gene) was very high (similar to expression in mature pseudostems) in all pseudostems and root samples and was the only plant gene expressed so abundantly in roots (Fig.3.6A). Expression of Nc25 was not detected in leaves, whereas TFF25 was barely detected even after a long exposure (of one week) (Fig. 3.6B). Overall, AMF infection did not seem to have any major affects on either Nc25 or TFF25 gene expression in any of the tissues examined.

\subsubsection{Expression of Nc12 is Up-Regulated by Phosphorus and AMF Colonization}

Expression of Nc12 was studied in stems and roots. Since this is a fungal gene, expression was only detected in E+ tall fescue samples (Fig. 3.6A). Interestingly, Nc12 expression was up-regulated by both phosphorus $(\mathrm{E}+\mathrm{M}-\mathrm{P}+)$ and by infection with $\mathrm{AMF}$ $(\mathrm{E}+\mathrm{M}+)$ in stems. No expression was detected in roots (Fig. 3.6A). Since expression of this gene is correlated with enhanced phosphorous uptake, it could be involved in phosphorus regulation. 

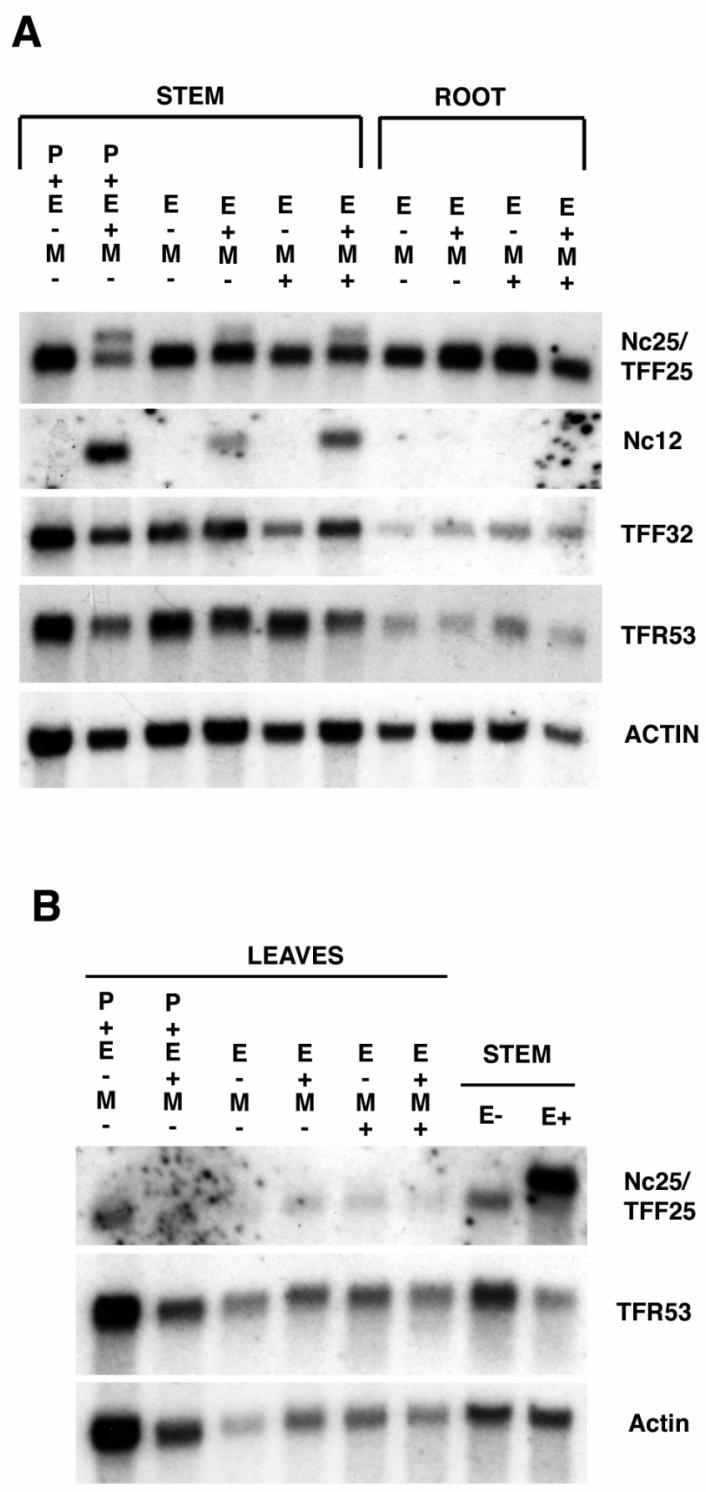

Figure 3.6. A \& B. Northern analysis of Nc25/TFF25, Nc12, TFF32, TFR53 transcripts in total RNA $(10 \mu \mathrm{g})$ extracted at 9 weeks from phosphorus-enriched, endophyte-free, nonmycorrhizal tall fescue (P+E-M-), phosphorus-enriched, endophyte-infected, non-mycorrhizal tall fescue $(\mathrm{P}+\mathrm{E}+\mathrm{M}-)$, endophyte-free, non-mycorrhizal tall fescue (E-M-), endophyte-free, mycorrhizal infected tall fescue (E-M+), endophyte-infected, non-mycorrhizal tall fescue (E+M-), endophyte-infected, mycorrhizal infected $(\mathrm{E}+\mathrm{M}+)$. A; total RNA extracted from pseudo-stems and roots, B; total RNA (10 $\mu \mathrm{g})$ extracted from leaves or from mature pseudo-stems of endophyte infected (E+) or endophyte-free (E-) tall fescue. A, Hybridization with the tall fescue actin gene (accession number AY194227) as a control for RNA loading. $\mathrm{B}, \mathrm{EtBr}$, ethidium bromide stained ribosomal RNA to indicate RNA loading. 


\subsubsection{TFF26 is Differentially Expressed by Infection with Endophyte but not by AMF Infection}

Expression of clone TFF26 was studied by semi-quantitative RT-PCR (as we were unable to detect expression of TFF26 by Northern analysis). Clone TFF26 putatively encodes an OMT-like protein with highest homology to a herbicide safener protein (Table 2.3). Expression of TFF26 was at first compared between E- and E+ mycorrhizal-free tall fescue plants (E-M- and E+M- respectively) to determine whether TFF26 is differentially expressed in young stems as it was in mature stems (Fig. 2.2). TFF26 was indeed similarly up-regulated in E+M- stems of 9 week old plants (Fig. 3.7). Semi-quantitative RT-PCR was then used to compare expression between E-M- and E$\mathrm{M}+$ plants and between $\mathrm{E}+\mathrm{M}-$ and $\mathrm{E}+\mathrm{M}+$ plants to determine if $\mathrm{AMF}$ colonization at 9 weeks had an affect on TFF26 expression in E- and E+ tall fescue. Semi-quantitative RTPCR results indicated that the effect of AMF colonization on TFF26 gene expression were negligible (results not shown). 


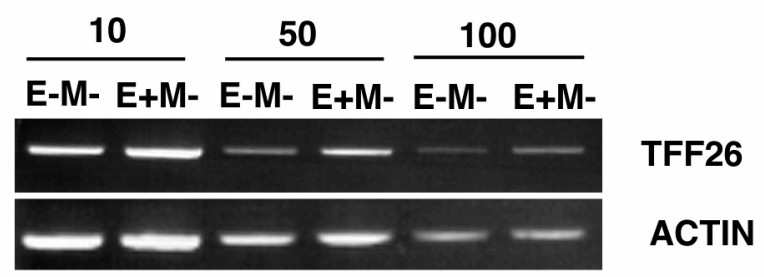

Figure 3.7. Semi-Quantitative RT-PCR Analysis of TFF26 in Immature Pseudostems Semi-quantitative RT-PCR analysis of TFF26 in non-mycorrhizal (M-) endophyte infected $(\mathrm{E}+)$ and endophyte-free (E-) tall fescue plants at 9 weeks. Serial dilutions $\left(1 / 10^{\text {th }}, 1 / 50^{\text {th }}\right.$ and $\left.1 / 100^{\text {th }}\right)$ of E-M- and E+M- cDNA were equalized with amplification of the tall fescue actin gene (accession number AY194227).

\subsubsection{TFF41 is not Differentially Expressed in Immature Stems}

TFF41 putatively encodes a chloroplast located omega 3-fatty acid desaturase (Table 2.3), that was previously demonstrated by competitive (quantitative) RT-PCR to be up-regulated by approximately 1000 fold in mature E+ tall fescue pseudostems (Fig. 2.3). In this study, competitive PCR was therefore used to analyze gene expression in the control pseudostems not inoculated with mycorrhizal fungi (E+M- and E-M-), to see if TFF41 also was up-regulated in young stems. Comparison of TFF41 expression in E-Mand E+M- stems was similar, indicating that TFF41 was not significantly differentially expressed in immature plants (Fig. 3.8). A similar lack of differential expression was obtained when E-M- and E-M+ samples were compared, indicating that both mycorrhizal infection and $N$. coenophialum infection did not affect TFF41 gene expression in immature stems. 

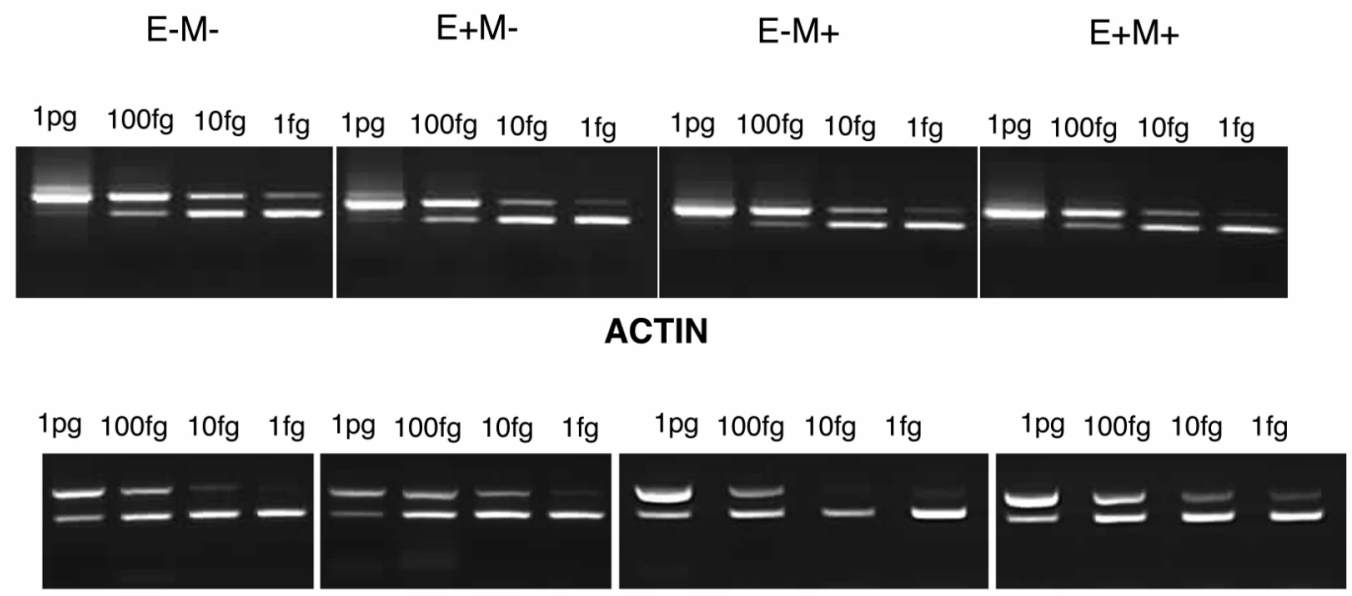

TFF41

Figure 3.8. Quantitative RT-PCR analysis of TFF41 in Mycorrhizal Infected Tall Fescue

Quantification of TFF41 expression by competitive RT-PCR; endophyte-free, nonmycorrhizal (E-M-), endophyte-infected, non-mycorrhizal (E+M-), endophyte-free, mycorrhizal infected $(\mathrm{E}-\mathrm{M}+)$, endophyte-infected, mycorrhizal infected $(\mathrm{E}+\mathrm{M}+)$. Equalization of cDNA samples was obtained by comparing the amplification of the tall fescue actin cDNA product to the amplification of known concentrations (shown from 1 pg to $1 \mathrm{fg}$ ) of a competing mimic molecule (engineered to contain actin primer binding sites). Quantification of TFF41 expression was compared to the amplification of another mimic molecule designed to contain competing TFF41 primer sites. 


\subsection{RESULTS: INFECTION OF E+ AND E- TALL FESCUE WITH COMPATIBLE FUNGUS PYRICULARIA GRISEA}

Two P. grisea fungal isolates, LpOH1 and LpKY97-1A (Table 3.3) that cause gray leaf spot in perennial ryegrass (Farman 2001), were chosen as fungal isolates that would likely produce a compatible pathogenic reaction with tall fescue. Inoculation with P. grisea isolates LpOH1 and LpKY97-1A resulted in lesions on stems and leaves of both E- and E+ tall fescue, indicative of a compatible pathogenic reaction (Fig. 3.9). Interestingly, the E- tall fescue plants produced fewer lesions than the E+ tall fescue, but without repeating the fungal inoculations, we cannot be sure whether this is the result of less fungal inoculum on the plant, or as a result of increase plant resistance to the fungal pathogens. No signs of disease symptoms were present on gelatin-inoculated control Eand E+ tall fescue plants as anticipated (Fig. 3.9).

Based on studies of Magnaporthe grisea on rice (McGee et al. 2001), a harvest point of $72 \mathrm{hrs}$ post-inoculation was selected to study gene expression from the compatible reaction produced by infection with $P$. grisea isolates LpOH1 and LpKY971A. 


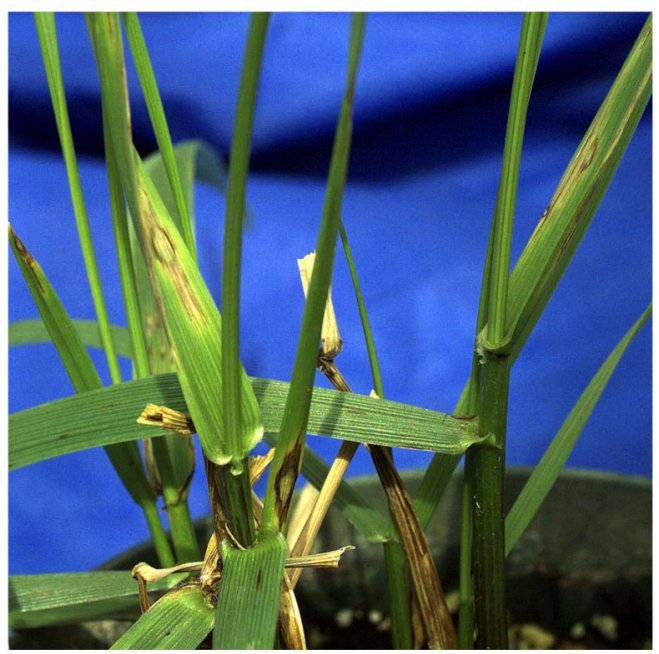

LpKY97-1A/Plant 19

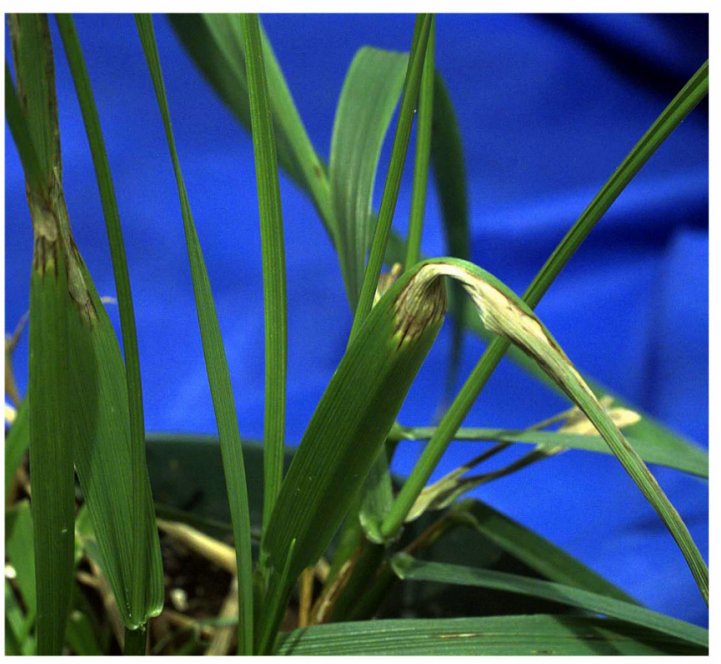

LpOH1/Plant 19

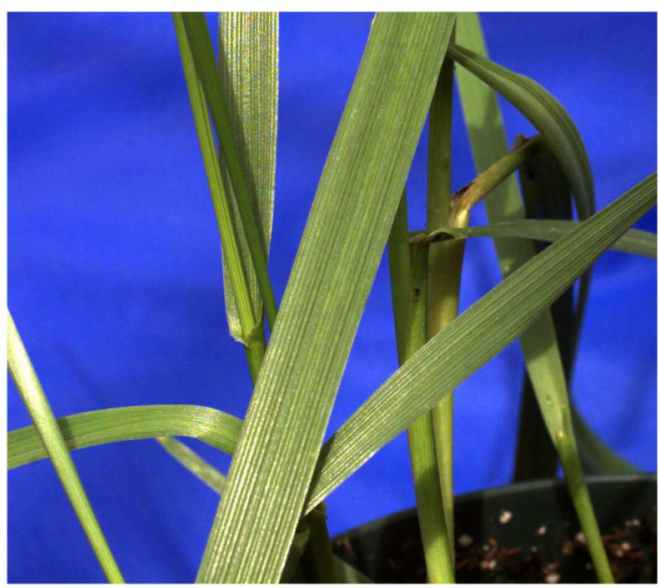

Control/Plant 18

Figure 3.9. Pyricularia grisea Disease Symptoms in Tall Fescue

Disease symptoms in $N$. coenophialum-infected tall fescue (Plant 19) or endophyte-free tall fescue (Plant 18), 11 days after inoculation with $P$. grisea fungal isolates LpKY971A, LpOH1, ML33 and $0.2 \%$ gelatin (control). 


\subsubsection{Expression of the Putative Tall Fescue PR-10 gene (TFR53) in Leaves}

In the control plants sprayed with $0.2 \%$ gelatin and incubated for 72 hours (E-C72 and $\mathrm{E}+\mathrm{C} 72)$, expression of TFR53 is clearly down-regulated in $\mathrm{E}+$ tall fescue $(\mathrm{E}+\mathrm{C} 72)$ leaves (Fig. 3.10A), in a manner similar to that observed in pseudostems used for other northern blot experiments (Fig. 3.1A). Compatible P. grisea isolates LpOH1 and LpKY97-1A both appear to up-regulate $P R-10$ independently of endophyte status in the leaves since expression of $P R-10$ is greater in both $\mathrm{E}+$ and $\mathrm{E}$ - infected samples, although up-regulation in E+ tall fescue (compared to E+ tall fescue not inoculated with $P$. grisea) is much more pronounced. $P R-10$ expression in E- control leaves without pathogen infection was already quite high (E-C72) and may therefore be the reason that $P R-10$ induction is less in E- tall fescue.

\subsubsection{Expression of the Putative Tall Fescue PR-10 gene (TFR53) in Pseudostems}

In the control samples that had been sprayed with gelatin, expression of $P R-10$ (after a $72 \mathrm{hr}$ incubation period) in the pseudostems was down-regulated in E+ tall fescue $($ E + C72) as expected from previous studies (Fig. 3.10B). Inoculation with either P. grisea isolate (LpOH1 or LpKY97-1A) followed by $72 \mathrm{hrs}$ incubation did not significantly alter $P R-10$ gene expression in either E+ or E- tall fescue samples (E+OH1, E+KY97, E-OH1, E-KY97). Overall, these results suggest that $P R-10$ is not significantly induced in stems, but is induced in leaves at the main site of pathogen invasion.

\subsubsection{Expression of the Putative Tall Fescue $A B C$ gene (TFF32) in Leaves}


Expression of TFF32 putatively encoding an ABC transporter (Table 2.3) was barely detected in leaves (after a film exposure of one week), although expression of this gene was clearly up-regulated in E+ tall fescue control and fungal inoculated leaf samples (Fig. 3.10A). Neither P. grisea isolate (LpOH1 or LpKY97-1A) appeared to have any significant affect above that already induced by endophyte on the expression of this gene in leaves and is therefore probably not pathogen inducible.

\subsubsection{Expression of Fungal Genes Nc12 and Nc25 in Pseudostems}

The expression of two endophyte genes ( $\mathrm{Nc} 12$ and Nc25, Table 2.3) that were shown by northern analysis to be both highly up-regulated in planta (Fig 2.6), also were analyzed during infection with $P$. grisea isolates LpOH1 and LpKY97-1A. No affect on gene expression was observed for either Nc12 or Nc25, and both were still highly up regulated in planta under all conditions (results not shown). 
A

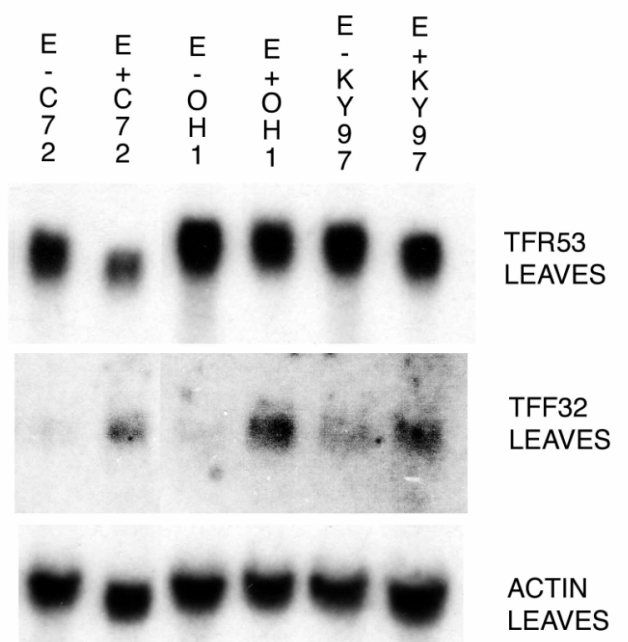

B

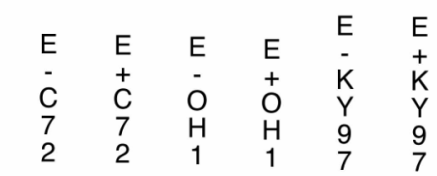

TFR53

STEMS

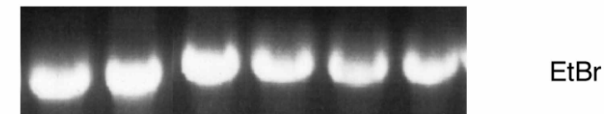

Figure 3.10. Northern analysis of Pyricularia grisea Infection of Tall Fescue on the Expression of Transcripts TFR53 and TFF32

Expression of TFR53 and TFF32 transcripts after inoculation with compatible fungal $P$. grisea isolates LpOH1 (OH1) and LpKY97-1A (KY97); and with $0.2 \%$ gelatin (C72) in $N$. coenophialum-infected tall fescue plant $19(\mathrm{E}+)$ and in endophyte-free tall fescue plant 18 (E-). A, $10 \mu \mathrm{g}$ of total RNA extracted from leaves 72 hours after inoculation are loaded in each lane. RNA loading was judged by actin hybridization. B, $10 \mu \mathrm{g}$ of total RNA extracted from pseudo-stems 72 hours after inoculation are loaded in each lane. $\mathrm{EtBr}$, ethidium bromide stained ribosomal RNA to indicate RNA loading. 


\subsection{DISCUSSION}

The differential expression of tall fescue genes TFR53, TFF32, TFF24 and TFF25 in $\mathrm{E}+$ and $\mathrm{E}$ - tall fescue plants (15 and 14 respectively) used for preparing the cDNA subtracted libraries by SSH, were confirmed by northern analysis (Fig. 3.1A, B \& C). The differential expression of TFF24, TFF32 and TFR53 also had been previously analyzed by RT-PCR (Fig. 2.2) where they were shown to be either up-regulated or down-regulated. The expression of TFR53, TFF32, TFF24 and TFF25 in other cultivars of $N$. coenophialum-infected tall fescue and endophyte-free tall fescue also were assessed. The expression of TFR53, encoding a putative $P R-10$ gene was down-regulated in three cultivars of $\mathrm{E}+$ tall fescue that all form an association with strain e19 of $N$. coenophialum (Fig. 3.1A). Although the differential expression of PR-10 was found consistently with most other strains of $N$. coenophialum-infected tall fescue, compared to endophyte-free tall fescue, the observed down-regulation was not universal (Fig. 3.1C). A similar type of expression profile with exceptions for some grasses also was observed with the up-regulated gene TFF32, putatively encoding an ABC transporter (Fig. 3.1B \& C). The majority of E+ tall fescue grasses had higher levels of $A B C$ expression than most other cultivars of endophyte-free tall fescue, although there was one exception. Differential expression of the two other up-regulated genes TFF24 and TFF25 also was variable amongst tall fescue grasses (Fig. 3.1C), with only some tall fescue cultivars showing the pattern originally observed from the SSH experiment with plants 15 and 14 (Table 3.1). However, all of these genes showed the expected pattern of expression (as determined by $\mathrm{SSH}$ ) in the cultivars used to generate the libraries.

The expression of genes putatively encoding PR-10 (TFR53) and an ABC 
transporter (ABC; TFF32) in grasses closely related to tall fescue also was investigated. Homologues of the tall fescue $A B C$ gene were expressed in the related grasses meadow fescue and perennial ryegrass, while transcripts hybridizing with $P R-10$ were only identified in perennial ryegrass. This $P R-10$ gene may not be similar enough to be detected in meadow fescue even under the low stringency conditions used. This is surprising considering the close phylogenetic relationship of meadow fescue to tall fescue (Darbyshire and Warwick 1992). Alternatively, the expression of $P R-10$ in meadow fescue may be too low to be detected by Northern analysis. Other members of the $P R-10$ gene family may well exist in meadow fescue, their dissimilarity occurring through the processes of gene duplication and divergent evolution. In addition, as the $P R-10$ probe was designed to the $3^{\prime}$ ' end of the gene, related $P R-10$ genes in meadow fescue were unlikely to be detected by northern blotting.

The variable pattern of transcript accumulation observed for these tall fescue genes among different cultivars of uninfected tall fescue indicates that the transcriptional regulation of these genes is inherently different. These particular differences are unrelated to the presence of an endophyte, since the plants in question are endophyte-free, and underscore the importance of paired comparisons of E+ with E- plants of the same cultivar. In spite of the observed variability among E- plants, the majority of E+ versus Epairs did show the pattern of gene expression expected based on the original E+ versus Etall fescue comparison. Three different cultivars of tall fescue (all infected with the same strain of endophyte) were consistently up-regulated for $A B C$ (TFF32) expression and down-regulated for $P R-10$ (TFR53) as anticipated. These data further confirm the hypothesis that endophyte infection causes the observed host differential gene expression. 
Suppression of the tall fescue $P R-10$ gene in E+ tall fescue supports the hypothesis that suppression of some plant defense mechanisms is required for the formation of an effective mutualistic association (Guenoume et al. 2001; Garcia-Garrido and Ocampo 2002; Mithofer et al. 2002). The apparent lack of any host-defense reaction from plant cells surrounding endophytic hyphae (Christensen 1995) also supports this hypothesis at the morphological level. Novel associations created from artificial inoculation studies revealed incompatibility reactions between some host grasses and Neotyphodium/Epichloe endophytes (Christensen 1995, Koga et al. 1993). This implies that the establishment and maintenance of these symbioses are intimate and requires adaptation and adjustment by both partners. These genotype-specific incompatibility reactions also suggest that endophytes are capable of eliciting a host defense response under certain circumstances. Both symbiotic partners must therefore have acquired ways to avoid triggering defense responses that would cause abortion of the symbiosis. However, some innate plant defenses may be necessary to confine fungal growth. Cessation and timing of endophyte growth must also be tightly coordinated with plant growth to maintain an association that is 'mutualistic' and not harmful. In the antagonistic Epichloe-grass relationships, hyphae can emerge from leaf sheaths to form a stroma that prevents emergence of the developing host inflorescence, resulting in reduced seed set. Elucidation of the nature of the signals that allow normal host reproduction to occur in plants associated with mutualistic fungi, in contrast to those presumed signals produced in plants associated with antagonistic endophytes that form stromata for horizontal spread, is crucial to our understanding of mutualism and the evolution of these endophyte-grass associations. These associations are thought to have co-evolved from a 
common ancestor, and so the development of these highly complex symbiotic partnerships has had millions of years for improvement to take place.

Association of AMF (G. clarum and G. etunicatum) with E- and E+ tall fescue at 9 weeks did not significantly affect expression of the putative tall fescue $P R-10$ gene (TFR53) in stems, roots or leaves of either plant. Expression of $P R-10$ was only slightly decreased in the stems of the immature E+ control plants (E+M-Vs E-M-), compared to an almost on/off pattern of expression in mature plants (Fig. 3.1A, plants $19 \& 18$ ). The expression of two fungal genes, $\mathrm{Nc} 12$ and $\mathrm{Nc} 25$ as well as the following tall fescue genes (up-regulated in E+ tall fescue), TFF25, TFF26, TFF32 and TFF41 also were studied in tissues of AMF-colonized tall fescue (Figs. 3.6, 3.7, 3.8). No notable affect on the expression of these tall fescue genes or on the expression of the fungal gene $\mathrm{Nc} 25$ was observed in tissues of either E- or E+ tall fescue suggesting that at least at this stage of the symbiosis with AMF, these genes are not involved. Interestingly, TFF25, TFF32 and TFF41 (Fig. 3.8) were not differentially expressed in immature control stems (E-M- Vs E+M-) and expression of the fungal transcript $\mathrm{Nc} 25$ was expressed at a much lower level than previously observed (Fig. 3.6A \& B).

The effect of plant maturity on acumulation of symbiois-related transcripts became apparent during this mycorrhizal study. During leaf development the fungus is metabolically active maintaining a tight coordination of fungal growth with that of its plant host (Christensen et al. 2002; Schmid et al. 2000). However, after a plant reaches maturity, surprisingly, the fungus is still metabolically active (Herd et al. 1997). It is probably not until this stage that the fungus can expend the necessary energy required to produce secondary metabolites. If expression of the putative tall fescue $A B C$ gene has a 
role in the secretion of a fungal secondary metabolite, then $A B C$ expression would be highest in the mature tissues of those plants infected with fungi producing high concentrations of secondary metabolites. Interestingly, $A B C$ expression was high in mature stems and low in immature ones. The concentration of hyphae in immature tissues was not investigated, but other researchers have shown that hyphal concentration is similar in young and old leaves of perennial ryegrass (Keogh et al. 1996; Tan et al. 1997) suggesting that $A B C$ expression was not reduced in immature plants due to a decreased stimulus resulting from decreased fungal colonization. Expression of $A B C$ also was lower in leaf blades (Fig. 3.10) compared to pseudo-stems (Fig. 3.1B).

Another point to consider as to why some of the endophyte-grass associations show variable expression of the tall fescue genes could be correlated to the amount of endophyte hyphae present in these associations, which in turn could affect the levels of plant gene expression. Endophyte biomass was not calculated for the endophyte-grass associations used, and could therefore differ since different endophyte-grass associations can have different overall hyphal concentrations and hyphal distribution patterns within leaves (Schmid et al. 1999). Remarkably, the same endophyte strain can show different patterns of hyphal distribution in the same cultivar of different plants and different endophyte strains can have distinct distribution patterns in the same host. In addition, the same endophyte genotype can affect the expression of fungal secondary metabolites differently in another grass cultivar (Hill et al. 1991). Therefore the phenotypic outcome of the symbiosis is dependant on the complex interaction of both plant and fungal genomes and dependant upon the complement of genes available to each partner. This plasticity shown among various grass-endophyte interactions also seems to be reflected at 
the molecular level.

The fungal gene Nc12 was induced by both phosphorus (P) supplementation $(\mathrm{P}+\mathrm{E}+\mathrm{M}-)$ and by colonization with $\mathrm{AMF}$ that are highly efficient at acquiring inaccessible $\mathrm{P}(\mathrm{E}+\mathrm{M}+$, Fig. 3.6A). Whether the correlation of increased $\mathrm{Nc12}$ gene expression with increase $\mathrm{P}$ uptake indicates a role for this gene in some aspect of $\mathrm{P}$ regulation requires further investigation. The endophyte does appear to play a role in $\mathrm{P}$ uptake and can even induce altered root morphology under $\mathrm{P}$ deficient conditions (Malinowski and Belesky 2000).

Access to phosphate, an essential compound for plant growth and development is often lacking (Holford 1997). Plants colonized with AMF are known to gain additional phosphorus with positive effects on plant growth and reproduction (Fig. 3.4). Therefore, such positive effects on plant health may have resulted in the up-regulation of fungal $N c 25$ in both $\mathrm{P}+\mathrm{E}+\mathrm{M}-$ and $\mathrm{E}+\mathrm{M}+$ plants. Expression of $\mathrm{Nc} 12$ was not detected in roots, but was highly expressed in stems, where endophyte colonization is typically the highest (Fig. 3.6).

In this current study, gene expression was not analyzed during the early stages of AMF colonization. Previous work with legumes has shown that plant defense genes are weakly and transiently induced in arbuscule-infected cells by mycorrhiza (GianinazziPearson et al. 1996). Other genes are probably involved in the establishment of the mycorrhiza and may therefore only be expressed at this early stage. Although none of the tall fescue genes we analyzed in AMF-colonized tall fescue were transcriptionally altered, we believe that there could be other tall fescue genes that are commonly expressed in both symbioses, and some perhaps at only specific time points. 
In a study to analyze the effects of fungal pathogen infection on gene expression of tall fescue, E- and E+ tall fescue were inoculated with the gray leaf spot fungus $P$. grisea. Expression of tall fescue PR-10 (TFR53) was induced in leaves of E+ and E- tall fescue after inoculation with the $P$. grisea compatible isolates LpOH1 and LpKY97-1A (Fig. 3.10A). PR-10 transcript levels did not appear to be altered in E+ tall fescue stems by infection with the pathogen, but a slight induction of $P R-10$ expression in E- tall fescue stems infected with isolate LpKY97-1A was observed (Fig. 3.10B). Up-regulation of $P R-10$ therefore appeared to be mainly localized at the site of pathogen invasion (leaves). The relatively low level of $P R-10$ expression in pathogen inoculated E+ stems could be as a result of the suppressive effect of the endophyte, since $P R-10$ is downregulated in E+ tall fescue (Fig. 3.1A). Overall, these results show that the $P R-10$ transcript is highly pathogen inducible in leaves of both E- and E+ tall fescue. These data further support the sequence information indicating that clone TFR53 does encode a PR10-like protein.

Expression of the tall fescue $A B C$ gene (TFF32) in leaves of E- or E+ tall fescue did not appear to be significantly affected 72 hours after inoculation with either P. grisea isolate LpOH1 or LpKY97-1A (Fig 3.10A). In contrast, an ABC transporter from rice was induced by inoculation with a compatible isolate of P. grisea (Xiong et al. 2001). The putative tall fescue $\mathrm{ABC}$ transporter does therefore not appear to be involved in transport at this stage in the $P$. grisea infection, perhaps reflecting the specificity for substrates of $\mathrm{ABC}$ transporters. However, up-regulation of this gene in $\mathrm{E}+$ tall fescue leaves compared to E- leaves was consistent with the studies discussed (Figs. 3.1B, $3.10 \mathrm{~A})$. 


\section{CHAPTER 4: GENERAL DISCUSSION}

In this study I have identified both plant and fungal differentially expressed genes involved in the tall fescue- $N$. coenophialum symbiosis. This analysis of gene expression in endophyte-grass symbioses represents the first glimpse into the complex molecular interactions between a grass host and its fungal symbiont. Prior research has concentrated primarily on the genetic and biochemical elucidation of endophyte secondary metabolite pathways. The physiology of the symbiosis also has been well documented, but the molecular basis behind this agriculturally important association has until now not been investigated. My research has initiated progress towards a greater understanding of how these complex biological systems function on the molecular level. It is now apparent from this study that the endophyte is actively recognized as a beneficial microorganism by its plant host, and that the endophyte can modify gene expression of its plant host. In this study I have identified a number of genes with known functions and others that are seemingly novel. The first step towards unravelling the mechanisms behind complex molecular systems is to find appropriate gene targets for functional analyses. In total 29 genes that may be fundamentally important for the effective functioning of this grassendophyte symbiosis have been identified. Broader applications from the functional analyses of some of these genes in the future may lead to the identification of novel targets for fungicides, novel components of plant systems that could lead to plant resistance, and the identification of genes responsible for enhanced plant health characteristics. A basic understanding of the interaction between plants and microbes is essential if we are to contemplate modifying plant or fungal genes by genetic engineering 
for superior plant characteristics.

In this study, my main aim was to investigate the mutually beneficial $N$. coenophialum-tall fescue interaction at the molecular level. Presently, the investigation of biotrophic plant-fungal interactions in general is still in its infancy and little is known about the molecular processes that control establishment, maintenance and overall finetuning of symbioses.

The fungal endophyte confers a suite of benefits to enhance host fitness, including the inducement of plant physiological changes for enhanced nutrient uptake and improved drought tolerance (Arechavaleta et al. 1989; Bacon 1993; Belesky and Malinowski 2000; Malinowski et al. 1999; West 1994). However, our understanding of the molecular basis behind these processes is still poor. Tall fescue is an agronomically important cool-season forage grass grown throughout the world and covers 35 million acres of pastures in the southeastern United States alone. Approximately $95 \%$ of these pastures contain tall fescue infected with its fungal endophyte $N$. coenophialum.

This mutually beneficial relationship is, however, detrimental to grazing livestock, due to the production of an array of fungal alkaloids in planta that may in part give tall fescue its edge over other cool-season grasses and therefore persistence. The toxic syndrome called fescue toxicosis has been linked with the production of fungal ergot alkaloids, primarily ergovaline (Thompson and Stuedemann 1993), and results in the losses of millions of dollars every year to the beef and horse industries. Therefore, an increased understanding of the molecular processes involved in endophyte-grass symbioses is of extreme importance agriculturally as well as of basic scientific interest.

Transcript profiling, the study of changes in gene expression, has enabled 
researchers to delve into the functioning molecular mechanisms operating during complex interactions. In this study, I chose a PCR-based subtractive technique, suppression subtractive hybridization ( $\mathrm{SSH}$ ) to search for differentially expressed genes in the $N$. coenophialum-tall fescue symbiosis. Tweny-nine transcripts were identified as differentially expressed, and 2 of these ( $\mathrm{Nc12}$ and $\mathrm{Nc} 25)$ were novel endophyte genes. In total, the differential expression of 13 tall fescue genes and 2 fungal genes were confirmed by a combination of RT-PCR and northern analysis (Figs. 2.2, 2.3, 2.6).

\subsection{Nc12 and Nc25 are Novel Fungal Genes}

$\mathrm{Nc12}$ is one of the two novel fungal genes identified from this study. Competitive RT-PCR showed that Nc12 was up-regulated approximately 1000 fold in E+ tall fescue compared to the fungus cultured in vitro (Fig. 2.8). Nc12 also was abundantly expressed in various tall fescue, perennial ryegrass, and meadow fescue associations (Fig. 2.7B) suggesting that its expression could universally be involved in some aspect of the symbiosis. Infection of E+ tall fescue with AMF that form mutualistic associations with plants induced higher levels of $\mathrm{Nc} 12$ expression. Also, additional phosphorous supplementation increased expression of this gene suggesting that $\mathrm{Nc12}$ could be involved in the regulation of phosphorus. Interestingly, the endophyte does appear to play a role in the uptake of phosphorus and can induce altered root morphology under phosphorus deficient conditions (Malinowski and Belesky 2000).

The fungal gene Nc25 is potentially another exciting fungal gene with an unknown role in the symbiosis. Expression of $\mathrm{Nc} 25$ in axenic culture was not detected by northern analysis indicating zero or very low levels of expression under these conditions 
(Fig. 2.6), yet in E+ tall fescue this fungal transcript was easily detected by northern hybridization. Nc25 also was abundantly expressed in the related endophyte-infected grasses meadow fescue and perennial ryegrass. Two different Nc25 transcript sizes were present in meadow fescue associated with $N$. uncinatum and $N$. siegelii indicating that these fungi have more than one copy of the gene. The coding region of $\mathrm{Nc} 25$ contains four repeating units of 27 amino acids, whereas the $N$. lolii $\mathrm{Nc} 25$ homologue contained two. Therefore, the difference in transcript sizes reflects a variation in the number of repeat units.

The identification of the two up-regulated fungal genes, $\mathrm{Nc} 12$ and $\mathrm{Nc} 25$ is the first step towards elucidating their functional roles and determining if their expression is essential to the symbiosis. Southern blot hybridization indicated that there is only one copy of Nc25 and more than one copy of Nc12 in N. coenophialum (Fig. 2.5). Gene knockout analysis of Nc25 in $N$. coenophialum followed by re-inoculation into tall fescue would therefore be a feasible approach to further characterise its role in the symbiosis. Functional analysis of $\mathrm{Nc12}$ by a knockout strategy would first require a survey of other fungal endophytes to find a strain containing one copy of this gene. Alternatively, reporter gene analysis or in situ hybridization also would provide information on the spatial distribution of the expressed genes within the symbiotum and could provide valuable information on the possible roles these genes play.

\subsection{Expression of select Tall Fescue Genes in other Endophyte-Grass} Associations

A total of 27 tall fescue genes were identified from this SSH study. A select 
number were then chosen for further analysis in other tall fescue-endophyte associations. Northern analysis showed that the differential expression of tall fescue clones TFF24, TFF25, TFF32 and TFR53 were not always consistent, although tall fescue grasses infected with the same endophyte strain typically showed the expected differential expression pattern when compared to the relevant endophyte-free control strain (Figs. 3.1A, B, C). In related grasses, homologues of TFR53 and TFF32 were found in perennial ryegrass, but only a homologue of TFF32 was found in meadow fescue (Fig. 3.2). This highlights the need to study other grass-endophyte associations to obtain a better overall view of the mechanics behind symbioses.

\subsection{Influence of AMF-Colonization on Tall Fescue Gene Expression}

The possibility that some of the genes analysed in this study are regulated during the interaction with another fungal micro-symbiont was analysed by infecting E- and E+ tall fescue simultaneously with the AMF G. clarum and G. etunicatum. The expression of selected tall fescue genes (TFF25, TFF26, TFF32, TFF41 and TFR53) did not appear to be significantly affected by infection with AMF, perhaps because these fungi are located to the roots. It would be highly interesting to repeat the $\mathrm{SSH}$ experiment using $\mathrm{AM}+$ and AM- interactions. Potentially, other tall fescue genes not identified from this study or not analysed in this interaction also may have vital roles in the AM symbiosis.

The expression of tall fescue genes in immature tissues of the control plants (not infected with AMF) was compared with their expression in mature pseudo-stems. Not all genes were differentially expressed at this stage and this is may be related to their functional roles in the symbiosis. Some of these genes may be developmentally 
regulated, or may only be induced in response to secondary metabolite biosynthesis by the endophyte. Lower levels of endophyte colonization at this stage also may be a factor. Also, the presence of the endophyte in tall fescue did not suppress AMF-colonization as reported by Chu-chou et al. (1992) with $48 \%$ colonization of E+ plants and $51 \%$ colonization of E- plants at 9 weeks.

\subsection{Identification of Possible Roles for some Tall Fescue Genes in the Symbiosis}

A number of the tall fescue genes identified by SSH are novel, with no matches to any sequences in the databases. These genes may therefore have roles that are unique to the physiology of grass-endophyte symbioses. Interestingly, many of the tall fescue genes with matches to known genes in the databases have roles associated with plant defense and stress tolerance. However, the same gene product in a pathogenic relationship may have a different role in another context such as during symbiosis development. This has been evident for defense-related genes in mycorrhiza where expression of some defense related genes have been correlated with AMF development (Garcia-Garrido and Ocampo 2002). Up-regulated clone TFF41 has high homology to Arabidopsis FAD7 and FAD8 genes (Table 2.3) encoding $\omega-3$ fatty acid desaturase enzymes. The action of this enzyme alters the amounts of trienoic fatty acids in chloroplast lipids affecting the plants ability to tolerate extreme cold and high temperatures (Murakami et al. 2000). Since tolerance of drought and tolerance of temperature extremes are apparently related, expression of this gene may contribute to drought tolerance documented in E+ tall fescue. In addition, expression of Arabidopsis FAD7 may have a role in plant defense signalling (Kirsch et al. 1997; Martin et al. 1999; Nishiuchi et al. 1997). 
The down-regulated clone TFR53 encodes a putative tall fescue $P R-10$ gene (Table 2.4). PR-10 proteins are involved in general plant defense mechanisms and plant developmental processes. Down-regulation of $P R-10$ also was reported in the lupinerhizobium symbiosis, but infection of tall fescue with AMF did not affect expression of $P R-10$ (Fig. 3.6A, B). To determine if tall fescue $P R-10$ could be induced by infection with a fungal pathogen, E- and E+ tall fescue were infected with the gray leaf spot fungus Pyricularia grisea (Fig. 3.9). Tall fescue $P R-10$ was induced in leaves of both E- and E+ plants providing some experimental evidence that TFR53 encodes a PR-10 protein (Fig. $3.10 \mathrm{~A}, \mathrm{~B})$. It is therefore significant that a gene with a role in plant defense is downregulated in E+ tall fescue, supporting the hypothesis that some plant defenses must be suppressed for an effective symbiosis. However, PR-10 proteins also are involved in developmental processes, therefore functional analysis of this gene is required to determine its true role in the symbiosis.

\subsection{Future Studies}

Future studies to delineate the functions of these plant genes in the symbiosis could include methods such as RNA silencing, generation of antisense constructs to mediate inhibition of gene expression as well as over-expression of a gene. Transformation of monocotyledonous grasses is now possible (Dalton et al. 1995; 1997; Ha et al. 1992; Spangenberg et al. 1995; Wang et al. 1992; Ye et al. 1997) allowing these approaches to be carried out. Functional identities of genes also can be assessed by complementation of mutants in other organisms such as Arabidopsis. Many such mutants are available from T-DNA tagged libraries [at the Torrey Mesa Research Institute 
(TMRI) at www.nadii.com]. Spatial expression patterns of these genes also could be studied by constructing promoter fusion constructs (using GUS or GFP for example), or by in situ hybridization. The linkage of phenotype with gene expression will take this study to the next logical level.

\subsection{Complementary Studies}

This SSH study successfully identified a number of genes involved in the tall fescue-endophyte association. Additional SSH studies also could be performed that compare a healthy E+ plants with those under abiotic stress for example. In addition, the combination of the power of micro-array technology with the subtractive power of SSH will allow genome wide global changes in gene expression to be assessed under specific conditions determined by the SSH probes. Complementary studies to elucidate the complex interactions that occur during symbioses also should include genomics, metabolomics (quantitative measurement of low molecular weight metabolites), and proteomics (changes in protein expression). Genomic approaches are already revolutionizing research on the complex interactions between plants and microbes, by revealing synteny between organisms.

\subsection{Final Remarks}

Overall a number of interesting genes have been identified from the mutualistic tall fescue- $N$. coenophialum symbiosis. Functional analyses of these genes in the future may expand our understanding of the molecular basis for some of the endophyte-induced benefits in grasses. This knowledge may be agronomically beneficial in the future by 
guiding the manipulation of these genes to enhance endophyte-associated host benefits. We may, for example, be able to identify or genetically modify endophytes in the future that induce the expression of particular genes for beneficial effects whilst simultaneously avoiding endophytes that produce harmful toxic metabolites. Alternatively, certain plant genes could be over-expressed in the absence of the endophyte (for example in non-host plants) to achieve these beneficial traits. Perplexing conceptual questions about how symbioses are established and maintained also may be answered by the continued investigation of genes identified in this study and in the future. 


\section{REFERENCES}

Adams, M.D., Kelley, J.M., Gocayne, J.D., Dubnick, M., Polymeropoulos, M.H., Xiao, H., Merril, C.R., Wu, A., Olde, B., Moreno, R.F., et al. 1991. Complementary DNA sequencing: expressed sequence tags and human genome project. Science 252:16511656.

Allen, M.F., Allen, E.B., and Friese, C.F. 1989. Responses of the non-mycotrophic plant Salsola kali to invasion by vesicular-arbuscular myocorrhizal fungi. New Phytol. 111:4549

Altschul, S.F., Madden, T.L., Schaffer, A.A., Zhang, J., Zhang, Z., Miller, W., and Lipman, D.J. 1997. Gapped BLAST and PSI-BLAST: a new generation of protein database search programs. Nucleic Acids Res. 25:3389-3402.

Arechavaleta, M., Bacon, C.W., Hoveland, C.S. and Radcliffe, D.E. 1989. Effect of the tall fescue endophyte on plant response to environmental stress. Agron. J. 81:83-90.

Arechaveleta, M., Bacon, C.W., Plattner, R.D., Hoveland, C.S., and Radcliffe, D.E. 1992. Accumulation of ergopeptide alkaloids in symbiotic tall fescue grown under deficits of soil water and nitrogen fertilizer. Appl. Environ. Microbiol. 58: 857-861.

Awade, A., Metz-Boutique, M.H., Le Ret, M., Genot, G., Amiri, I. and Burkard, G. 1991. The complete amino acid sequence of pathogenesis-related (PR2) protein induced in chemically stressed bean leaves. Biochim. Biophys. Acta. 1077:241-244.

Azevedo, M.D., and Welty, R.E. 1985. A study of the fungal endophyte Acremonium coenophialum in the roots of tall fescue seedlings. Mycologia 87:289-297.

Bachem, C.W.B., van der Hoeven, R.S., de Bruijin, S.M. Vreugdenhil, D. Zabeau M and Visser, R.G.F. 1996. Visualization of differential gene expression using a novel method of RNA fingerprinting based on AFLP: analysis of gene expression during potato tuber development. Plant J. 9:745-753.

Bacon, C.W. 1993. Abiotic stress tolerances (moisture, nutrients) and photosynthesis in endophyte-infected tall fescue. Agric. Ecosyst. Environ. 44:123-141.

Bantignies, B., Seguin, J., Muzac, I., Dedaldechamp, F., and Gulick, P. 2000. Direct evidence for ribonucleolytic activity of a PR-10-like protein from white lupine roots. Plant Mol. Biol. 42:871-881.

Barea, J.M. and Azcon-Aguilar, C. 1982. Production of plant growth-regulating substances by vesicular-arbuscular mycorrhizal fungus Glomus mosseae. Appl. Environ. Microbiol. 43:810-813. 
Becard, G et al. 1985. Flavonoids are not necessary plant signals in arbuscular mycorrhizal symbiosis. Mol. Plant-Microbe Interact. 8:252-258.

Belesky, D.P., and Malinowski, D.P. 2000. Abiotic stresses and morphological plasticity and chemical adaptations of Neotyphodium-infected tall fescue plants. Pages 455-48 in: Microbial Endophytes. C.W. Bacon and J.F. White, Jr. eds. Marcel Dekker, New York, U.S.A.

Belesky, D.P., Devine, O.J., Pallas, JE. Jr., and Stringer, W.C. 1987. Photosynthetic activity of tall fescue as influenced by a fungal endophyte. Photosynthetica 21:82-87.

Berberich, T., Harada, M., Sugawara, K., Kodama, H., Iba, K., and Kusano, T. 1998. Two maize genes encoding $\omega-3$ fatty acid desaturase and their differential expression to temperature. Plant Mol. Biol. 36:297-306.

Beyer, K., Binder, A., Boller, T., and Collinge, M. 2001. Identification of potato genes induced during colonization by Phytophthora infestans. Mol. Plant Pathol. 2:125-134.

Beyrle, H. 1995. The role of phytohormones in the function and biology of mycorrhizas. In: Varma A, Hock B, eds. Mycorhhiza structure, function, molecular biology and biotechnology. Berlin: Springer-Verlag, 365-390.

Birch, P.R.J., Avrova, A.O., Duncan, J.M. Lyon, G.D., and Toth, R.L. 1999. Isolation of potato genes that are induced during an early stage of the hypersensitive response to Phytophthora infestans. Mol. Plant-Microbe Interact. 12:356-361

Blankenship, J.D., Spiering, M.J., Wilkinson, H.H., Fannin, F.F., Bush, L.P., and Schardl, C.L., 2001. Production of loline alkaloids by the grass endophyte, Neotyphodium uncinatum, in defined media. Phytochemistry 58:395-401.

Bonfante, P. 2001. At the interface between the mycorrhizal fungi and plants: the structural organization of cell wall, plasma membrane and cytoskeleton. The Mycota IX Fungal Associations. Hock (Ed.). pp 45-61.

Bonfante, P., and Genre, A. 2000. Outside and inside the roots: AM fungi differentially interact with epidermal and cortical cells of their host plants. In: de Wit PJGM, Bisseling T, Stiekema WA (eds) 2000 IC-MPMI Proceedings: Biology of Plant-Microbe Interactions, vol 2.

Breiteneder, H., Pettenburger, K., Bito, A., Valenta, R., Kraft, D., Rumpold, H., Schneider, O., and Breitenbach, M. 1989. The gene coding for the major birch pollen allergen BetvI is highly homologous to a pea disease resistance response gene. EMBO J. 8:1935-1938.

Buchanan-Wollaston, V. 1994. Isolation of cDNA clones for genes that are expressed during leaf senescence in Brassica napus. Plant Physiol. 105: 839-846. 
Bultman, T.L., J.F. White, Jr., T.I. Bowdish, and Welch, A.M. 1998. A new kind of mutualism between fungi and insects. Mycol. Res. 102:235-238.

Bush, L.P., Fannin, F.F., Siegel, M.R., Dahlman, D.L. and Burton, H.R. 1993. Chemistry, occurrence and biological effects of saturated pyrrolizidine alkaloids associated with endophyte-grass interactions. Agric. Ecosyst. Environ. 44:81-102.

Bush, L.P., Wilkinson, H.H., and Schardl, C.L. 1997. Bioprotective alkaloids of grassfungal endophyte symbioses. Plant Physiol. 114: 1-7.

Butt, A., Mousley, C. Morris, K., Beynon, J., Can, C., Holub, E., Greenberg, J.T., and Buchanan-Wollaston, V. 1998. Differential expression of a senescence-enhanced metallothionein gene in Arabidopsis in response to isolates of Peronospora parasitica and Pseudomonas syringae. Plant J. 16:209-221.

Charbonnel-Campaa, L., Lauga, B., and Combes, D. 2000. Isolation of a type 2 metallothionein-like gene preferentially expressed in tapetum in Zea mays. Gene 25:199208.

Chen, H-J., Hou, W-C., and Lin, Y-H. 2000. Isolation and characterization of a cDNA clone (accession no. AF177760) for type II metallothionein-like protein from senescent leaves of sweet potato (Ipomoea batatas cv. Tainong 57). Plant Physiol. 122:291.

Cho, Y-J., Meade, J.D., Walden, J.C., Chen, X., Guo, Z., and Liang, P. 2001. Multicolor fluorescent differential display. Biotechniques 30:562-571.

Christensen, M.J. 1995. Variation in the ability of Acremonium endophytes of Lolium perenne, Festucae arundinacea and $F$. pratensis to form compatible associations in the three grasses. Mycol. Res. 99:466-470.

Christensen, M.J. 1996. Antifungal activity in grasses infected with Acremonium and Epichlö̈ endophytes. Australasian Plant Pathology 25:186-191.

Christensen, M.J., Ball, O.J.-P., Bennett, R.J., and Schardl, C.L. 1997. Fungal and host genotype effects on compatibility and vascular colonization by Epichlö̈ festucae. Mycol. Res. 101:493-501.

Christensen, M.J., Bennett, R., and Schmid, J. 2002. Growth of Epichloë/Neotyphodium and p-endophytes in leaves of Lolium and Festuca grasses. Mycol Res. 106:93-106.

Chu-Chou, M., Guo, G., An, Z.-Q., Hendrix, J.W., Ferris, R.S., Siegel, M.R., Dougherty, C.T., and Burrus, P.B. 1992. Suppression of mycorrhizal fungi in fescue by the Acremonium coenophialum endophyte. Soil Biol. Biochem. 24:633-637. 
Chung, K.-R., and Schardl, C.L. 1997a. Sexual cycle and horizontal transmission of the grass symbiont, Epichloë typhina. Mycol. Res. 101:295-301.

Chung, K.-R., and Schardl, C.L. 1997b. Vegetative compatibility between and within Epichlö̈ species. Mycologia 89:558-565.

Clay, K. 1987. Effects of fungal endophytes on the seed and seedling biology of Lolium perenne and Festuca arundinacea. Oecologia 73:358-362.

Clay, K. 1988. Fungal endophytes of grasses: a defensive mutualism between plants and fungi. Ecology 69:10-16.

Clay, K., and Cheplick, G.P. 1989. Effect of ergot alkaloids from fungal endophyteinfected grasses on fall armyworm (Spodoptera frugiperda). J. Chem. Ecol. 15:169-182.

Clay, K., and Leuchtmann, A. 1989. Infection of woodland grasses by fungal endophytes. Mycologia 81: 805-811.

Craven, K.D., Blankenship, J.D., Leuchtmann, A., Hignight, K., and Schardl, C.L. 2001a. Hybrid fungal endophytes symbiotic with the grass Lolium pratense. Sydowia 53:44-73.

Craven, K.D., Hsiau, P.T.W., Leuchtmann, A., Hollin, W., Schardl, C.L. 2001 b. Multigene phylogeny of Epichlö̈ species, fungal symbionts of grasses. Ann. Miss. Bot. Gard. 88:14-34.

Dahlman, D.L., Siegel, M.R., and Bush, L.P. 1997. Insecticidal activity of N-formyloline. Proceedings of the XVIII International Grasslands Congress 8-10 June 1997, Winnipeg, Canada, pp.13/5-13/6.

Dakora, F.D., and Phillips, D.A. 1996. Diverse functions of isoflavonoids in legumes transcend antimicrobial definitions of phytoalexins. Physiol. Mol. Plant Path. 49:1-20.

Dalton, S.J., Bettany, A.J.E., Timms, E., and Morris, P. 1995. The effect of selection pressure on transformation frequency and copy number in transgenic plants of tall fescue (Festuca arundinacea Schreb.) Plant Sci. 108:63-70.

Dalton, S.J., Bettany, A.J.E., Timms, E., and Morris, P. 1998. Transgenic plants of Lolium multiflorum, Lolium perenne, Festuca arundinacea and Agrostis stolonifera by silicon carbide fibre-mediated transformation of cell suspension cultures. Plant Sci. 132:33-43.

Darbyshire, S.J. 1993. Realignment of Festuca subgenus Schedonorus with the genus Lolium (Poaceae). Novon 3:239-243. 
Darbyshire, S.J., and Warwick, SI. 1992. Phylogeny of North American Festuca (Poaceae) and related genera using chloroplast DNA restriction site variation. Can. J. Bot. 70:2415-2429.

Davies, T.G.E., and Coleman, J.O.D. 2000. The Arabidopsis thaliana ATP-binding cassette proteins: an emerging superfamily. Plant Cell Environ. 23:431-443.

De Battista, J.P., Bacon, C.W., Severson, R., Plattner, R.D., and Bouton, J.H. 1990. Indole acetic acid production by the fungal endophyte of tall fescue. Agron. J. 82:878880 .

Diatchenko, L., Lau, Y.-F.C., Campbell, A.P., Chenchik, A., Moqadam, F., Huang, B., Lukyanov, S., Lukyanov, K., Gurskaya, N., Sverdlov, E.D., and Siebert., P.D. 1996. Suppression subtractive hybridization: A method for generating differentially regulated or tissue-specific cDNA probes and libraries. Proc. Natl. Acad. Sci. USA. 93:6035-6030.

Diatchenko, L., Lukyanov, S., Lau, Y.-F.C, and Siebert, P.D. 1999. Suppression subtractive hybridization: a versatile method for identifying differentially expressed genes. Methods Enzymol. 303:349-80.

Dixon, R.A., and Paiva, N.L. 1995. Stress-induced phenylpropanoid metabolism. Plant Cell 7:1085-1097.

Dubos, C., and Plomion, C. 2001. Drought differentially affects expression of a PR-10 protein, in needles of maritime pine (Pinus pinaster Ait.) seedlings. J. Exp. Bot. 52:11421144.

Edwards, R., and Dixon, R.A. 1991. Isoflavone O-methyltransferase activities in elicitortreated cell suspension cultures of Medicago sativa. Phytochemistry 30:2579-2606.

Elmi, A.A., West, C.P., Robbins, R.T., and Kirkpatrick, T.L. 2000. Endophyte effects on reproduction of a root-knot nematode (Meloidogyne marylandi) and osmotic adjustment in tall fescue. Grass Forage Sci. 55:166-172.

Farman, M.L. 2001. Pyricularia grisea Isolates causing gray leaf spot on perennial ryegrass (Lolium perenne) in the United States: Relationship to P. grisea isolates from other host plants. Phytopathology 91:245-254.

Fedoroff, N.V. 2002. RNA-binding proteins in plants: the tip of an iceberg? Curr. Opin. Plant Biol. 5:1-8.

Fletcher, L.R., Popay, A.J., Stewart, A.V., Tapper, B.A., 2000. Herbage and seed production from meadow fescue with and without the endophyte Neotyphodium uncinatum. Pages 447-453 in: 4th International Neotyphodium/Grass Interactions Symposium. V.H. Paul, and P.D. Dapprich, eds. Fachbereich Agrarwissenschaften und Chemie. Universitat Paderborn, Soest, Germany. 
Flor, H. H. 1971. Current status of the gene-for-gene concept. Annu. Rev. Phytopathol. 9:275-296.

Freeman, E. M. 1904. The seed fungus of Lolium temulentum L., the darnel. Philos. Trans. R. Soc. London Ser. B 196:1-27.

Gallagher, R.T., Hawkes, A.D., Steyn P.S., and Vleggaar, R. 1984. Tremorgenic neurotoxins from perennial ryegrass causing ryegrass staggers disorder of livestock: structure elucidation of lolitrem B. J. Chem. Soc. Chem. Commun. 614-616.

Gamas, P. de Billy, F., and Truchet, G. 1998. Symbiosis-specific expression of two Medicago trucatula nodulin genes, MtN1 and MtN13, encoding products homologous to plant defense proteins. Mol. Plant-Microbe Interact. 11:393-403.

Garcia-Garrido, J.M., and Ocampo, J.A. 2002. Regulation of the plant defense response in arbuscular mycorrhizal symbiosis. J. Exp. Bio. 53:1377-1386.

Garcia-Garrido, J.M., Tribak, M., Rejon-Palomares, A., Ocampo, J.A. and GarciaRomera, I. 2000. Hydrolytic enzymes and ability of arbuscular mycorrhizal fungi to colonize roots. J. Exp. Bio. 51:1443-1448.

Gianinazzi-Pearson, V. 1996. Plant cell response to arbuscular mycorrhizal fungi: Getting to the roots of the symbiosis. Plant Cell 8:1871-1883.

Gianinazzi-Pearson, V., Arnould, C., Oufattole, M., Arango, M., Gianinazzi, S. 2000. Differential activation of H+-ATPase genes by an arbuscular mycorrhizal fungus in root cells of transgenic tobacco. Planta 211:609-613.

Gibson, S., Arondel, V., Iba, K., and Somerville, C. 1994. Cloning of a temperatureregulated gene encoding a chloroplast w-3 fatty acid desaturase from Arabidopsis thaliana. Plant Physiol. 106:1615-1612.

Glenn, A.E., C. W. Bacon, R. Price, and R. T. Halin. 1996. Molecular phylogeny of Acremonium and its taxonomic implications. Mycologia 88: 369-383.

Gray, N.K., Coller, J.M., Dickson, K.S., and Wickens, M. 2000. Multiple portions of poly(A)-binding protein stimulate translation in vivo. EMBO J. 19:4723-4733.

Grenier, E., Blok, V.C., Jones, J.T., Fouville, D. and Mugniery, D. 2002. Identification of gene expression differences between Globodera pallida and G. 'mexican' by suppressive subtraction hybridzation. Mol. Plant Pathol. 3:217-226.

Groppe, K. and Boller, T. 1997. PCR assay based on a microsatellite-containing locus for detection and quantification of Epichloe endophytes in grass tissue. Appl. Environ. Microbiol. 63:1543-1550. 
Guenome, D., Galili, S., Philips, D.A. Volpin, H., Chet, I., Okon, Y., and Kapulnik. 2001. The defense response elicited by the pathogen Rhizoctonia solani is suppressed by colonization of the AM-fungus Glomus intraradices. Plant Sci. 160:925-932

Gwinn, K.D., and Gavin, A.M. 1992. Relationship between endophyte infestation level of tall fescue seed lots and Rhizoctonia zeae seedling disease. Plant Dis. 76:911-914.

Ha, S.-B., Wu, F.-S., and Thorne, T.K. 1992. Transgenic turf-type tall fescue (Festuca arundinacea Schreb.) plants regenerated from protoplasts. Plant Cell Rep. 11:601-4.

Harrison, M.J. 1999. Molecular and cellular aspects of the arbuscular mycorrhizal symbiosis. Annu. Rev. Plant Physiol. Plant Mol. Biol. 50:361-389.

Harrison, M.J., and van Buuren, M.L. 1995. A phosphate transporter from the mycorrhizal fungus Glomus versiforme. Nature 378:626-629.

Held, B.M., Wang, H., John, I., Wurtele, E.S., and Colbert, J.T. 1993. A mRNA putatively coding for an O-methyltransferase accumulates preferentially in maize roots and is located predominately in the region of the endodermis. Plant Physiol. 102:10011008 .

Hentschel, U., Steinert, M., and Hacker, J. 2000. Common molecular mechanisms of symbiosis and pathogenesis. Trends Microbiol. 8:227-234.

Herd, S., Christensen, M.J., Saunders, K., Scott, D.B., and Schmid, J. 1997. Quantitative assessment of in planta distribution of metabolic activity and gene expression of an endophytic fungus. Microbiology 143: 267-275.

Hill, N. S., Parrott, W. A., and Pope, D. D. 1991. Ergopeptine alkaloid production by endophytes in a common tall fescue genotype. Crop Sci. 31:1545-1547.

Hirsch, A.M., and Kapulnik, Y. 1998. Signal transduction pathways in mycorrhizal associations: Comparisons with the rhizobium-legume symbiosis. Fungal Genet. Biol. 23:205-212.

Holford, J.C.R. 1997. Soil phosphorus:Its measurement, and its uptake by plants. Aust. J. Soil Res. 35:227-239.

Hsieh, H., Liu, W., Chang, A., and Huang, P.C. 1996. RNA expression patterns of type 2 metallothionein-like gene from rice. Plant Mol. Biol. 32:525-529.

Hubank, M., and Schatz, D.G. 1994. Identifying differences in mRNA expression by representational difference analysis of cDNA. Nucleic Acids Res. 22:5640-5648 
Jagoueix-Eveillard, S., Tarendeau, F., Guolter, K., Danet, J.-L., Bove, J.M., and Garnier, M. 2001. Catharanthus roseus genes regulated differentially by mollicute infections. Mol. Plant-Microbe Interact. 2001. 14:225-233

Jakobsen, I., Abbott, L.K., and Robson, A.D. 1992. External hyphae of vesiculararbuscular mycorrhizal fungi associated with Trifolium subterraneum L. 2: Hyphal transport of ${ }^{32} \mathrm{P}$ over defined distances. New Phytol.120:509-516.

Jansson, S. 1994. The light-harvesting chlorophyll a/b-binding proteins. Biochim. Biophys. Acta 1184:1-19

Jasinski, M., Stukkens, Y., Degand, H., Purnelle, B., Marchand-Brynaert, J., and Boutry, M. 2001. A plant plasma membrane ATP binding cassette-type transporter is involved in antifungal terpenoid secretion. Plant Cell 13:1095-1107.

Ju, Y., Sacalis, J.N., and Still, C.C. 1998. Bioactive flavonoids from endophyte-infected blue grass (Poa ampla). J. Agric. Food Chem. 46:3785-3788.

Keogh, R.G., Tapper, B.A., and Fletcher, R.H. 1996. Distributions of the fungal endophyte Acremonium lolii, and of the alkaloids lolitrem B and peramine, within perennial ryegrass. NZ. J. Agric. Res. 39:121-127.

Kim, W. Y., Kim, C.Y., Cheong, N.E., Choi, Y.O., Lee, K.O., Lee, S-H., Park, J.B., Nakano, A., Bahk, J.D., Cho, M.J., and Lee, S.Y. 1999. Characterization of two fungalelicitor-induced rice cDNAs encoding functional homologues of the rab-specific GDPdissociation inhibitor. Planta. 2101:143-9.

Kauss, H., Franke, R., Krause, K., Conrath, U., Jeblick, W., Grimmig, B., and Matern, U. 1993. Conditioning of Parsley (Petroselinum crispum L.) Suspension Cells Increases Elicitor-Induced Incorporation of Cell Wall Phenolics. Plant Physiol. 102:459-466.

Kimmons, C.A., Gwinn, K.D., and Bernard, E.C. 1990. Nematode reproduction on endophyte-infected and endophyte-free tall fescue. Plant Dis. 74:757-761.

Kirby, E.J.M. 1961. Host-parasite relations in the choke disease of grasses. Trans. Br. Mycol. Soc. 44:493-503.

Kirsch, C., Takamiya-Wik, M., Reinold, S., Hahlbrock, K., and Somssich, I.E. 1997. Rapid, transient, and highly localized induction of plastidial [omega ]-3 fatty acid desaturase mRNA at fungal infection sites in Petroselinum crispum. Proc. Natl. Acad. Sci. USA. 94:2079-2084.

Kistner, C., and Parniske M. 2002. Evolution of signal transduction in intracellular symbiosis. Trends Plant Sci. 7:511-8. 
Koga, H., Christensen, M.J., and Bennett, R.J. 1993. Cellular interactions of some grass/Acremonium endophyte associations. Mycol. Res. 97: 1237-1244.

Koistinen, K.M., Hassinen, V.H., Gynther, P.A.M., Lehesranta, S.J., Keinanen, S.I., Kokko, H.I., Oksanen, E.J., Tervahauta, A.I., Auriola, S., and Karenlampi, S.O. 2002. Birch PR-10c is induced by factors causing oxidative stress but appears not to confer tolerance to these agents. New Phytol. 155:381-391.

Kozak, M. 1991. Structural features in eukaryotic mRNAs that modulate the initiation of translation. J. Biol. Chem. 266:19867-19870.

Kruger, W.M., Pritsch, C., Chao, S., and Muehlbauer, G.J. 2002. Functional and comparative bioinformatics analysis of expressed genes from wheat spikes infected with Fusarium graminearum. Mol. Plant-Microbe Interact. 15:445-455.

Kuldau, G.A., Tsai, H-F., and Schardl C.L. 1999. Genome sizes of Epichloë species and anamorphic hybrids. Mycologia 91:776-782.

Lam, C. K., Belanger, F. C., White, J. F., Jr., and Daie, J. 1994. Mechanism and rate of sugar uptake by Acremonium typhinum, an endophytic fungus infecting Festuca rubra: Evidence for presence of a cell wall invertase in endophytic fungi. Mycologia 86:408415.

Lambais, M.R., 2000. Regulation of plant defense-related genes in arbuscular mycorrhizae. Pages 45-59 in: Current advances in mycorrhizae research. G.K., Podila D.D., Douds, eds. The American Phytopathological Society, Minnesota, U.S.A.

Lane, G. A., Christensen, M. J., and Miles, C. O. 2000. Coevolution of fungal endophytes with grasses: The significance of secondary metabolites. Pages 342-388 in: Microbial Endophytes. C.W. Bacon and J.F. White, Jr. eds. Marcel Dekker, New York, U.S.A.

Latch, G.C.M. 1993. Physiological interactions of endophytic fungi and their hosts. Biotic stress tolerance imparted to grasses by endophytes. Agric. Ecosyst. Environ. 44:143-156.

Laplaze, L., Gherbi, H., Duhoux, E., Pawlowski, K., Auguy, F., Guermache, F., Franche, C., Bogusz, D. 2002. Symbiotic and non-symbiotic expression of cgMTl, a metallothionein-like gene from the actinorhizal tree Casuarina glauca. Plant Mol Biol. 49:81-92.

Li Z.-Y., and Chen, S.-Y. 2000. Isolation and characterization of a salt- and drought inducible gene for S-adenosylmethionine decarboxylase from Wheat (Triticum aestivum L.). J. Plant Physiol. 156:386-393.

Liang, P., and Pardee, A.B. 1992. Differential display of eukaryotic messenger RNA by means of the polymerase chain reaction. Science 257: 967-971. 
Lievens, S., Goormachtig, S., and Holsters. M. 2001. A critical evaluation of differential display as a tool to identify genes involved in legume nodulation: looking forward and looking back. Nucleic Acids Res. 29:3459-3469.

Lindstrom, J. T., and Belanger, F. C. 1994. Purification and characterization of an endophytic fungal proteinase that is abundantly expressed in the infected host grass. Plant Physiol. 106:7-16.

Lisitsyn, N., Lisitsyn, N., and Wigler, M. 1993. Cloning the differences between two complex genomes. Science 259:946-951.

Lo, S.-C, Hipskind, J.D., and Nicholson, R.L. 1999. cDNA cloning of a sorghum pathogenesis-related protein (PR-10) and differential expression of defense-related genes following inoculation with Cochliobolus heterostrophus or Colletotrichum sublineolum. Mol. Plant-Microbe Interact. 12:479-489.

Lockhart, D.J., Dong, H., Byrne, M.C., Follettie, M.T., Gallo, M.V., Chee, M.S., Mittmann, M., Wang, C., Kobayashi, M., Horton. et al. 1996. Expression monitoring by hybridization to high-density oligonucleotide arrays. Nat. Biotechnol. 14:1675-1680.

Long, S. 1989. Rhizobium-legume nodulation: living together in the underground. Cell 56:203-214.

Mackie, A.J., Roberts, A.M., Callow, J.A., and Green, J.R. 1991. Molecular differentiation in pea powdery-mildew haustoria. Planta 183:399-408.

Malinowski, D.P., and Belesky, D.P. 1999. Neotyphodium coenophialum-endophyte infection affects the ability of tall fescue to use sparingly available phosphorus. J. Plant Nutr. 22:835-853.

Malinowski, D., and Belesky, D.P. 2000. Adaptations of Endophyte-Infected CoolSeason Grasses to Environmental Stresses: Mechanisms of Drought and Mineral Stress Tolerance. Crop Sci. 40:923-940.

Malinowski, D., Leuchtmann, A., Schmidt, D., and Nösberger, J. 1997a. Growth and water status in meadow fescue is affected by Neotyphodium and Phialophora species endophytes. Agron. J. 89:673-678.

Malinowski, D., Leuchtmann, A., Schmidt, D., and Nösberger, J. 1997b. Symbiosis with Neotyphodium uncinatum endophyte may increase the competitive ability of meadow fescue. Agron. J. 89:833-839.

Malinowski, D.P., Alloush, G.A., and Belesky, D.P. 1998. Evidence for chemical changes on the root surface of tall fescue in respsonse to infection with the fungal endophyte Neotyphodium coenophialum. Plant and Soil 205:1-12. 
Malinowski, D.P., Brauer, D.K., and Belesky, D.P. 1999. Neotyphodium coenophialum-endophyte affects root morphology of tall fescue grown under phosphorus deficiency. J. Agron. Crop. Sci. 183:91-102.

Maniatis, T., Fritsch, E.F., and Sambrook, J. 1982. Molecular cloning: A Laboratory Manual. Cold Spring Harbor Laboratory Press, Cold Spring Harbor, N.Y.

Manners, J.M., and Gay, J.L. 1983. The host-parasite interface and nutrient transfer in biotrophic parasitism. In: JA Callow ed. Biochemical plant pathology. John Wiley \& Sons Ltd, 163-168.

Marsh, J.F., and Schultze, M. 2001. Analysis of arbuscular mycorrhizas using symbiosisdefective plant mutants. New Phytol. 150:525-532

Martin, K.J., Graner, E., Li, Y., Price, L.M., Kritzman, B.M., Fournier, M.V., Rhei, E., and Pardee, A.B. 2001. High-sensitivity array analysis of gene expression for the early detection of disseminated breat tumor cells in periperal blood. Proc. Natl. Acad. Sci. USA. 98:2646-25651.

Martin, M., Leon, J., Dammann, C., Albar, J.-P., Griffiths, G., and Sanchez-Serrano, J.J. 1999. Antisense-mediated depletion of potato leaf w-3 fatty acid desaturase lowers linolenic acid content and reduces gene activation in response to wounding. Eur. J. Biochem. 262:283-290.

Matsumura, H., Nirasawa, S., and Terauchi, R. 1999. Transcript profiling in rice (Oryza sativa L.) seedling using serial analysis of gene expression. Plant J. 20:719-726.

Matton, D.P., and Brisson, N. 1989. Cloning, expression, and sequence conservation of pathogenesis-related gene transcripts of potato. Mol. Plant-Microbe Interact. 2:325-331.

McGee, J.D., Hamer, J.E., and Hodges, T.K. 2001. Characterization of a PR-10 pathogenesis-related gene family induced in rice during infection with Magnaporthe grisea. Mol. Plant-Microbe Interact. 14:877-886.

Michalakis, Y., Olivieri, I., Renaud, F., and Raymond, M. 1992. Pleiotropic action of parasites: How to be good for the host. Trends Ecol. Evol. 7: 59-62.

Miles, C.O., Wilkins, A.L., Gallagher, R.T., Hawkes, A., Munday, S.C., and Towers, N.R. 1992. Synthesis and tremorgenicity of paxitriols and lolitriol: Possible biosynthetic precursors of lolitrem-B. J. Agric. Food Chem. 40: 234-238.

Mithofer, A. 2002. Suppression of plant defense in rhizobia-legume symbiosis. Trends Plant Sci. 7:440-444. 
Moiseyev, G.P., Beintema, J.J., Fedoreyeva, L.I., and Yakovlev, G.I. 1994. High sequence similarity between a ribonuclease from ginseng calluses and fungus-elicited proteins form parsley indicates that intracellular pathogenesis-related proteins are ribonucleases. Planta 193:470-472.

Moiseyev, G.P., Fedoreyeva, L.I., Zhuravlev, Y.N., Yasnetskaya, E., Jekel, P.A., and Beintema, J.J. 1997. Primary structures of two ribonucleases from ginseng calluses. New member of the PR-10 family of intracellular pathogenesis-related plant proteins. FEBS Lett. 402-207-210.

Moon, C. D., Scott, B., Schardl, C. L., and Christensen, M. J. 2000. Evolutionary origins of Epichloë endophytes from annual ryegrasses. Mycologia 92:1103-1118.

Moon, C.D., Miles, C.O., Jarlfors, U., and Schardl, C.L. 2002. The evolutionary origins of three new Neotyphodium endophyte species from grasses indigenous to the Southern Hemisphere. Mycologia 94:694-711.

Moons, A., Prinsen, E., Bauw, G., and Van Montagu, M. 1997. Antagonistic effects of abscisic acid and jasmonates on salt stress-inducible transcripts in rice roots. Plant Cell 9:2243-2259.

Morton, J.B., and Benny, G.L. 1990. Revised classification of arbuscular mycorrhizal fungi (Zygomycetes): A new order, Glomales, two new suborders, Glomineae and Gigasporineae, and two new families, Acaulosporaceae and Gigasporaceae, with an emendation of Glomaceae. Mycotaxon 37:471-491.

Murakami, Y., Tsuyama, M., Kobayashi, Y., Kodama, H., and Iba, K. 2000. Trienoic fatty acids and plant tolerance of high temperature. Science 287:476-479.

Nicholson, R.L., and Hammerschmidt, R. 1992. Phenolic compounds and their role in disease resistance. Annu. Rev. Phytopathol. 30:369-389.

Nishiuchi, T., Hamda, T., Kodama, H., and Iba, K. 1997. Wounding changes the spatial expression pattern of the Arabidopsis plastid w-3 fatty acid desaturase gene (FAD7) through different signal transduction pathways. Plant Cell 9:1701-1712.

Ober, D., and Hartmann, T. 1999. Homospermidine synthase, the first pathway-specific enzyme of pyrrolizidine alkaloid biosynthesis, evolved from deoxyhypusine synthase. Proc. Natl. Acad. Sci. USA. 96:14777-14782.

Osherov, N., Mathew, J., Romans, A., and May, G.S. 2002. Identification of conidialenriched transcripts in Aspergillus nidulans using suppressive subtractive hybridization. Fungal Genet. Biol. 37:197-204. 
Panaccione, D.G., Johnson, R.D., Wang, J., Young, C.A., Damrongkool, P., Scott, B., and Schardl, C.L. 2001. Elimination of ergovaline from a grass-Neotyphodium endophyte symbiosis by genetic modification of the endophyte. Proc. Natl. Acad. Sci. USA 98:12820-12825.

Parniske, M. 2000. Intracellular accommodation of microbes by plants: a common developmental program for symbiosis and disease? Curr. Opin. Plant Biol. 3:320-328.

Pfeffer, P.E., Douds, Jr. D.D., Becard, G., and Shachar-Hill, Y. 1999. Carbon uptake and the metabolism and transport of lipids in an arbuscular mycorrhiza. Plant Physiol. 120:587-98.

Philipson, M.N., and Christey, M.C. 1986. The relationship of host and endophyte during flowering, seed formation, and germination of Lolium perenne. NZ. J. Bot. 24:125-134.

Pirozynski, K.A., and Malloch, D.W. 1975. The origin of land plants: a matter of mycotrophism. BioSystems 6:153-164.

Pnueli, L., Hallak-Herr, E., Rozenberg, M., Cohen, M., Goloubinoff, P., Kaplan, A., and Mittler, R. 2002. Molecular and biochemical mechanisms associated with dormancy and frought tolerance in the desert legume Retama raetam. Plant J. 31:319-330.

Popay, A.J., and Rowan, D.D. 1994. Endophytic fungi as mediators of plant insect interactions. Pages 83-103 in: Insect-Plant Interactions. E.A. Bernays, eds. CRC Press, Boca Raton, FL.

Porter, J. K., Cutler, H. G., Bacon, C. W., Arrendale, R. F., and Robbins, J. D. 1985. In vitro auxin production by Balansia epichlö̈. Phytochemistry 24:1429-1431.

Porter, J.K. 1994. Chemical constituents of grass endophytes. Pages 103-123 in: Biotechnology of Endophytic Fungi. C.W. Bacon and J.F. White, Jr. eds. CRC Press, Boca Raton, Florida, U.S.A.

Poupard, P., Brunel, N., Leduc, N., Viemont, J.D., Stullu, D.G., and Simoneau, P. 2001. Expression of a Bet $v 1$ homologue gene encoding a PR 10 protein in birch roots: Induction by auxin and localization of the transcripts by in situ hybridization. Aust. $\mathrm{J}$. Plant Physiol. 25:459-464.

Powell, R.G., Te Paske, M.R., Plattner, R.D., White, J.F., and Clement, S.L. 1994. Isolation of resveratrol from Festuca versuta and evidence for the widespread occurrence of this stilbene in the Poaceae. Phytochemistry 35:335-338.

Rausch, C., Daram, P., Brunner, S., Jansa, J., Laloi, M., Leggewie, G., Amrhein, N., Bucher, M. 2001. A phosphate transporter expressed in arbuscule-containing cells in potato. Nature 414:462-470. 
Rauyaree, P., Choi, W., Fang, E., Blackmon, B., and Dean, R.A. 2001. Genes expressed during early stages of rice infection with the rice blast fungus Magnaporthe grisea. Mol. Plant Pathol. 2:347-354.

Read, J.C., and Camp, B.J. 1986. The effect of the fungal endophyte Acremonium coenophialum in tall fescue on animal performance, toxicity, and stand maintenance. Agron. J. 78:848-850.

Reddy, P.V., Lam, C.K., and Belanger, F.C. 1996. Mutualistic fungal endophytes express a proteinase that is homologous to proteases suspected to be important in fungal pathogenicity. Plant Physiol. 111:1209-1218.

Reed, K.C., and Mann, D.A. 1985. Rapid transfer of DNA from agarose gels to nylon membranes. Nucleic Acids Res. 13:7207-7221.

Remy, W., Taylor, T.N., Hass, H., and Kerp, H. 1994. Four hundred-million-year-old versicular arbsucular mycorrhizae. Proc. Natl. Acad. Sci. USA 91:11841-11843.

Rice, J.S., Pinkerton, B.W., Stringer, W.C., and Undersander D.J. 1990. Seed production in tall fescue as affected by fungal endophyte. Crop Sci. 30:1303-1305.

Riedell, W.E., Kieckhefer, R.E., Petroski, R.J., and Powell, R.G., 1991. Naturally occurring and synthetic loline alkaloid derivatives: insect feeding behavior modification and toxicity. J. Entomol. Sci. 26:122-129.

Roberts, C. A., Marek, S. M., Niblack, T. L., and Karr, A.L. 1992. Parasitic Meloidogyne and mutualistic Acremonium increase chitinase in tall fescue. J. Chem. Ecol. 18:11071116.

Robinson, N.J., Tommey, A.M., Kuske, C., and Jackson, P.J. 1993. Plant metallothioneins. Biochem. J. 295:1-10.

Rowan, D.D. 1993. Lolitrems, paxilline, and peramine: mycotoxins of the ryegrass/endophyte interaction. Agric. Ecosyst. Environ. 44:103-122.

Rowan, D.D., and Gaynor, D.L. 1986. Isolation of feeding deterrents against Argentine stem weevil from ryegrass infected with the endophyte Acremonium lolii. J. Chem. Ecol. 12:647-658.

Roy, M., and Wu, R. 2002. Overexpression of $S$-adenosylmethionine decarboxylase gene in rice increases polyamine level and enhances sodium chloride-stress tolerance. In Press. Plant Sci.

Salzer, P., and Boller, T. 2000. Elicitor-induced reactions in mycorrhizae and their suppression. Pages 1-10 in: Current Advances in Mycorrhizae Research. G.K. Podila, and D.D. Douds, eds. APS Press, St. Paul, Minnesota, U.S.A. 
Salzer, P., Bonanomi, A., Beyer, K., Vogeli-Lange, R., Aeschbacher, R.A., Lange, J., Wiemken, A., Kim, D., Cook, D.R., and Boller, T. 2000. Differential expression of eight chitinase genes in Medicago truncatula roots during mycorrhiza formation, nodulation, and pathogen infection. Mol. Plant-Microbe Interact. 13:763-777.

Sambrook, J., Fritsch, E.F., and Maniatis. T. 1989. Molecular Cloning: A Laboratory Manual, 2nd ed. Cold Spring Harbor Laboratory Press, Cold Spring Harbor, NY, U.S.A.

Sampson, K. 1933. The systemic infection of grasses by Epichloë typhina (Pers.) Tul. Trans. Br. Mycol. Soc. 18:30-47.

Schardl, C.L. 1996. Epichlö species: fungal symbionts of grasses. Ann. Rev. Phytopathol. 34:109-130.

Schardl, C.L. 2001. Epichloë festucae and Related Mutualistic Symbionts of Grasses. Fungal Genet. Biol. 33:69-82.

Schardl, C.L., and Clay, K. 1997. Evolution of mutualistic endophytes from plant pathogens. Pages 221-238 in: The Mycota. V. Plant Relationships. Part 3. G.C. Carroll, and P. Tudzynski, eds. Springer-Verlag, Berlin, Germany.

Schardl, C.L., and Phillips, T.D. 1997. Protective grass endophytes: where are they from and where are they going? Plant Dis. 81:430-437.

Schardl, C.L., and Wilkinson, H.H. 2000. Hybridization and cospeciation hypotheses for the evolution of grass endophytes. Pages 63-83 in: Microbial Endophytes. C.W. Bacon and J.F. White, Jr. eds. Marcel Dekker, New York, U.S.A.

Schardl, C.L., Leuchtmann A., Chung, K.-R., Penny, D., and Siegel, M.R. 1997. Coevolution by common descent of fungal symbionts (Epichlö̈ spp.) and grass hosts. Mol. Biol. Evol. 14:133-143.

Schardl, C.L., Leuchtmann A., Tsai, H-F., Collett, M.A., Watt, D.M., and Scott, D.B. 1994. Origin of a fungal symbiont of perennial ryegrass by interspecific hybridization of a mutualist with the ryegrass choke pathogen, Epichlö̈ typhina. Genetics 136:1307-1317.

Schena, M., Shalon, D., Davis, R.W., and Brown, P.O. 1995. Quantitative monitoring of gene expression patterns with a complementary DNA microarray. Science 270:467-470.

Schmid, J., and Christensen, M.J. 1999. Ryegrass endophyte: host/fungus interaction. Grassland Research and Practice Series No. 7:101-106. 
Schmid, J., Spiering, M.J., and Christensen, M.J. 2000. Metabolic activity, distribution and propagation of grass endophytes in planta. Investigations using the GUS system. Pages 295-322 in: Microbial Endophytes. J.F. White, Jr, and C.W. Bacon, eds. Marcel Dekker, New York, U.S.A.

Scott, B. 2001. Epichlö̈ endophytes: fungal symbionts of grasses. Curr. Opin. Microbiol. 4:393-398.

Scott-Craig, J.S., Casida, J.E., Poduje, L., and Walton, J.D. 1998. Herbicide safenerbinding protein of maize. Purification, cloning, and expression of an encoding cDNA. Plant Physiol. 116:1083-9

Siegal, M.R., Latch, G.C. M., Bush, L.P., Fannin, F.F., Rowan, D.D., Tapper, B.A., Bacon, C.W., and Johnson, M.C. 1990. Fungal endophyte-infected grasses: alkaloid accumulation and aphid response. J. Chem. Ecol. 16:3301-3315.

Siegel, M.R., and L.P. Bush. 1997. Toxin production in grass/endophyte associations. In: Carroll and Tudzynski (eds) The Mycota Vol. 5, Part A Plant Relationships. SpringerVerlag, Berlin, pp221-238.

Siegel, M.R., Jarlfors, U., Latch, G.C.M., and Johnson, M.C. 1987. Ultrastructure of Acremonium coenophialum, Acremonium lolii, and Epichlö̈ typhina endophytes in host and nonhost Festuca and Lolium species of grasses. Can. J. Bot. 65:2357-2367.

Siegel, M.R., Johnson, M.C., Varney, D.R., Nesmith, W.C., Buckner, R.C., Bush, L.P., Burrus, II, P.B., Jones, T.A. and Boling, J.A. 1984. A fungal endophyte in tall fescue: Incidence and dissemination. Phytopathology. 74:932-937.

Sikorski, M.M., Biesiadka, J., Kasperska, A.E., Kopcinska, J., Lotocka, B., Golinowski, W., and Legocki, A.B. 1999. Expression of genes encoding PR10 class pathogenesisrelated proteins is inhibited in yellow lupine root nodules. Plant Sci. 149: 125-137.

Smart, C. C., and Fleming, A. J. (1996). Hormonal and environmental regulation of a plant PDR-like ABC transporter. J. Bio. Chem. 271:19351-19357.

Smith, F.A., and Smith, S.E. 1997. Tansley Review No. 96 Structural diversity in (vesicular)-arbuscular mycorrhizal symbioses. New Phytol. 137:373-388.

Smith, F.A., and Smith, S.E. 1989. Membrane transport at the biotrophic interface: an overview. Aust. J. Plant Physiol. 16:33-43.

Smith, J.R., and Leong, S.A. 1994. Mapping of a Magnaporthe grisea locus affecting rice (Oryza sativa) cultivar specificity. Theor. Appl. Genet. 88:901-908.

Smith, S.E., and Read, D.J. 1997. Mycorrhizal Symbiosis. (London: Academic Press). 
Somssich, I.E., and Hahlbrock, K, 1998. Pathogen defense in plants: a paradigm of biological complexity. Trends Plant Sci. 3:86-90.

Somssich, I.E., Schmeizer, E., Kawalleck, P., and Hahlbrock, K. 1988. Gene structure and in situ transcript localization of pathogenesis-related protein 1 in parsley. Mol. Gen. Genet. 213:93-98.

Spangenburg, G., Wang, Z.-Y., Wu, X.L., Nagel, J., and Potrykus, I. 1995. Transgenic perennial ryegrass (Lolium perenne) plants from microprojectile bombardment of Embryonic suspension cells. Plant Sci. 1008:209-17.

Spiering, M. J. 2000. Distribution of Neotyphodium lolii-Endophyte Metabolic Activity in Perennial Ryegrass (Lolium perenne L.) and Its Implications for Alkaloid Distribution and Photosynthesis. Massey University, Palmerston North, New Zealand. [Ph.D. thesis]

Spiering, M. J., Wilkinson, H.H., Blankenship, J.D., and Schardl, C.L. 2002. Expressed sequence tags and genes associated with loline alkaloid expression by the fungal endophyte Neotyphodium uncinatum. Fungal Genet. Biol. 36:242-254.

Stougaard, J. 2001. Genetics and genomics of root symbiosis. Curr. Opin. Plant Biol. $4: 328-335$

Stracke, S. et al. 2002. A plant receptor-like kinase required for both fungal and bacterial symbiosis. Nature 417:959-962

Swoboda, L., Hoffmann-Sommergrube, K., O’Riordain, G., Scheiner, O., Herberle-Bors, E., and Vicente, O. 1996. Bet $v 1$ proteins, the major birch pollen allergens and members of a family of conserved pathogenesis-related proteins, show ribonulcease activity in vitro. Physiol. Plant. 96:433-438.

Sylvia, D.M., and Sinclair, W.A. 1983. Phenolic compounds and resistance to fungal pathogens induced in primary roots of Douglas-fir seedlings by the ectomycorrhizal fungus Laccaria laccata. Phytopathology 73:390-397.

Tan, Y.Y., Spiering, M., Christensen, M.J., Saunders, K., and Schmid, J. 1997. In planta metabolic state of Neotyphodium mycelium assessed through use of the Gus reporter gene in combination with hyphal enumeration. Pages 85-87: in Neotyphodium/grass Interactions. C.W. Bacon, and N.S. Hill, eds. Plenum Press, New York. U.S.A.

Thomas, S.W., Glaring, M.A., Rasmussen, S.W., Kinane, J.T., and Oliver, R.P. 2002. Transcript profiling in the barley mildew pathogen Blumeria graminis by serial analysis of gene expression (SAGE). Mol. Plant-Microbe-Interact. 15:847-856.

Thompson, F.N., and Stuedemann, J.A. 1993. Pathophysiology of fescue toxicosis. Agric. Ecosyst. Environ. 44:263-281. 
Tsai, H.-F., Liu, J-S., Staben, C., Christensen, M.J., Latch, G.C.M., Siegel, M.R., and Schardl C.L. 1994. Evolutionary diversification of fungal endophytes of tall fescue grass by hybridization with Epichloë species. Proc. Natl. Acad. Sci. USA 91:2542-2546.

Turner, N.C. 1986. Adaptation to water deficits: a changing perspective. Aust. J. Plant. Physiol. 13:175-190.

Valent, B., Farrall, L., and Chumley, F.G. 1986. Genetic studies of fertility and pathogenicity in Magnaporthe grisea (Pyricularia oryzae). Iowa State J. Res. 60:569594.

van den Brule, S., Muller, A., Fleming, A.J., and Smart, C.C. 2002. The ABC transporter SpTUR2 confers resistance to the antifungal diterpene sclareol. Plant J. 30:649-662.

van Loon, L.C., Pierpoint, W.S., Boller, T., and Conejero, V. 1994. Recommendations for naming plant pathogenesis-elated proteins. Plant Mol. Biol. Rep. 12:254-264.

van Rhijn, P., Fang, Y., Galili, S., Shaul, O., Atzmon, N., Wininger, S., Eshed, Y., Lum, M., and Li, Y. To, V.V., Fujishige, N., Kapulnik, Y., Hirsch, A.M.1997. Expression of early nodulin genes in alfalfa mycorrhizae indicates that signal transduction pathways used in forming arbuscular mycorrhizae and Rhizobium-induced nodules may be conserved. Proc Natl Acad Sci USA 94:5467-5472.

Velculescu,V.E., Zhang, L., Volgelstein, B., and Kinzler, K.W. 1995. Serial analysis of gene expression. Science 270:484-486.

Vierheilig, H., Bago, B., Albrecht, C., Poulin, M.J., and Piche, Y. 1998. Flavonoids and arbuscular-mycorrhizal fungi. Adv. Exp. Med. Biol. 439:9-33.

Voiblet, C., Duplessis, S., Encelot, N., and Martin, F. 2001. Identification of symbiosisregulated genes in Eucalyptus globulus-Pisolithus tinctorius ectomycorrhiza by differential hybridization of arrayed cDNAs. Plant J. 25:181-191.

Walters, D., Cowley, T., and Mitchell, A. 2002. Methyl jasmonate alters polyamine metabolism and induces systemic protection against powdery mildew infection in barley seedlings. J. Exp. Bot. 53:747-56.

Walters, D.R. 2000. Polyamines in plant-microbe interactions. Physiol. Mol. Plant Pathol. 57:137-146.

Walters, D.R., and Wylie, M.A. 1986. Polyamines in discrete regions of barley leaves infected with the powdery mildew fungus, Erysiphe graminis. Physiol. Plant. 67:630-633. 
Walters, D.R., Wilson, P.W.F., and Shuttleton, M.A. 1985. Relative changes in levels of polyamines and activities of biosynthetic enzymes in barley infected with the powdery mildew fungus, Erysiphe graminis DC. Ex Merat f.sp. hordei Marchal. New Phytol. 101:695-705.

Wang, C.-S., Huang, J.-C., and Hu, J.-H. 1999. Characterization of two subclasses of PR10 transcripts in lily anthers and induction of their genes through separate signal transduction pathways. Plant Mol. Biol. 40:807-814.

Wang, Z.-Y., Takamizo, T., Igelesias, V.A., Osusky, M.A., Nagel, J. Potrykus, I., and Spangenberg, G. 1992. Transgenic plants of tall fescue (Festuca arundinacea Schreb.) obtained by direct gene transfer to protoplasts. Biotechnology 10:691-6.

Warner, S., Scott, R., and Draper, J. 1992. Characterization of a wound-induced transcript from the monocot asparagus that shares similarity with a class of intracellular pathogenesis-related (PR) proteins. Plant Mol. Biol. 19:555-561.

Warner, S., Scott, R., and Draper, J. 1993. Isolation of an asparagus intracellular PR-gene (AoPR1) wound-responsive promoter by the inverse polymerase chain reaction and its characterization in transgenic tobacco. Plant J. 3:191-201.

Welford, S.M., Gregg, J., Chen, E., Garrison, D., Sorensen, P.H., Denny, C.T., and Nelson, S.F. 1998. Detection of differentially expressed genes in primary tumour tissues using representational differences analysis coupled to microarray hybridization. Nucleic Acids Res. 26:3059-3065.

West, C. P. 1994. Physiology and drought tolerance of endophyte-infected grasses. Pages 87-99 in: Biotechnology of Endophytic Fungi of Grasses. C.W. Bacon and J.F. White, Jr. eds. CRC Press, Boca Raton, Florida, U.S.A.

West, C.P., Elbersen., H.W., Elmi, A.A., and Buck, G.W. 1994. Acremonium effects on tall fescue growth:parasite or stimulant? Pages 102-111 in: Sourthern Pasture Forage Crop Improvement. G.E. Brink, ed. Conf. Knoxville. TN., 50 ${ }^{\text {th }} .23-25$ May 1994.

Western, J.H., and Carvett, J.J. 1959. The choke disease of cooksfoot (Dactylis glomerata) caused by Epichloë typhina. Trans. Br. Mycol. Soc. 42:298-307.

Whetten, R.W., MacKay, J.J., and Sederoff, R.R. 1998. Recent advances in understanding lignin biosynthesis. Annu. Rev. Plant Physiol. Plant Mol. Biol. 49:585609.

White J.F., Jr. 1988. Endophyte-host associations in forage grasses. XI. A proposal concerning origin and evolution. Mycologia 80:442-446. 
White, J.F., Jr., Morrow, A.C., Morgan-Jones, G., and Chambless, D.A. 1991. Endophyte-host associations in forage grasses. XIV. Primary stromata formation and seed transmission in Epichloë typhina: Developmental and regulatory aspects. Mycologia $83: 72-81$.

Whitelaw, C.A., Le Huquet, J.A., Thurman, D.A., and Tomsett, A.B. 1997. The isolation and characterization of type II metallothionein-like genes from tomato (Lycopersicon esculentum L.). Plant Mol. Biol. 33:503-511.

Wilkinson, H. H., Siegel, M. R., Blankenship, J. D., Mallory, A. C., Bush, L. P., and Schardl, C. L. (2000). Contribution of fungal loline alkaloids to protection from aphids in a grass-endophyte mutualism. Mol. Plant-Microbe Interact. 13:1027-1033.

Xiong, L., Lee, M-W., Qi, M., and Yang, Y. 2001. Identification of defense-related rice genes by suppression subtractive hybridzation and differential screening. Mol. PlantMicrobe Interact. 14:685-692.

Yamauchi, Y., Ejiri, Y., and Tanaka, Y. 2001: Purification of an aminopeptidase preferentially releasing $\mathrm{N}$-ternimal alanine frm cucumber leaves and its identification as a plant aminopepidase N. Biosci. Biotechnol. Biochem. 65:2802-5.

Yang, G.P., Ross, D.T., Kuang, W.W., Brown, P.O., and Weigel. R.J. 1999. Combining SSH and cDNA microarrays for rapid identification of differentially expressed genes. Nucleic Acids Res. 27:1517-1523.

Ye, Z., Wang, Z.Y., WU, Z., Potrykus, I., and Spangenberg, G. 1997. Transgenic Italian ryegrass (Lolium multiflorum) plants from microprojectile bombardment of embryonic suspension cells. Plant Cell Reports 16:379-84

Yoder, O.C. 1988. Cochliobolus heterostrophus, cause of southern leaf blight. Adv. Plant Pathol. 6:93-112.

Yohn, C.B., Cohen, A., Danon, A., and Mayfield, S.P. 1998. A poly(A) binding protein functions in the chloroplast as a message-specific translation factor. Proc. Natl. Acad. Sci. USA 95:2238-2243.

Young, C., McMillan, L., Telfer, E., and Scott, B. 2001. Molecular cloning and genetic analysis of an indole-diterpene gene cluster from Penicillium paxilli. Mol. Microbiol. 39:754-764.

Zhou, X.-J., Lu, S., Xu, Y-H., Wang, J.-W., Chen, X.-Y. 2002. A cotton cDNA (GaPR10) encoding a pathogenesis-related 10 protein with in vitro ribonuclease acitivity. Plant Sci. 162: 629-636. 